Fisheries Research

September 2016, Volume 181 Pages 198-213

http://dx.doi.org/10.1016/i.fishres.2016.03.023

http://archimer.ifremer.fr/doc/00333/44430/

(c) 2016 Elsevier B.V. All rights reserved.

\title{
Adult-mediated connectivity affects inferences on population dynamics and stock assessment of nursery- dependent fish populations
}

\author{
Archambault Benoit ${ }^{1,2}$, Le Pape Olivier ${ }^{1}$, Baulier Loic ${ }^{1,3}{ }_{*}$, Vermard Youen ${ }^{4,5}$, Véron Matthieu ${ }^{1}$, \\ Rivot Etienne ${ }^{1,}$
}

${ }^{1}$ Agrocampus Ouest, UMR 985 ESE Ecologie et Santé des Écosystèmes, Rennes, France

${ }^{2}$ AgroParisTech, Paris, France

${ }^{3}$ Ifremer, Délégation de Guyane, Cayenne, France

${ }^{4}$ Ifremer, Channel and North Sea Fisheries Department,Boulogne Sur Mer, France

${ }^{5}$ Ifremer, Department of Fisheries Ecology and Modelling, Nantes, France

*Corresponding author : Etienne Rivot, email address : etienne.rivot@agrocampus-ouest.fr

benarcha@gmail.com ; Olivier.Le.Pape@agrocampus-ouest.fr ; loic.baulier@ifremer.fr ; youen.vermard@ifremer.fr ; matthieu.veron@agrocampus-ouest.fr

\begin{abstract}
:
We explore how alternative hypotheses on the degree of mixing among local subpopulations affect statistical inferences on the dynamics and stock assessment of a harvested flatfish population, namely, the common sole population in the Eastern Channel (ICES area VIId). The current paradigm considers a single, well-mixed, spatially homogeneous population with juveniles from all coastal nursery grounds along the French and UK coasts that contribute to a single adult population and one pool of eggs. Based on the available data and ecological knowledge, we developed a spatial Bayesian integrated lifecycle model that consists of three subpopulations (one near the UK coast and two near the French coast, denoted UK, West FR and East FR, respectively) supported by their respective local nurseries, with the connectivity among the three components limited to low exchanges during larval drift. Considering the population dynamics among three subpopulations (instead of a single homogeneous one) drastically changes our inferences on the productivity of nursery sectors and their relative contribution to total recruitment. Estimates of the East FR subpopulation's contribution to total recruitment increase (29\% in the single population model; $48 \%$ in the three subpopulation model), balanced by a decrease in the UK subpopulation's contribution (53\%; 34\%). Whereas an assessment based on the hypothesis of a single spatially homogeneous population in the EC indicates exploitation far above MSY (current F/FMSY = 1.8), an assessment that considers a metapopulation with three loosely connected subpopulations revealed a different status, with the UK and East FR subpopulations being exploited above MSY (current F/FMSY = 1.9 and 2, respectively) and the West FR subpopulation approaching full exploitation (current F/FMSY = 1.05). This approach contributes to the quantitative assessment of spatial fishery and coastal habitat management plans.
\end{abstract}


Keywords : Solea solea, Spatial life-cycle model, Coastal nurseries, Connectivity, Stock assessment, Hierarchical bayesian model 


\section{1. Introduction}

44 Integrated life-cycle modeling approaches that account for the spatial structure of populations 45 are needed to improve our understanding of the impacts of multiple pressures on populations

46 (Carson et al., 2011; Stelzenmuller et al., 2011; Wolfshaar et al., 2011; Petitgas et al. 2013).

47 The concepts of metapopulation were introduced long ago in the optimal harvesting theory for 48 fisheries (Tuck and Possingham, 1994 and references therein; Hilborn and Walters, 1992).

49 Spatially explicit models can help decision making in spatial management plans either to 50 adapt fisheries management to local productivities (Carruthers et al., 2011; Ying et al., 2011;

51 Guan et al., 2013) or to design networks for marine protected areas (Botsford et al., 2009;

52 Gaines et al., 2010; Grüss et al., 2011).

53 However, the current paradigm in population dynamics for the assessment of the most

54 exploited marine stocks continues to ignore metapopulation structure. One often assumes a

55 fish stock as a single, well-mixed and spatially homogeneous population that produces a

56 single larval pool that undergoes extensive dispersal and massive export covering the

57 population's entire distribution area. When it is addressed at all, the question of connectivity

58 and population structure is mostly focused on early life stages (Petitgas et al., 2013; Frisk et

59 al., 2014), with a large body of studies designed to evaluate the influence of physical and

60 biological processes on the survival and dispersion of eggs and larvae (Miller, 2007; Savina et

61 al., 2010; Hinrichsen et al., 2011; Peck and Hufnagl, 2012) that govern the variability of

62 recruitment in space and time (Chambers and Trippel, 1997; Gallego et al., 2012). The

63 importance of larval retention in marine populations has also been emphasized (Cowen et al.,

64 2000; Warner and Cowen, 2002), because populations that display strong retention may be

65 locally more vulnerable to local recruitment overfishing or depletion caused by catastrophic

66 events (Strathmann et al., 2002). However, although adult-mediated connectivity is suspected

67 to play a major role in population functioning, much less attention has been paid to its role

68 (Frisk et al., 2014). The movements of adults may determine the structure and dynamics of

69 metapopulations (Stelzenmuller et al., 2011; Cianelli et al., 2013), especially when larval and

70 juvenile retention occurs (Grosberg and Levitan, 1992), thus indicating the need for

71 population models that account for spatial structure and connectivity at all stages (Petitgas et

72 al., 2013; Frisk et al., 2014).

73 New challenges arise when building and parameterizing population models that account for

74 the spatial structure along the life cycle: (i) Long spatial data series of catches, abundance 
indices and fishing effort are rarely available; (ii) Coupling oceanographic circulation models

76 and larval individual-based models provides a way to explore larval dispersal, but larval

77 stages are rarely accessible to observation and the validation of those models remains an open

78 question (Miller 2007); and (iii) Movements in the adult stage are difficult to quantify. Mark-

79 recapture data (Drouineau et al., 2010; Carruthers et al., 2011), natural markers and genetic

80 studies (Hellberg et al., 2002) are costly and sometimes fail to reveal the metapopulation

81 structure (Ward et al., 1994; Smedbol et al., 2002; Rolland et al., 2007).

82 It thus remains a methodological challenge to embed spatial life-cycle models within a

83 statistical approach to derive inferences on key parameters (Planque et al., 2011). The

84 Hierarchical Bayesian modeling (HBM) framework has proven successful for embedding complex demographic processes with various sources of noisy and incomplete data on various spatial and temporal scales (Clark, 2005; Buckland et al., 2007; Parent and Rivot, 2013); thus it can help address some of these challenges. HBM has been successfully applied to build fish population dynamic models that assimilate various sources of field surveys (Rivot et al., 2004; Massiot-Granier et al., 2014), integrate mark-recapture data to capture the spatial structure of populations (Cunningham et al., 2007; Taylor et al., 2011), and incorporate complex interactions with environmental drivers of recruitment (Ruiz et al., 2009; Rochette et al., 2013).

93 In this paper, using the common sole (Solea solea) population in the Eastern Channel (EC;

94 ICES area VIId; Fig. 1a) as a case study, we investigate how considering alternative

95 hypotheses about adult-mediated connectivity can affect statistical inferences on population

96 dynamics and stock assessment. The common sole is a coastal and estuarine nursery-

97 dependent flatfish species (Le Pape et al., 2003a; Gibson, 2004). Its population in the EC is

98 exploited, with annual landings of approximately 4,000t. The sole's life cycle in the EC is

99 well described (Rochette et al., 2013 and references therein): adults reproduce in early spring;

100 pelagic eggs and larvae drift and survivors will eventually settle and metamorphose into

101 benthic juveniles in late spring in a restricted nursery in which they grow for 2 years (Riou et

102 al., 2001; Rochette et al., 2010). Afterwards, the fish move to wider and deeper adult areas,

103 where their migrations remain limited (Burt and Millner, 2008). 
a)

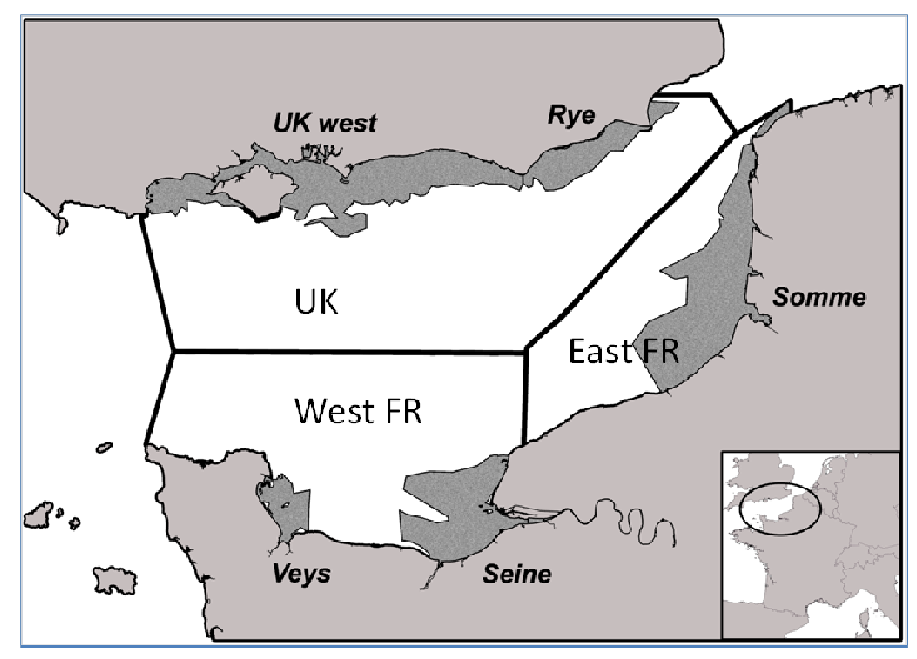

104

105

106

107

108

109

110

111 Rochette et al. (2013) have proposed an integrated life-cycle model for the EC's sole

112 population that combines approaches that are usually considered independently: (i) Outputs of

113 an individual-based model for larval drift that provided yearly estimates of the dispersion and

114 mortality of eggs and larvae from spawning grounds to settlement in several coastal nurseries;

115 (ii) A habitat suitability model based on juvenile trawl surveys combined with habitat maps to

116 estimate the surface of each nursery sector and juvenile densities; and (iii) A statistical catch-

117 at-age model for estimation of numbers-at-age and the fishing mortality of subadults and

118 adults. A strong assumption in Rochette et al. (2013) considers that various nurseries

119 contribute to the recruitment of a single homogeneous population in the EC. This hypothesis

120 is consistent with the stock-assessment model (ICES, 2013). However, results from the larval

121 drift model (Rochette et al., 2012) suggest consistent larval retention areas with strong

122 relationships between spawning areas and nursery sectors. Additionally, ancillary data and

123 expertise suggest only very low displacement of juveniles on nurseries (Coggan and Dando,

124 1988; Anon., 1989; Riou et al., 2001; Le Pape and Cognez, 2016) and only moderate

125 movements of adults (Kotthaus, 1963; Anon., 1965; Burt and Millner, 2008) that would result 
126 in a low adult-mediated connectivity (Frisk et al., 2014). Thus, there is a strong presumption

127 that very low connectivity exists among the three isolated subpopulations associated with

128 different nurseries sectors, thus fostering an exploration of the impact of considering various

129 spatial structures on (meta)population dynamics.

130 In this paper, we elaborate on the HBM framework proposed by Rochette et al. (2013) to

131 explore how considering three (quasi)isolated subpopulations instead of a single

132 homogeneous one (as considered by ICES (2013) and Rochette et al. (2013)) can affect

133 statistical inferences on population dynamics. In particular, we assess how considering three

134 subpopulations of adults (instead of a single homogeneous one) can change our evaluation of

135 the productivity of each nursery area and its contributions to recruitment. We point out how

136 consideration of three adult subpopulations ultimately affects not only the estimation of

137 management reference points but also the assessment of the stock status with respect to the

138 fishery's spatial dynamics.

\section{2. Materials and methods}

140 We first describe the model considering three (quasi)isolated subpopulations of sole in the EC

141 (Fig. 2a), together with the available data and other model inputs based on results from

142 previous models (Table 1). The second model that assumes a single, homogeneous adult

143 population is derived as a simplification of the first model (Fig. 2b). Third, we provide details

144 of the simulation method used to derive management reference points.

145 The life-cycle model is written in a state-space form (hierarchical) that integrates stochasticity

146 in both the process equations for the population dynamics (process errors) and the observation

147 equations (observation errors). All of the model equations, priors and values on fixed

148 parameters are fully detailed in Appendix A. Posterior distributions were approximated via

149 Monte Carlo Markov Chain methods using JAGS software (see Sup. Mat. S1 for details about 150 the MCMC simulations and the convergence diagnostics). 
155 Table 1. Synthesis of data and results of previous models used as inputs for the integrated life156 cycle model.

\begin{tabular}{|c|c|c|c|c|}
\hline & & \\
\hline & & $\begin{array}{l}\text { Nature of the } \\
\text { information used }\end{array}$ & Source & Time series \\
\hline 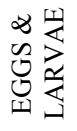 & $\begin{array}{l}\text { Survival and allocation from spawning areas to } \\
\text { the five nursery sectors }\end{array}$ & $\begin{array}{l}\text { Outputs of biophysical } \\
\text { IBM model }\end{array}$ & $\begin{array}{l}\text { Upgraded run of Rochette } \\
\text { et al. (2012); Savina et al., } \\
\text { in press. }\end{array}$ & 1982-2007 \\
\hline \multirow{6}{*}{ 至 } & \multicolumn{4}{|l|}{ Abundance indices available for each nursery sector } \\
\hline & West UK & $\begin{array}{l}\text { Outputs of a habitat } \\
\text { suitability model }\end{array}$ & Rochette et al. (2010) & 1982-1999 \\
\hline & Rye & /1 & Rochette et al. (2010) & 1982-2006 \\
\hline & Somme & /1 & Rochette et al. (2010) & $1982-1983 ; 1987-2011$ \\
\hline & Seine & /1 & $\begin{array}{l}\text { Rochette et al. }(2010)+ \\
\text { GIP Seine Aval }\end{array}$ & $\begin{array}{l}1995-2002 ; 2006 ; 2008- \\
2011\end{array}$ \\
\hline & Veys & /1 & Rochette et al. (2010) & 2006;2010-2011 \\
\hline \multirow{7}{*}{ 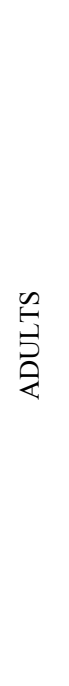 } & \multicolumn{4}{|l|}{ Available on the scale of the Eastern Channel } \\
\hline & Catches at age & Data & ICES & $1982-2011$ \\
\hline & UK commercial CPUE (UKCBT) & Data & ICES & 1986-2011 \\
\hline & Belgium commercial CPUE (BECBT) & Data & ICES & $1982-2011$ \\
\hline & \multicolumn{4}{|l|}{ Available for the three subpopulations } \\
\hline & $\begin{array}{l}\text { Spatial repartition of catches (total weights, no } \\
\text { age structure) among the three areas (East FR, } \\
\text { UK, West FR) }\end{array}$ & Data & $\begin{array}{l}\text { ICES }(2003-2011) \\
\text { Y. Vermard, Pers. comm. } \\
(1982-2002)\end{array}$ & $1982-2011$ \\
\hline & Spatial Scientific Abundance Index (UKBTS) & Data & Y. Vermard, Pers. comm. & 1990-2004; 2006-2011 \\
\hline
\end{tabular}

157 
a)

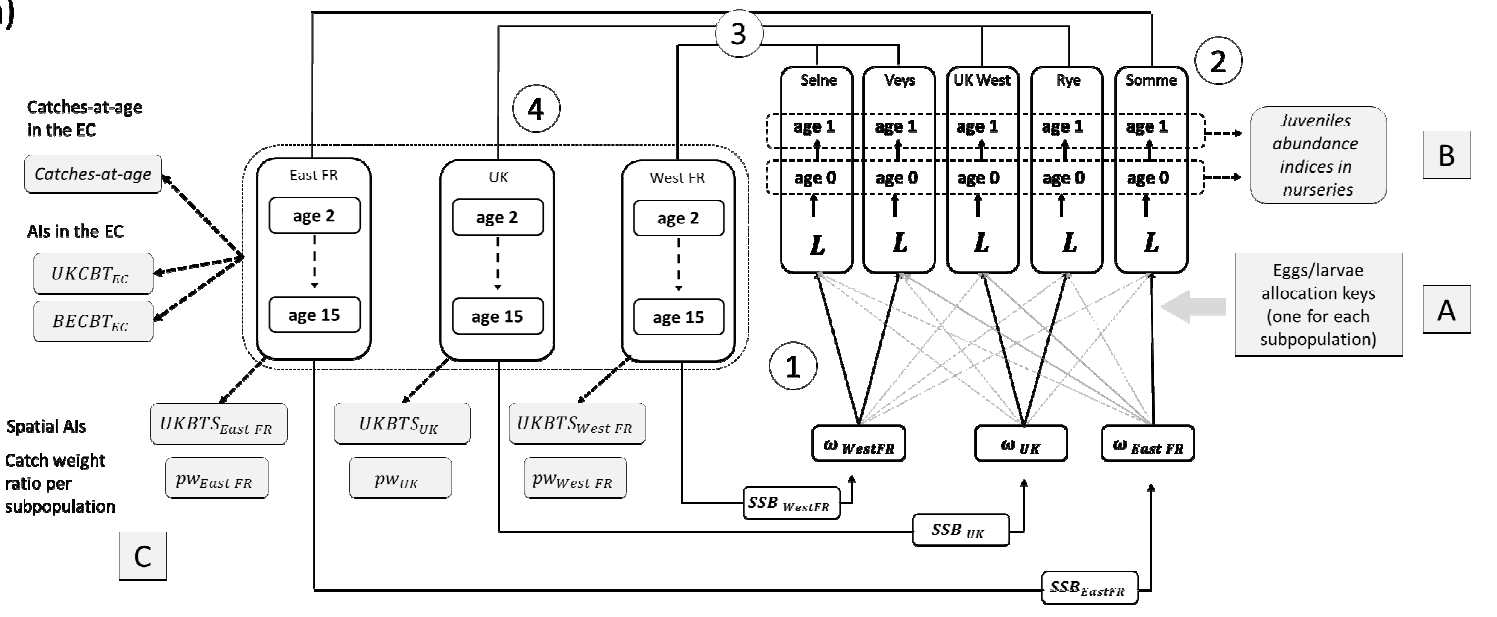

b)

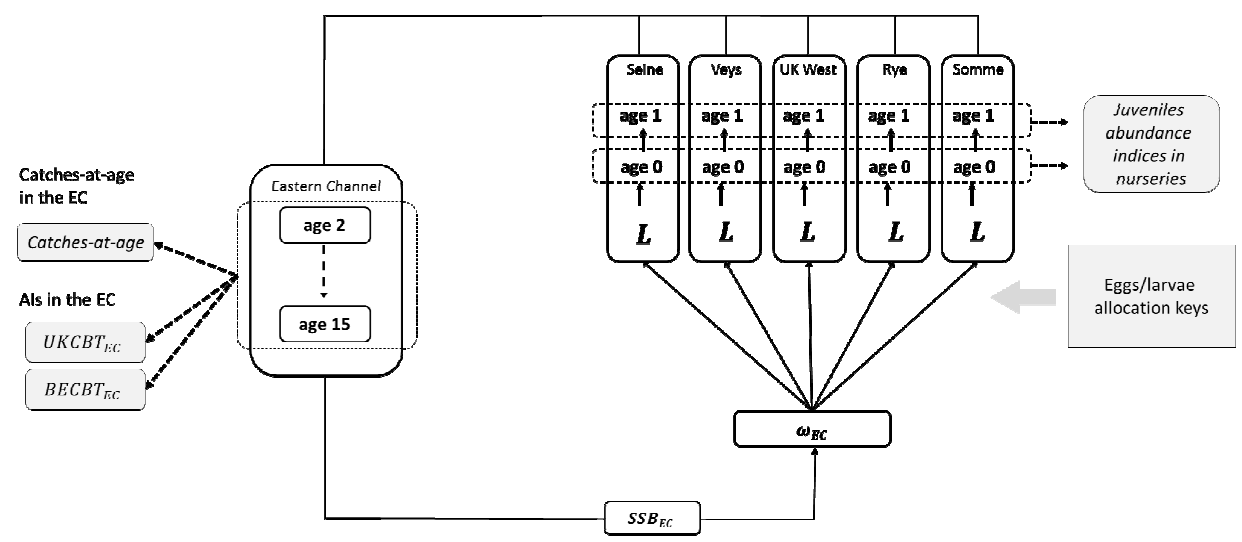

159 Figure 2. Hierarchical Bayesian Models for the life cycle. (a) Model with three isolated

160 subpopulations in which only very limited mixing occurs through egg and larval drift; (b)

161 Model considering a single population. Lettering and numbering refer to corresponding points

162 in the Materials \& Methods section. White boxes: non-observed state variables; Shaded boxes:

163 data or external model outputs considered as data. Dashed arrows indicate observation

164 equations to link latent state variables to observations.

\subsection{Model considering three quasi-isolated populations}

\section{2.1.1. Spatial structure}

168 The EC population is supported by five nursery areas (Rochette et al., 2010) along the French

169 (Veys, Seine and Somme nurseries) and UK coasts (UK West and Rye nurseries) (Fig. 1a).

170 Rochette et al. (2012) demonstrate the low dispersion of eggs and larvae during the pelagic

171 stages of the common sole (Fig. 1b). Indications of the reduced movements of juveniles and 
172 adults suggest that connectivity is almost null for juveniles and only very limited for adults.

173 Considering this limited connectivity along the life cycle and the presence of natural barriers

174 (e.g., rocky shores in the central southern coast and deep gravel grounds in the central part of

175 the EC; Rochette et al., 2010), three subpopulations associated with three spawning areas

176 (denoted $r=1,2,3$ ) and attached nursery sectors were identified (Fig. 1a): the Western French

177 subpopulation (West FR; Seine and Veys nursery sectors), the UK subpopulation (UK West

178 and Rye nursery sectors) and the Eastern French subpopulation (East FR; Somme nursery

179 sector).

180 2.1.2. Population dynamics

181 The population dynamics were modeled for 30 years from 1982 to 2011 . The model is stage-

182 structured from eggs to settled larvae and then age-structured from juveniles to adults (Fig.

$1832 \mathrm{a})$.

Eggs and larvae (see 1 in Fig. 2a)

185 Egg hatching is parameterized following the characteristics of the spawning season and the

186 spatial distribution of eggs (Rochette et al., 2012), and the annual quantity of eggs spawned in

187 each of the three subpopulations directly depends on the spawning biomass. Eggs and larvae

188 are transported from spawning areas and settle in the five identified nursery sectors according

189 to a drift/survival matrix estimated from a biophysical model (Rochette et al. (2012). Outputs

190 from the larval-drift model (Rochette et al., 2012; Fig. 1b) indicate very low connectivity

191 between the three spawning areas and distant nursery sectors over the time series, each

192 spawning area almost exclusively feeding the closest coastal and estuarine nursery grounds.

193 Only very limited mixing of individuals between the three subpopulations then occurs through

194 larval drift (Fig. 2a). The UK — and in lesser proportions the East FR - subpopulations were

195 also subject to larval inputs from the North Sea's (NS) sole population (Savina et al., in press),

196 which were integrated into the model as a constant term (not shown in Fig. 2).

197 Juvenile from age 0 to age 2 (see 2 in Fig. 2a)

198 Because of competition for space and food resources (Iles and Beverton, 2000; Le Pape and

199 Bonhommeau, 2015), settled larvae experience density-dependent post-settlement mortality

200 over nursery sectors between settlement (late spring) and the end of summer (growth period). 
201 Following previous modeling work in Rochette et al. (2013) and Archambault et al. (2014),

202 the resulting expected number of age- 0 juveniles is modeled through a compensatory density-

203 dependent Beverton-Holt $(\mathrm{BH})$ relationship parameterized with local parameters $\alpha_{i}$, the

204 maximum survival rate (i.e., the survival rate without density dependence) and $K_{i}$, the

205 carrying capacity per unit of surface (i.e., the maximum number of age- 0 juveniles that can

206 survive per unit of surface), which is then scaled to the total surface of each nursery, $S_{i}$

207 (fixed). Unexplained random variations are captured by independent lognormal random noise.

208 Because only limited information is available to estimate site-specific parameters,

209 exchangeable hierarchical structures (Gelman et al., 2004) were used to model the between-

210 nursery variability of parameters $\alpha_{i}$ and $K_{i}$, enabling "borrowing strength" between nursery

211 sectors (Rivot and Prévost, 2002; McAllister et al., 2004). Available juvenile abundance

212 indices on nursery sectors may contain enough information to estimate the carrying capacity

213 parameters $K_{i}$. However, because very few observations are available at low levels of settling

214 larvae, the maximum survival rates $\alpha_{i}$ could be difficult to estimate. Informative priors were

215 set on the $\alpha_{i}$ (see Appendix A) based on a meta-analysis of flatfish stock-recruitment

216 relationships (Archambault et al. 2014).

217 Late age-0 juveniles (in September, after the summer growth period) experience a fixed

218 natural mortality during 4 months until they reach age 1 in January. Age-1 juveniles spend

219 one year in nursery grounds with both natural (fixed) and fishing (estimated) mortalities.

220 From nurseries to sub-adults (see 3 in Fig. 2a)

221 Young fish are assumed to leave their nurseries at age 2, in January. No quantitative data were

222 directly available on the connectivity from nursery sectors to deeper areas where older fish

223 live (ages 2-15). Therefore, age-2 fish leaving nurseries are supposed to contribute directly to

224 the subpopulation adjacent to the nursery (Fig. 1a).

225 Sub-adults and adults (see 4 in Fig. 2a)

226 Fish from ages 2-15 are structured in three different subpopulations, with cohort dynamics

227 accounting for both natural (age-specific, fixed) and fishing (age-/ year-/ subpopulation-

228 specific, estimated) mortalities. All of the remaining fish are then assumed to die at age 15.

229 Because the cumulative natural mortality up to age 12 is near 1, including an age+ group in 
230 the model would not change the results. Fishing mortality is a function of fishing effort

231 (estimated) and age-specific gear selectivity (estimated).

232 Fish between the age of 3 and 15 participate in reproduction. The number of eggs for each

233 year and each subpopulation is calculated from the spawning stock biomass.

\section{2.1.3. Integration of results of previous models, data sources and observation models}

235 Eggs and larvae survival and allocation key (see A in Fig. 2a)

236 Egg and larval survival and allocation from spawning areas to the five nursery sectors over 26

237 years between 1982 and 2007 were available as outputs from an upgraded run of Rochette et

238 al.'s (2012) biophysical model (Savina et al., in press). That model ultimately provided the

$2393 \times 5 \times 26$ probability key that eggs from each of the 3 subpopulations would reach one of

240 the 5 different nursery sectors, accounting for inter-annual variability over the 26 years of

241 simulation. No outputs of larval drift model were available for the last 4 years (2008-2011;

242 Table 1). Because no particular time trend appears in the time series, the $3 \times 5$ probability key

243 for years 2008-2011 was set equal to the average over the entire series.

244 Abundance indices of juveniles in each nursery sector (see B in Fig. 2a)

245 The abundance indices (AI) of juveniles and the total surface of each nursery sector are

246 outputs from the habitat suitability model developed by Rochette et al. (2010) and used in

247 Rochette et al. (2013). Juvenile (ages 0 and 1) AIs over the five nursery sectors were obtained

248 from an upgrade of Rochette et al.'s (2010) habitat-suitability model, using updated scientific

249 trawl survey data. They were considered as lognormal random observations of juvenile

250 abundance accounting for gear/ age-specific catchability.

251 Catches-at-age (see C in Fig. 2a)

252 Annual catches-at-age were available from stock assessment reports only at the scale of the

253 EC; however, they were not available separately for the three subpopulations. Catches-at-age

254 predicted by the model for each subpopulation were then first aggregated at the scale of the

255 EC and considered observed with lognormal errors. 
256 Ancillary data for the catch weight ratio per subpopulation (total weight; no age structure)

257 also exist, thus showing that higher proportions of catches are regularly realized in the East

258 FR area (subpopulation associated with the Somme nursery sector). An additional likelihood

259 term for the catch weight ratio per subpopulation was added to assimilate this information in

260 the model.

261 Abundance indices of adults (see C in Fig. 2a)

262 Different AIs for adults were available at various spatial scales (EC and subpopulations). Two

263 time series of AIs were available at the scale of the EC: the UK (UKCBT) and the Belgium

264 (BEBCT) commercial fleet catch-per-unit effort. The scientific UK Bottom Trawl Survey

265 (UKBTS) provided AIs at the adult stage for each of the three subpopulations. One

266 observation equation is written for each time series of AIs, each contributing to the whole

267 likelihood function. All of the AIs were considered as lognormal random observations of

268 abundance at age, but with catchability parameters specific to the fleet (UKBCT, BEBCT,

269 UKBTS) age and year.

\section{2.1.4. Choice of priors and values of fixed parameters}

271 Some parameters were fixed from the literature (Appendix A, Table A.1). All of the estimated

272 parameters except for the selectivity curve parameters and the slopes of the BH relationships

273 over nursery areas $\left(\alpha_{i}\right)$ were given weakly informative a priori distributions in the sense of

274 Gelman (2004), i.e., they let the data speak while excluding unrealistic values (Appendix A).

\section{2.2. Simplifying the model to a single, homogeneous adult population}

276 The model considering three isolated subpopulations can easily be simplified into a single

277 population model that corresponds to the structure of Rochette et al. (2013) and to the stock-

278 assessment working group (ICES, 2013). This single population model assumes that the five

279 nursery sectors contribute to one single population covering the whole EC (Fig. 2b). The

280 distribution of eggs over the spawning area is assumed to follow the distribution observed in

2811991 (Rochette et al., 2012). All other processes (e.g., juvenile dynamics) are unchanged

282 except for the fishing mortality of adults that is now considered homogeneous at the EC scale.

283 The same sources of data are used, but no catch weight ratios per subpopulation are 
284 considered and only the adult AIs available at the EC scale (i.e., UKCBT and BECBT) are 285 used (Fig. 2b).

\section{2.3. Evaluating the fit to each data sources}

287 We conducted posterior predictive checking to evaluate the fit of the model to each data

288 source assimilated in the model. For each data source, observed data (denoted $y^{\text {obs }}$ ) were

289 compared to the distribution of replicated data sets $\left(y^{\text {pred }}\right)$ simulated from their posterior

290 predictive distribution (Gelman et al., 2004). To check that the model was able to replicate

291 data similar to the observations, we compare synthetic statistics calculated from the observed

292 data $\left(T\left(y^{o b s}\right)\right)$ with statistics calculated from replicated data $\left(T\left(y^{r e p}\right)\right)$. We calculated

293 Bayesian p-values (Gelman et al., 2004), defined as the probability that the statistics

294 calculated from the replicated data $T\left(y^{r e p}\right)$ are more extreme than the statistics calculated

295 from the observed data $T\left(y^{o b s}\right)$ :

296 (1)

$$
\text { p-values }=\operatorname{Pr}\left(T\left(y^{\text {rep }}\right) \geq T\left(y^{o b s}\right)\right)
$$

297 We chose the standard discrepancy statistic calculated for the observed and simulated data as 298 follows:

$$
T\left(y^{o b s}\right)=\sum\left(y^{o b s}-E(y)\right)^{2} \text { and } T\left(y^{\text {pred }}\right)=\sum\left(y^{\text {pred }}-E(y)\right)^{2}
$$

300 where $y^{o b s}$ is an observation, $y^{\text {pred }}$ is a simulated value in the posterior predictive

301 distribution of the state variable $y$ and $E(y)$ is the expected mean of $y$ in the model (the fit of

302 the model). $y^{\text {obs }}, y^{\text {pred }}$ and $E(y)$ were log-transformed for all variables observed with

303 lognormal random noise. Depending upon the data source, the sums in eq. (2) are calculated

304 either across the entire time series of available data (for age-0 and age- 1 AIs in nursery

305 sectors and for the catch weight ratio per subpopulation) or across both time and age classes

306 (for adults AIs and aggregated catches-at-ages). $p$-values close to 0 or 1 reveal the potential

307 failure of the model (Gelman et al. 2004).

308 In addition, we assessed the contribution of the various data sources in the model, considering

309 three loosely connected populations by examining how the final inferences change when

310 cumulating the data sources. Three runs of the model were conducted, successively adding the

311 various spatial data series (i.e., spatial UKBTS AIs and catch weight ratio per subpopulation;

312 Table 2). In run (a), only spatial UKBTS AIs are introduced in the likelihood. Run (b)

313 considers a likelihood function for the catch weight ratio per subpopulation, but does not 
314 integrate spatial UKBTS AIs. Finally, run (c) corresponds to the final model that assimilates

315 both the spatial UKBTS AIs and the catch weight ratio per subpopulation.

317 Table 2. Configuration of the three model runs to explore the respective contributions of data

318 sources to the fit of the model with three subpopulations.

\begin{tabular}{ccc}
\hline Run & Spatial Abundance Index (UKBTS) & $\begin{array}{c}\text { Proportion of total catches } \\
\text { among subpopulations } \\
\text { (total catches in weight, no age } \\
\text { structure) }\end{array}$ \\
\hline a & Yes & No \\
b & No & Yes \\
c & Yes & Yes \\
\hline
\end{tabular}

\subsection{Stock-assessment and management reference points}

321 The spawning stock biomass $(S S B)$, recruitment $(R)$, fishing mortality $(F)$, and Maximum

322 Sustainable Yield ( $M S Y$, the associated fishing mortality $\left(F_{M S Y}\right)$ and spawning stock biomass

$323\left(S S B_{M S Y}\right)$ were estimated on different scales (for each subpopulation and on the scale of the

324 EC).

325 The evaluation of $M S Y, F_{M S Y}$, and $S S B_{M S Y}$ is not analytically straightforward, because the

326 production of each subpopulation results from a combination of stochastic $\mathrm{BH}$ relationships

327 fitted on each nursery sector (two in West Fr: Veys and Seine; two in the UK: UK West and

328 Rye; and one in East FR: Somme; Fig. 1a). The empirical equilibrium curves were obtained

329 using Monte Carlo simulations to integrate both process and parameter uncertainty (see the

330 methods in Appendix B). In the model considering three subpopulations, reference

331 equilibrium points for each subpopulation $r$, denoted $B_{M S Y, r}, F_{M S Y, r}$ and $C_{M S Y, r}$, were

332 estimated conditionally by fixing the fishing pressure for the two other subpopulations equal

333 to the estimates averaged over the last five years of the data series (2007-2011). 


\section{3. Results}

\section{3.1. Model evaluation}

336 For both of the model configurations, the convergence diagnostics indicate convergence of

337 the MCMC chains after $10^{6}$ iterations for all variables (see Sup. Mat. S1 for more details

338 about the MCMC simulations and the convergence diagnostics). To reduce the autocorrelation

339 in the sample used for final inferences, one out of 100 iterations was kept (thinning $=100$ ).

340 Final inferences were derived from a sample of $3 \times 10,000$ iterations that resulted from

341 merging the three chains.

342 Because the two models integrate different sources of data (e.g., the spatial AIs of adults and

343 catch weight ratios that are not included in the model considering a single, homogeneous

344 adult population), the usual goodness of fit criteria cannot be used directly to compare the two

345 model structures. The component of deviance associated with the data shared by the two

346 model structures (i.e., the juvenile AIs in the five nursery sectors and the non-spatial AIs for

347 ages 2-15) was revealed as slightly lower for the model with one single population than for

348 the model with three isolated subpopulations (not shown). However, the difference is very

349 low, indicating that the likelihood of the two models is quite comparable when considering

350 the data shared by the two model structures.

351 Although this is not formally considered in the likelihood function, we also compared egg

352 distribution among the three spawning areas (i.e., the function of the SSB associated with

353 each subpopulation) to the spatial distribution of eggs given by the single available

354 observation originating from the 1991 eggs survey (Rochette et al., 2012). Results indicate

355 that the spatial distribution of eggs derived from the fit of the model with three isolated

356 subpopulations (West FR, 29\%; UK, 33\%; East FR, 38\%) was highly consistent with the egg

357 distribution observed in 1991 (25\%,34\% and 41\%), thus providing evidence that the spatial

358 repartition of the SSB inferred from the model considering three subpopulation is consistent

359 with some external data sources.

360 Overall, a posterior predictive check conducted for the two model configurations (one

361 homogeneous population and three isolated subpopulations) did not reveal any strong and

362 general inconsistencies between the fitted model and the data. Almost all of the $p$-values are

363 between 0.05 and 0.95 for all model compartments (Table 3 ). The additional figures included

364 in Sup. Mat. S2 (Fig. S2.1- S2.9) show a good consistency between the posterior predictive 
365 distributions and the data, providing additional evidence of a lack of conflict between the

366 different sources of observations assimilated in the model. Interestingly, the p-values

367 associated with the data sources that are common to the two model configurations (juveniles

368 AIs, aggregated catches-at-ages and commercial CPUEs) were quite similar between the two

369 model configurations (Table 3).

370 Table 3. p-values of posterior predictive checking calculated for each source of observation 371 and for the two model configurations: the model considering a single, homogeneous adult 372 population and the model considering three subpopulations. $p$-values are the probability that 373 the discrepancy static calculated for predicted values is greater than the one calculated with 374 observed values (see text for details).

\begin{tabular}{|c|c|c|c|c|c|}
\hline & & \multicolumn{2}{|c|}{ One single population } & \multicolumn{2}{|c|}{ Three subpopulations } \\
\hline \multirow{6}{*}{ 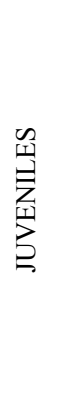 } & $\mathrm{AI}$ in each nursery sector & Age- 0 & Age-1 & Age- 0 & Age-1 \\
\hline & Solent (West UK) & 0.72 & 0.74 & 0.92 & 0.51 \\
\hline & Rye & 0.29 & 0.84 & 0.33 & 0.80 \\
\hline & Somme & 0.12 & 0.26 & 0.23 & 0.11 \\
\hline & Seine & 0.65 & 0.70 & 0.71 & 0.83 \\
\hline & Veys & 0.61 & 0.55 & 0.72 & 0.64 \\
\hline \multirow{13}{*}{$\begin{array}{l}\text { 点 } \\
\text { 它 }\end{array}$} & \multicolumn{5}{|l|}{ Aggregated data (Eastern Channel) } \\
\hline & Catches-at-age & \multicolumn{2}{|c|}{0.54} & \multicolumn{2}{|c|}{0.56} \\
\hline & UK commercial CPUE (UKCBT) & \multicolumn{2}{|c|}{0.82} & \multicolumn{2}{|c|}{0.88} \\
\hline & Belgium commercial CPUE (BECBT) & \multicolumn{2}{|c|}{0.72} & \multicolumn{2}{|c|}{0.78} \\
\hline & \multicolumn{5}{|l|}{ Spatial data } \\
\hline & \multicolumn{5}{|c|}{ Proportion of total catches (weight) among the three areas (East FR, UK, West FR) } \\
\hline & West FR & \multicolumn{2}{|c|}{-} & \multicolumn{2}{|c|}{0.54} \\
\hline & UK & \multicolumn{2}{|c|}{ - } & \multicolumn{2}{|c|}{0.57} \\
\hline & East FR & \multicolumn{2}{|c|}{-} & \multicolumn{2}{|c|}{0.47} \\
\hline & \multicolumn{5}{|l|}{ Spatial Scientific AI Index (UKBTS) } \\
\hline & West FR & \multicolumn{2}{|c|}{-} & \multicolumn{2}{|c|}{0.85} \\
\hline & UK & \multicolumn{2}{|c|}{-} & \multicolumn{2}{|c|}{0.91} \\
\hline & East FR & \multicolumn{2}{|c|}{-} & \multicolumn{2}{|c|}{0.27} \\
\hline
\end{tabular}

376 There was however evidence of poor fit between the posterior predictive distribution from the 377 model and the observed data for the abundance indices of age- 0 juveniles in the Solent 378 nursery sector in the case of a model considering three subpopulations ( $p$-value $=0.92)$ (Fig. 
379 S2.1). Additionally, p-values for commercial AIs (UKCBT and BECBT) and for the spatial

380 AIs of adults (UKBTS) for the UK subpopulation are relatively high, indicating that the

381 dispersion of the predictive distribution around the model fit is higher than the dispersion of

382 observations (see also Fig. S2.1 and S2.8).

\section{3.2. Posterior estimates of parameters}

384 Marginal posterior distributions of all of the parameters obtained under both model

385 configurations reveal that the parameters are generally estimated with low uncertainty (Sup.

386 Mat. S3, Figs. S3.2 and S3.5 and Tabs. S3.1 and S3.2). Overall, the differences between the

387 prior and the posterior reveal that the distributions are mostly driven by the data (Sup. Mat. S3,

388 Figs. S3.2 and S3.5).

389 Interestingly, considering the more complex spatial structure of the population (three

390 subpopulations of adults versus a single, homogeneous population) does not increase the

391 posterior uncertainty about parameters. In contrast, uncertainty about posterior estimates of

392 biomass, recruitment, and fishing mortality is higher in the model that considers three

393 subpopulations (Fig. 3).

394 Nevertheless, one exception to this rule relates to the parameters for the density-dependent

395 recruitment process in each nursery sector; those parameters are estimated with much more

396 uncertainty than are the other parameters for both model configurations (Sup. Mat. S3, Fig.

397 S3.1 and S3.4). Uncertainty is particularly high for the maximum survival rate $\alpha$ for the

398 Somme and Rye nursery sectors. The posterior distribution of $\alpha$ for the Bay of Veys is not

399 different from the posterior predictive distribution because juvenile abundance indices are

400 only available for three years for this nursery sector.

401 For both model configurations, the selectivity parameters are estimated with very low

402 uncertainty that leads to a knife-edge selectivity curve, with selectivity near 0 for age- 1 fish,

403 near 0.5 for age-2 fish and 1 for older fish. 
Eastern Channel
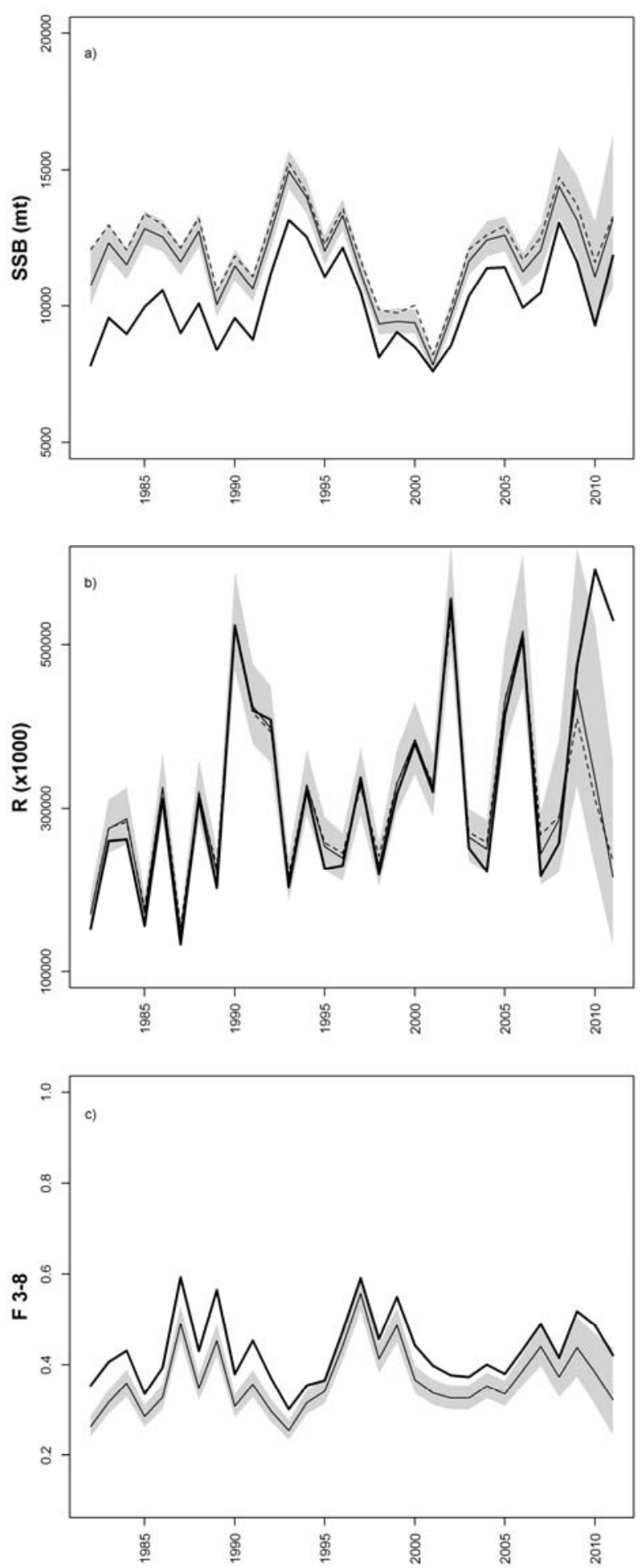

- ICES WG - Single pop. $\quad$-.. Three sub, pop
Three subpopulations
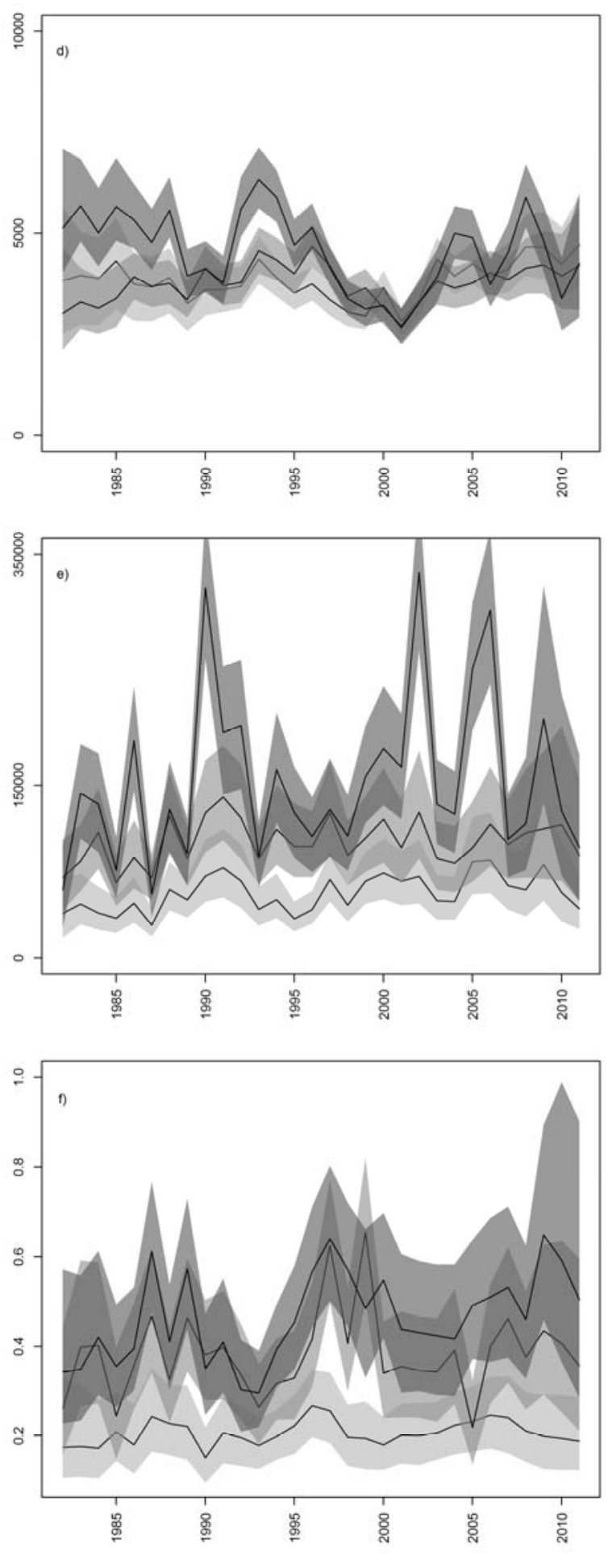

ㅁ WESTFR $\square$ UK $\square$ EASTFR

Figure 3. Left column (a, b, c). Comparison of estimates of $S S B, R$ and $F_{3-8}$ at the Eastern Channel scale obtained by the ICES WG (bold line) both by the model considering one homogeneous adult population (solid line) and by the model considering three components of the adult population (dotted line). Right column (d, e, f). Estimates of $S S B, R$ and $F_{3-8}$ for the three subpopulations. Plain lines: posterior medians. Shaded areas: 95\% Bayesian credible 410 intervals. 
411 As expected, the process error variance of the larvae to age- 0 transition is greater than for the 412 age-0 to age-1 transition (Sup. Mat. S3, Tabs. S3.1 and S3.2). This residual variability does

413 not reveal any particular departure from the hypotheses of constant variance across the five

414 nursery grounds and of the time independence of residuals (not shown).

415 In both model configurations, the variance of observation error in catches is very low. In the

416 model considering a single, homogeneous population, the observation error on juveniles and

417 adults' abundance indices are of the same order of magnitude. In contrast, the variance of

418 observation error among juveniles is much higher in the model that considers three

419 subpopulations.

420 Additional results (Sup. Mat. S3, Tabs. S3.3 and S3.4) reveal that some parameters are

421 correlated and thus partially confounded. Results are similar for the two model configurations.

422 In particular, parameters $(\alpha, K)$ for each nursery sector are negatively correlated. Catchabilities

423 associated with age- 0 and age- 1 abundance indices $\left(q_{0}\right.$ and $\left.q_{1}\right)$ are positively correlated;

424 moreover, they are positively correlated with the variance of observation errors on juveniles

$425\left(\sigma_{I j u v}^{2}\right)$. Similarly, catchabilities associated with adults' abundance indices $\left(q_{U K C B T}, q_{B E C B T}\right.$

426 and $\left.q_{U K B T S}\right)$ are positively correlated, and they are positively correlated with the variance of

427 observation error $\left(\sigma_{I A d}^{2}\right)$.

\section{3.3. Contribution of the different data sources to posterior estimates}

429 We assessed the contribution of each dataset to the final estimations of the model with three

430 subpopulations. Three runs of the model were conducted, successively assimilating the

431 different sources of spatial data series (i.e., spatial UKBTS AIs and proportion of catches

432 among areas; Table 2). The spatial AIs and the spatial distribution of aggregated catches make

433 different contributions to the final estimates. In the run with spatial AIs only, although the

434 uncertainty about local SSB is relatively high, the total SSB at the scale of the EC is precisely

435 estimated (not shown) and the repartition is relatively balanced among the three

436 subpopulations (Fig. 4a), which is consistent with the information provided by the spatial

437 UKBTS AIs. When including spatial catches only (no spatial AIs), differences in SSB among

438 subpopulations are higher (Fig. 4b), with higher estimates of SSB in the UK and East FR

439 areas than in the West FR area, which is consistent with the higher proportion of catches

440 observed in the East FR area (see Fig. S2.6 in Sup. Mat. S2). Finally, when assimilating all

441 available data, uncertainty in SSB estimates is drastically reduced and the variability across 
subpopulations is shrunken (Fig. 4c) according to the information provided by the spatial AIs,

443 and unbalanced catch ratios translate into unbalanced fishing mortality among subpopulations.

(a)

With spatial UKBTS

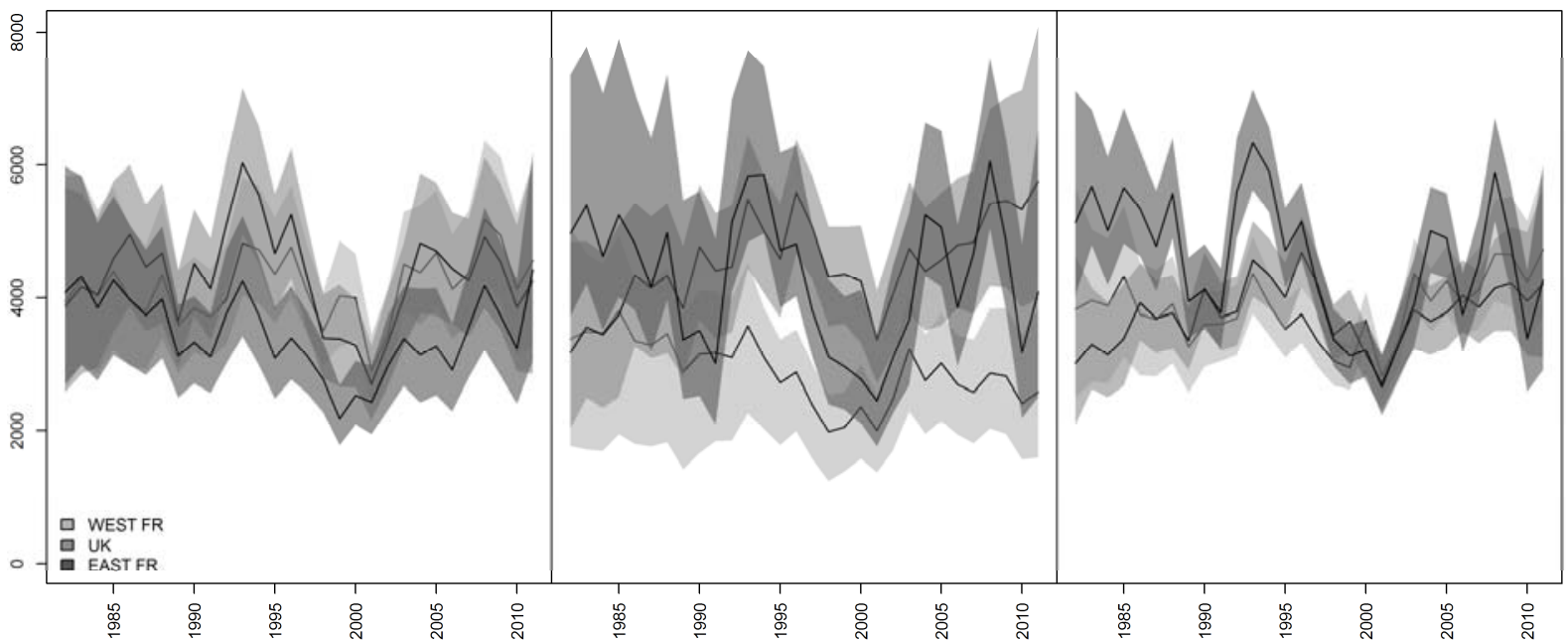

Figure 4. Time series of posterior estimates of $S S B$ for the three subpopulations obtained with the three data configurations of the Table 2. Solid lines: posterior medians. Shaded areas: $95 \%$ Bayesian credibility intervals.

\subsection{The effect of considering three isolated subpopulations on stock productivity}

The effect of considering three isolated populations (instead of one homogeneous population) considering three subpopulations provide similar estimates of $S S B$, recruitment and fishing mortality considered on the EC scale (Fig. 3a,b,c). These estimates were also consistent with

454 ICES estimates, although overall they displayed a slightly higher SSB balanced by a lower $F$.

455 However, the consideration of three subpopulations provides a spatial perspective on

456 population dynamics. It also impacts inferences on stock productivity and therefore the

457 assessment of stock status with respect to reference points.

\subsubsection{Reevaluation of the productivity of nurseries}

459 The hypothesis on the spatial structure of the population strongly affects estimates of the

460 carrying capacity per unit of surface (Fig. 5a), with $K$ for the Somme nursery sector being

461 largely reevaluated when considering a model structure with three isolated subpopulations,

462 balanced by a decrease in estimates of $K$ for all other nursery sectors. Estimates of parameters 
$463 \alpha$ for the UK West and Veys decrease when considering a model with three subpopulations,

464 whereas the estimate increases for the Somme (Fig. 5b). Additional figures S3.3 and S3.6 in

465 Sup. Mat. S3 provide a plot of the resulting Beverton-Holt curve in each nursery sector that

466 illustrates the change in the local recruitment dynamics between the two model configurations.

467 As a result, the contributions of each nursery sector to recruitment in the EC are also strongly

468 affected. In the single-population model, the Seine, Veys, UK West, Rye and Somme sectors

469 contributed an average of 16, 3, 28, 24 and 29\%, respectively, but with high variability among

470 years (Fig. 6a). When considering three isolated subpopulations (Fig. 6b), these contributions

471 were estimated at $14,4,17,17$ and $48 \%$ and were much less variable in time. At the

472 subpopulation level, this translates into a strong increase in the contribution from East FR

473 subpopulation (Somme: from $29 \%$ to $48 \%$ ) balanced by decreases in contributions from West

474 FR (Seine + Veys: from 19\% to 18\%) and UK subpopulations (UK West + Rye: from 52\% to

$47534 \%)$.
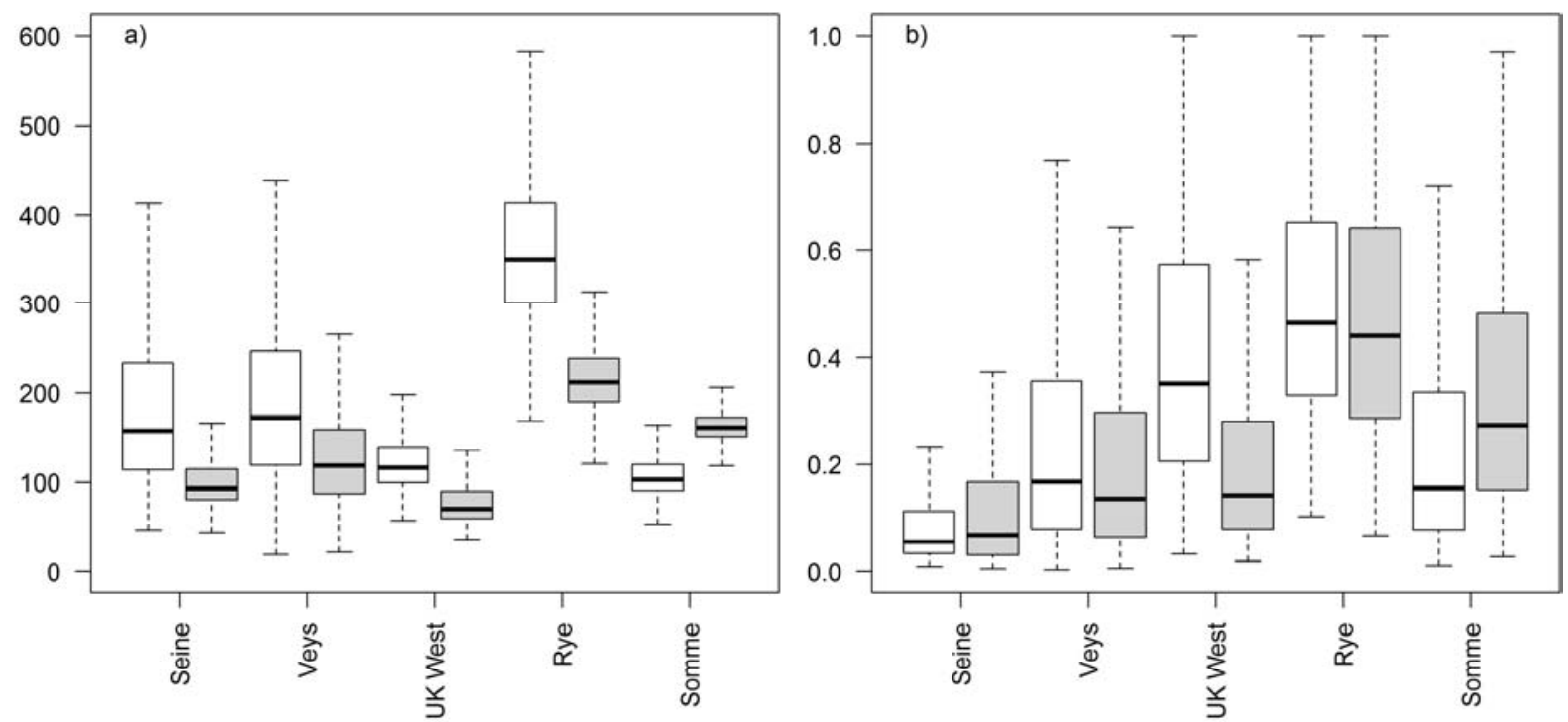

476

Figure 5. Marginal posterior distributions of the nursery-specific Beverton-Holt parameters $K$ (a) and $\alpha$ (b) obtained with the model considering one homogeneous adult population (white) and with the model considering three isolated subpopulations (gray). $K$ is in thousands of fish per $\mathrm{km}^{2} . \alpha$ is a maximum survival rate.

Overall, those results are consistent with the high proportion of catches recorded in the East

3 FR area (the area associated with the Somme nursery sector), logically leading to a high SSB

84 in this area in the model that considers three subpopulations (Fig. 3d); in turn, this leads to

higher recruitment in the Somme nursery sector. 
a)

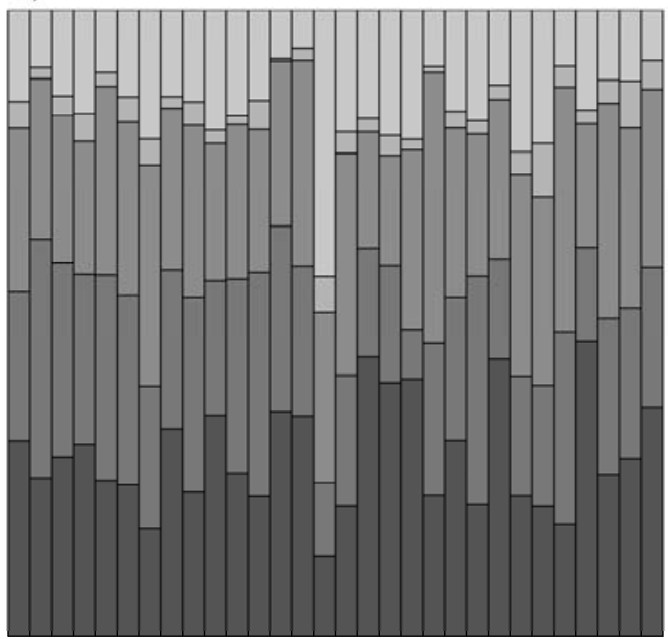

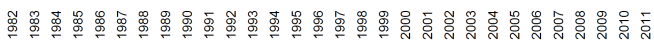

b)

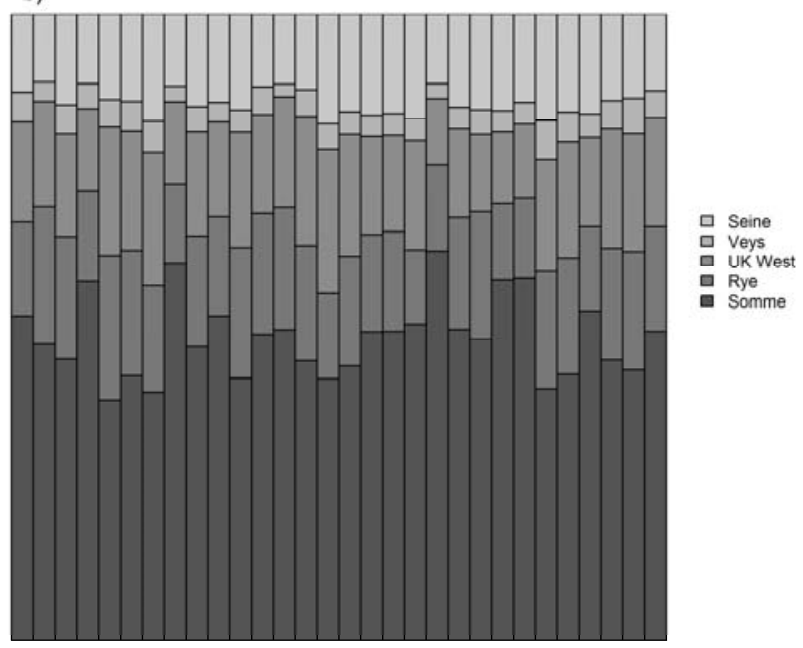

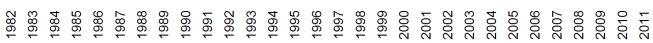

487 Figure 6. Contributions of the five nursery sectors to the total $0+$ recruitment obtained from

488 the model considering a) one single adult population and b) three isolated subpopulations. The 489 contribution is calculated from the posterior median estimates of the recruitment (age- 0

490 abundance).

\subsubsection{Management reference points and stock assessment}

492 Whereas the results obtained on the scale of the entire EC indicate that the sole population is 493 overexploited, the results obtained when considering a three-subpopulation structure revealed

494 highly contrasting levels of exploitation among subpopulations.

495 When considering a single population, the average $S S B$ and $F_{3-8}$ over the past four years 496 were approximately 12,950 t and 0.38 , respectively (Fig. 3a,b,c). $S S B_{M S Y}, C_{M S Y}$ and $F_{M S Y}$ are 497 estimated at 28,090t, 5,470t and 0.21, respectively (Table 4; Fig. 7a), thus indicating that the 498 sole population is currently overexploited, with an average ratio of $F / F_{M S Y}$ near 1.8 and that of $499 S S B / S S B_{M S Y}$ near 0.5 during the last four years.

500 The model with three isolated populations provides a spatial perspective on the population 501 dynamics and the impact of fishing pressure. Estimates of $S S B$ among the various 502 subpopulations (Fig. 3d) are essentially equivalent, with an average $S S B$ of 4,570 t for the 503 West FR subpopulation, 4,130t for the UK subpopulation, and 4,590t for the East FR 504 subpopulation. By contrast, average $F$ are highly contrasted among populations, with average $505 F$ over the past 4 years estimated at $0.20,0.39$ and 0.55 for the West FR, UK and East FR 506 subpopulations, respectively. 
508 Table 4. Summary of point estimates of the management reference points $S S B_{M S Y}, C_{M S Y}$ and $509 F_{M S Y}$ obtained in the models considering (i) a single population and (ii) three isolated 510 subpopulations.

\begin{tabular}{cccc}
\hline Reference points & One single population & \multicolumn{2}{c}{ Three subpopulations } \\
\hline$S S B_{M S Y}$ & 28,090 & West FR & 4,880 \\
& & UK & 8,540 \\
& & East FR & 8,300 \\
$C_{M S Y}$ & 5,470 & West FR & 870 \\
& & UK & 1,670 \\
& & East FR & 2,150 \\
$F_{M S Y}$ & & West FR & 0.19 \\
& 0.21 & UK & 0.21 \\
& & East FR & 0.28 \\
\hline
\end{tabular}

512 The reference points $S S B_{M S Y}, C_{M S Y}, F_{M S Y}$ (Table 4; Fig. 7b) associated with each

513 subpopulation were estimated at 4,880t, $870 \mathrm{t}$ and 0.19 for West FR, 8,540t, 1,670t and 0.21

514 for UK and 8,300t, 2,150t and 0.28 for East FR, respectively. When considering the current

515 state of exploitation (average over four years), it appears that the West FR subpopulation is at

516 full exploitation level, with $F / F_{M S Y}$ at 1.05 and $S S B / S S B_{M S Y}$ at 0.94 , whereas the UK and East

517 FR subpopulations are overexploited (Fig. 7b), with $F / F_{M S Y}$ dramatically greater than 1 (1.9

518 and 2.0, respectively) and $S S B / S S B_{M S Y}$ dramatically lower than 1 ( 0.48 and 0.54 , respectively). 

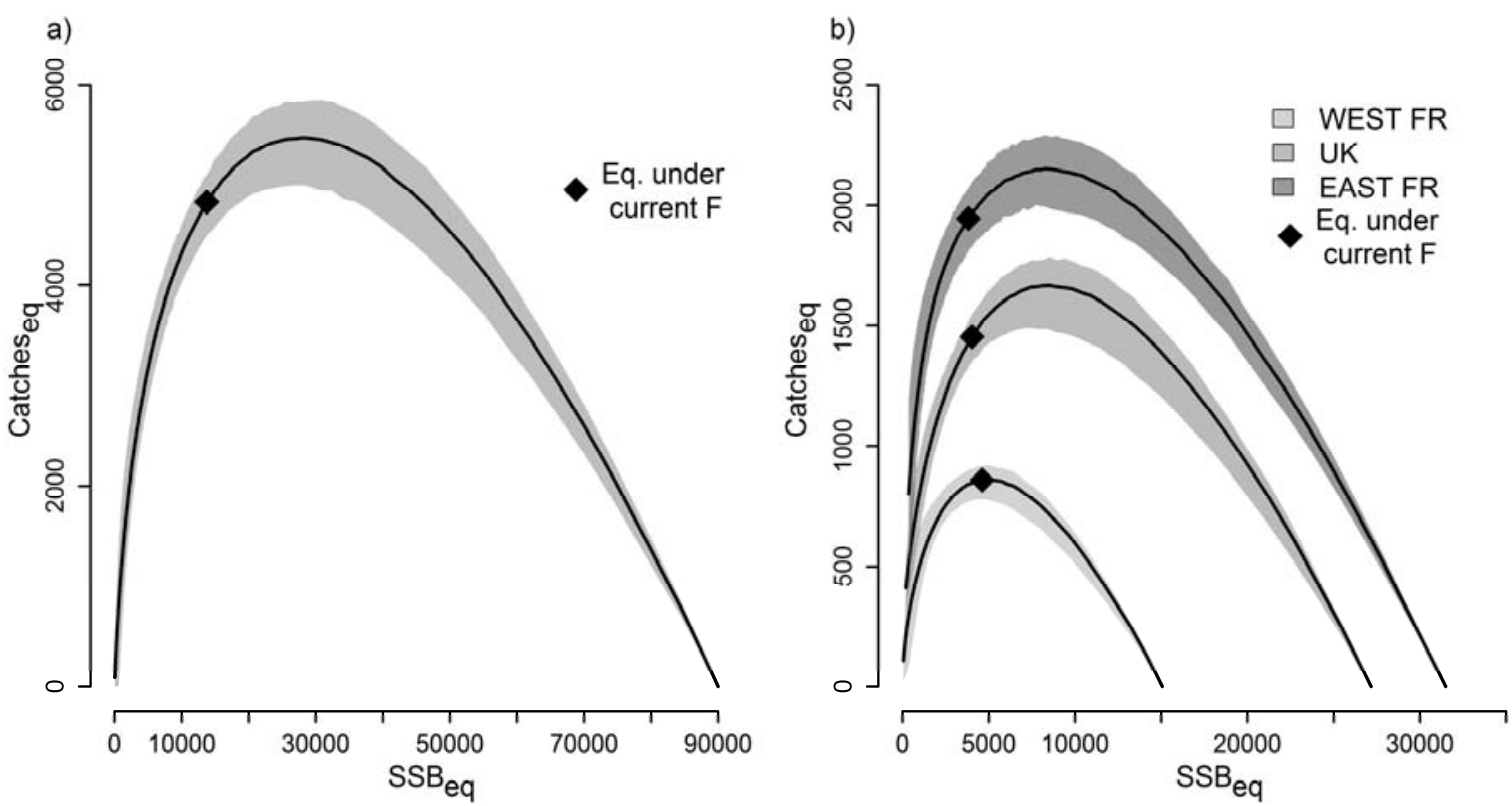

520 Figure 7. Relation between the $S S B$ and catches at equilibrium obtained through the 521 simulation approach in the model considering (a) a single population and (b) three isolated 522 subpopulations. Shaded area: 50\% credibility interval obtained from the Monte Carlo 523 simulation integrating both process and parameters uncertainty. Black diamond: Eq. under 524 current $F$ represents the position on the equilibrium curve obtained with the current fishing 525 mortalities (average over the 4 most recent years).

\section{Discussion}

\subsection{An integrated modeling framework for a better understanding of} metapopulation dynamics

Our results make a significant contribution to the understanding of the sole population dynamics in the EC. The model used to assess the stock of the sole population in the EC considers a simple, homogeneous population with no spatial structure (ICES, 2013). Using the HBM framework, Rochette et al. (2013) make an important contribution by establishing

534 the fundamental basis for a population model that embeds egg and larval drift and survival

535 derived from an oceanic circulation model within a stage-structured life cycle, accounting for

536 the spatial nature of the recruitment process in distinct coastal nursery sectors. The model

537 presented here elaborates on Rochette et al. (2013) and provides additional insights into

538 population dynamics by exploring a metapopulation structure with very low connectivity

539 among three subpopulations. The capacity of Bayesian models to incorporate prior 
540 information also presented the possibility of an efficient use of the available information

541 through the informative prior distribution for the maximum survival rate between settled

542 larvae and 0+ juveniles derived from a meta-analysis on flatfish (Archambault et al., 2014).

543 The consideration of three loosely connected subpopulations increased the model's state-

544 space dimension of the model. But because the two models integrate different sources of data

545 (e.g., spatial AIs of adults and catches that are not included in the model considering one

546 single homogeneous adult population), the usual goodness-of-fit criteria such as the deviance

547 information criterion (Spiegelhalter et al., 2014) are not adapted to compare the tradeoff

548 between the two model structures' complexity and quality of fit. A posterior predictive check

549 conducted for both model configurations did not reveal any strong, general inconsistencies

550 between the fitted model and the different sources of data for both model configurations.

551 Interestingly, when considering the data sources that are common to the two model

552 configurations (i.e., juveniles AIs, catch-at-ages and commercial CPUEs aggregated at the

553 scale of the EC), both model configurations showed similar quality of fit. Additional results

554 (not shown) indicate that the likelihood components restricted to the data shared by the two

555 model structures are comparable between the two models.

556 However, although we were unable to demonstrate that the model considering three isolated

557 subpopulations provides a better fit to the data, a body of ecological knowledge and clues

558 continues to strongly argue for a priori consideration of such a metapopulation structure, and

559 posterior inferences provide a portfolio of ecologically meaningful results.

560 First, strong prior knowledge exists in favor of the limited movements of juveniles (Coggan

561 and Dando, 1988; Anon., 1989; Le Pape and Cognez, 2016) and adults (Kotthaus, 1963;

562 Anon., 1965; Burt and Millner, 2008), and barriers linked to sediment structure limit

563 exchanges between regions (Rochette et al., 2010; 2012). This knowledge was used a priori

564 to define the spatial contours of three subpopulations of the common sole in the EC.

565 Second, taking into account the moderate connectivity between the successive life stages, we

566 were able to produce a diagnosis of the population that, while consistent with ICES estimates

567 at the scale of the EC, provided contrasting, meaningful results on a local scale. This approach

568 allowed us to reconstruct local biomasses' evolution during the past three decades that were

569 revealed as consistent with the time series of spatial abundance indices and catches. The

570 consideration of three subpopulations also led to a substantial reevaluation of the productivity

571 of the various nursery sectors that are quantitatively consistent with the juveniles AIs, catches 
572 and local biomasses estimated for their associated subcomponents. It also drastically reduced

573 the between-years variability of the relative contribution of each nursery sector to total $0+$

574 recruitment, which is consistent with both the concentration hypothesis (Rijnsdorp et al., 1992;

575 Iles and Beverton, 2000; Rooper et al., 2004) and the low recruitment variability described for

576 common sole (Le Pape et al., 2003b; Archambault et al., 2014).

577 Finally, results indicate that the spatial distribution of eggs derived from the fit of the model

578 with three subpopulations with low connectivity matches the observed egg repartition derived

579 from the 1991 eggs survey (Rochette et al., 2012). Because the comparison between the

580 spatial distribution of eggs observed (1991) and simulated a posteriori by the model is not

581 included in the likelihood function, this result can be considered as an element that validates

582 the spatial structure of the adult population.

\section{4.2. Weaknesses and directions for future research}

584 Our modeling approach has some weaknesses. Below, we discuss some of those weaknesses along with some critical needs for knowledge and data about the spatial ecological process

586 that the modeling approach has helped identify. Finally, we highlight a few research avenues

587 that would improve both the knowledge and the models.

\subsubsection{Simulations to explore the tradeoff between model complexity and data} availability

590 Several studies have shown that in the case of complex spatial population dynamics, the

591 explicit consideration of spatial structures in stock-assessment models that are better aligned

592 with ecological reality (instead of simpler models) provide better estimates, when sufficiently

593 informative data are available (Hulson et al., 2013; Hintzen et al., 2015). However, our case

594 study is a data-poor situation because only a few data provide information about the spatial

595 structure of the population. In particular, no time series of spatial catch-at-age data are

596 available. Thus, it is difficult to formally conclude that fitting a spatial structure to the

597 available data results in reliable estimates of abundance and population dynamics. To

598 reinforce the analysis, one interesting perspective for future work would consist of conducting

599 simulations that would cross a few hypotheses about how the dynamics of the true population

600 work with various model and data configurations for the statistical stock-assessment model.

601 This would enable us not only to show which type of assessment might provide reliable 
602 estimates given our data limitations but also to illustrate how gathering more informative data

603 about the spatial processes (for instance spatial catch-at-age or mark-recapture data) would

604 improve the quality of our inferences.

605

606

607

608

609

610

611

612

613

614

615

616

617

618

619

620

621

622

623

624 Based on previous modeling work by Rochette et al. (2013), strong hypotheses were made on 625

\subsubsection{Sensitivity to priors}

Uncertainty about estimates and sensitivity to the prior choice varied according to model compartment. As analyzed (with respect to a previous version of the model) by Rochette et al. (2013), numbers-at-age and all other variables associated with the demographic of ages 1-15, such as $S S B$, recruitment and fishing mortality, are estimated with low uncertainty. Indeed, the demographics of ages 1-15 consist of a catch-at-age model for 14 age classes tracked over 30 years; both catch and abundance indices are available for almost all years and ages.

By contrast, parameters for the density-dependent recruitment process in nursery sectors are estimated with much more uncertainty and are partly confounded. Those parameters are generally difficult to estimate from the data alone (Conn et al., 2010) and we therefore developed a method based on a previous meta-analysis on flatfish (Archambault et al., 2014) to build an informative prior distribution about the maximum survival rates of settled larvae on nursery ground $(\alpha)$. Relying on a previous analysis by Rochette et al. (2013), our results are likely to be sensitive to the choice of priors on those parameters, and using weakly informative priors on the $\alpha_{i}$ 's would certainly lead to poor inferences about stock productivity. Because the models developed in this manuscript have many similarities and the data are the same, and to keep the main message centered on the impact of changing the spatial structure of the model, we did not report any additional sensitivity analysis.

\subsubsection{Improving the model for the recruitment process}

the recruitment process: $(i)$ Within each nursery sector, variability of the recruitment process was modeled as independent lognormal random noise, with no time series autocorrelation; ( $i i)$ The variance of lognormal process noise was considered homogeneous among nurseries; and (iii) Between-years random variations were considered as independent among nursery sectors.

9 Consistent with results found by Rochette et al. (2013), a careful examination of the residual variability did not reveal any particular departure from the hypotheses of constant variance across the five nursery grounds and the time independence of residuals. This is consistent 
632 with previous analysis on the low synchronicity in inter-annual variability of juvenile

633 abundance between the nursery sectors (Riou et al., 2001). Because there are many gaps in the 634 time series of juvenile-abundance indices on nursery sectors ( $47 \%$ missing data; see Tab. 1),

635 data are lacking to estimate parameters for the covariance in the recruitment process among

636 nursery sectors. Including covariance in the recruitment process among nursery sectors would

637 likely impact the population dynamics and stock assessment (Ranta et al., 1997; Liebhold et

638 al., 2004). Therefore, an investigation of how the inclusion of covariance in the time series of

639 recruitment process noise among nursery sectors would change estimates and population

640 dynamics for the sole population in the EC would be an interesting focus for future research.

\section{4.2.4. The need for better knowledge of adult-mediated connectivity}

642 Data on sub-adult and adult migration were lacking, and we were unable to estimate the 643 degree of mixing among the three subpopulations. Our approach thus considered two extreme

644 scenarios of adult-mediated connectivity: full connectivity and full spatial segregation

645 between subpopulations associated with nursery sectors. Whereas a body of ecological

646 knowledge advocates for a loose connectivity among the three subpopulations, improved data

647 collection on movements and connectivity is a top priority. Natural markers, which include

648 genetic markers, xenobiotics, stable isotopes, otolith microchemistry and parasites and their

649 possible combination (Selkoe et al., 2008; Fodrie and Herzka, 2013), are a first source of data.

650 The analysis of genetic-neutral markers could help infer population structure (Smedbol et al.,

651 2002), although the open nature of the marine environment may prevent a significant signal

652 from emerging (Waples, 1998; Exadactylos et al., 2003; Rolland et al., 2007). Recent

653 approaches using genetic-adaptive markers (Diopere et al., 2013) and combined multi-marker

654 approaches (Cuveliers et al., 2012) provide fruitful perspectives to quantify connectivity

655 among marine subpopulations with a finer spatial resolution. Analyses of the differences in

656 otolith elemental composition have been used to identify the estuarine origin of individuals

657 (Cuveliers et al., 2010). Mark-recapture is also widely used to quantify migration (Hilborn,

658 1990; Rijnsdorp and Pastoors, 1995; Polacheck et al., 2010). Recent work focusing on older

659 juvenile, sub-adult and adult flatfish emphasizes the interest of these approaches (Sackett et

660 al., 2008; Fairchild et al., 2009; Furey et al., 2013). Future methodological work should

661 include the development of integrated models that enables the consideration of multiple

662 sources of data into space-structured population models (Darnaude and Hunter, 2008; Korman

663 et al., 2012; Goethel et al., 2014). 


\subsection{Implications for spatial management}

665 The sole population in the EC, like most exploited marine fish stocks, is currently assessed as 666 a single population. However, our results suggest that the consideration of metapopulation 667 dynamics strongly impacts inferences on stock productivity and conclusions about both stock 668 assessment and (ultimately) fisheries advice.

669 The consideration of three subpopulations induced a substantial reevaluation of the 670 productivity of the various nursery sectors; estimates of the contribution of the East FR 671 subpopulation to the total recruitment doubled, balanced by a decrease in contributions from 672 the West FR and UK subpopulations. Whereas results obtained on the scale of the entire EC 673 indicate that the sole population is exploited far above MSY, assessments obtained when 674 considering a three-subpopulation structure revealed highly contrasting levels of exploitation 675 among subpopulations, with over-exploitation of some of the metapopulation components.

676 Indeed, estimates of local management reference points associated with each subpopulation

677 revealed that the West FR subpopulation is approaching full exploitation, whereas the UK and 678 East FR subpopulations are overexploited. The practical consequences of our conclusions 679 may even increase when considering the local fisheries, which are characterized by fleets with 680 limited movement, without large-scale tracking of fish (Tidd et al., 2015).

681 Beyond our case study, this work emphasizes the role of space in population functioning for 682 species whose different life-history stages are segregated among specific habitats. Larval 683 retention in marine populations is suspected to occur more than originally thought (Cowen et 684 al., 2000; Warner and Cowen, 2002). Juvenile segregation in restricted nursery areas is also a 685 common feature of fish populations (Vasconcelos et al., 2014). As noted by Frisk et al. (2014), 686 our case study stresses the need to more thoroughly assess the importance of adult-mediated connectivity. Spatial integrated life-cycle models such as the one developed in this work provides a contribution to the quantitative assessment of spatial fishery and coastal habitat management plans. First, as previously shown by several authors, ignoring metapopulation

690 structure in stock assessment models could result in local over/under exploitation (Tuck and

691 Possingham, 1994; Ying et al., 2011; Yau et al., 2014) and improving data collection and 692 statistical methods to estimate the parameters of spatial life-cycle models is a top priority for 693 the optimal allocation of fishing pressure. Second, accounting for metapopulation dynamics is 694 critical for an optimal assessment of essential habitat preservation and/or restoration that 
695 could be at least as efficient as assessing fishing pressure for restoring populations of nursery696 dependent species (Levin and Stunz, 2005; van de Wolfshaar et al., 2011).

\section{Acknowledgements}

698 This work was funded partly by the European Community's Seventh Framework Programme 699 (FP7/2007-2013) under Grant Agreement No. 266445 for the project Vectors of Change in 700 Oceans and Seas Marine Life, Impact on Economic Sectors (VECTORS). The authors thank 701 the various people and institutes that provided data: the GIP Seine-Aval and Marie Laure 702 Cochard, Paul Marchal and Marie Savina-Rolland (Ifremer). We are grateful to Sophie 703 Pasquier for compiling the references. 


\section{References}

Anon. 1965. Report of the working group on sole. ICES Coop.Res. Rep. 5: 1-126.

Anon. 1989. Report of ad hoc study group on juvenile sole tagging. ICES CM 1989/G: 21, $34 p p$.

Archambault, B., Le Pape, O., Bousquet, N., and Rivot, E. 2014. Density-dependence can be revealed by modelling the variance in the stock-recruitment process: an application to flatfish. ICES J. Mar. Sci. 71(8): 2127-2140.
Botsford, L.W., Brumbaugh, D.R., Grimes, C., Kellner, J.B., Largier, J., O’Farrell, M.R.,

Ralston, S., Soulanille, E., and Wespestad, V. 2009. Connectivity, sustainability, and yield: bridging the gap between conventional fisheries management and marine protected areas. Rev. Fish Biol. Fish. 19: 69-95.

Buckland, S.T., Newman, K.B., Fernández, C., Thomas, L., and Harwood, J. 2007. Embedding population dynamics models in inference. Stat. Sci. 22(1): 44-58.

Burt, G. J., and Millner, R. S. 2008. Movements of sole in the southern North Sea and eastern English Channel from tagging studies (1955-2004). Sci. Ser. Tech. Rep. 44.

Brooks, S. P., and Gelman, A. 1998. General methods for monitoring convergence of iterative simulations. J. Comp. Graph. Stat. 7(4): 434-455.

\section{Carruthers, T.R., McAllister, M.K., and Taylor, N.G. 2011. Spatial surplus production} modeling of Atlantic tunas and billfish. Ecol. Appl. 21: 2734-2755.

Carson, H.S., Cook, G.S., López-Duarte, P.C., and Levin, L.A. 2011. Evaluating the importance of demographic connectivity in a marine metapopulation. Ecology 92: 1972-1984. Chambers, R.C., and Trippel, E.A. 1997. Early life history and recruitment in fish populations. Chapman and Hall, New York.

Cianelli, L., Fisher, J., Skern-Mauritzen, M., Hunsicker, M., Hidalgo, M., Frank, K., and Bailey, K. 2013. Theory, consequences and evidence of eroding population spatial structure in harvested marine fishes: a review. Mar. Ecol. Prog. Ser. 480: 227-243.

30 Clark, J.S. 2005. Why environmental scientists are becoming Bayesians? Ecol. Lett. 8: 2-14.

1 Coggan, R.A., and Dando, P.R. 1988. Movements of juvenile Dover sole, Solea solea (L.), in 32 the Tamar Estuary, South-western England. J. Fish Biol. 33: 177-184. 
733 Conn, P.B., Williams, E.H., and Shertzer, K.W. 2010. When can we reliably estimate the

734 productivity of fish stocks? Can. J. Fish. Aquat. Sci. 67:511-523.

735 Cowen, R.K., Lwiza, K.M.M., Sponaugle, S., Paris, C.B., and Olson, D.B. 2000. Connectivity

736 of Marine Populations: Open or Closed? Science 287: 857-859.

737 Cunningham, C., Reid, D., McAllister, M., Kirkwood, G., and Darby, C. 2007. A Bayesian

738 state-space model for mixed-stock migrations, with application to Northeast Atlantic

739 mackerel Scomber scombrus. Afr. J. Mar. Sci. 29(3): 347-367.

740 Cuveliers, E.L., Geffen, A.J., Guelinckx, J., Raeymaekers, J.A.M., Skadal, J., Volckaert,

741 F.A.M., and Maes, G.E. 2010. Microchemical variation in juvenile Solea solea otoliths as a

742 powerful tool for studying connectivity in the North Sea. Mar. Ecol. Prog. Ser. 401: 211-220.

743 Cuveliers, E., Larmuseau, M., Hellemans, B., Verherstraeten, S., Volckaert, F., and Maes, G.

744 2012. Multi-marker estimate of genetic connectivity of sole (Solea solea) in the North-East

745 Atlantic Ocean. Mar. Biol. 159: 1239-1253.

746 Darnaude, A., and Hunter, E. 2008. Coupled use of data storage tags and otolith

747 microchemistry to assess population dispersal and intra-specific diversity in migratory

748 behaviour in North Sea plaice (Pleuronectes platessa L.). Comp. Biochem. Phys. A 150: S205.

749 Diopere, E., Hellemans, B., Volckaert, F.A.M., and Maes, G.E. 2013. Identification and

750 validation of single nucleotide polymorphisms in growth- and maturation-related candidate

751 genes in sole (Solea solea L.). Mar. Genom. 9: 33-38.

752 Drouineau, H., Mahévas, S., Bertignac, M., and Duplisea, D. 2010. A length-structured

753 spatially explicit model for estimating hake growth and migration rates. ICES J. Mar. Sci.

754 67(8) 1697-1709.

755 Exadactylos., A., Geffen, A.J., Panagiotaki, P., and Thorpe, J.P. 2003. Population structure of

756 Dover sole Solea solea: RAPD and allozyme data indicate divergence in European stocks.

757 Mar. Ecol. Prog. Ser. 246: 253-264.

758 Fairchild, E.A., Rennels, N., and Howell, H. 2009. Using telemetry to monitor movements

759 and habitat use of cultured and wild juvenile winter flounder in a shallow estuary. In Tagging

760 and Tracking of Marine Animals with Electronic Devices, Springer Netherlands. pp. 5-22.

761 Fodrie, F., and Herzka, S. 2013. A comparison of otolith geochemistry and stable isotope

762 markers to track fish movement: describing estuarine ingress by larval and post-larval halibut.

763 Estuar. Coast. 39: 906-917. 
764 Frisk, M.G., Jordaan, A., and Miller, T.J. 2014. Moving beyond the current paradigm in 765 marine population connectivity: are adults the missing link? Fish Fish. 15(2): 242-254.

766 Furey, N., Dance, M., and Rooker, J. 2013. Fine-scale movements and habitat use of juvenile 767 southern flounder Paralichthys lethostigma in an estuarine seascape. J. Fish Biol. 82: 14697681483.

769 Gaines, S.D., White, C., Carr, M.H., and Palumbi, S.R. 2010. Designing marine reserve 770 networks for both conservation and fisheries management. P. Natl. Acad. Sci. 107: 1828677118293.

772 Gallego, A., North, E.W., and Houde, E.D. 2012. Understanding and quantifying mortality in 773 pelagic, early life stages of marine organisms - Old challenges and new perspectives. J.

774 Marine Syst. 93: 1-3.

775 Gelman, A. 2009. Bayes, Jeffreys, prior distributions and the philosophy of statistics. Stat. Sci. $776 \quad 24(2): 176-178$.

777 Gelman, A., Carlin, J.B., Stern, H.S., and Rubin, D.B. 2004. Bayesian Data Analysis.

778 Chapman \& Hall/CRC. 717 pp.

779 Gibson, R.N. 2004. Flatfishes: Biology and Exploitation. Wiley. 419 pp.

780 Goethel, D.R., Legault, C.M., and Cadrin, S.X. 2014. Demonstration of a spatially explicit, 781 tag-integrated stock assessment model with application to three interconnected stocks of 782 yellowtail flounder off of New England. ICES J. Mar. Sci. 72(1): 164-177.

783 Grosberg, R.K., and Levitan, D.R. 1992. For adults only? Supply-side ecology and the history 784 of larval biology. Trends Ecol. Evol. 7: 130-133.

785 Grüss, A., Kaplan, D., Guenette, S., Roberts, C., and Botsford, L. 2011. Consequences of 786 adults and juvenile movement for marine protected areas. Biol. Conserv. 144: 692-702.

787 Guan, W., Cao, J., Chen, Y., and Cieri, M. 2013. Impacts of population and fishery spatial 788 structures on fishery stock assessment. Can. J. Fish. Aquat. Sci. 70: 1178-1189.

789 Hellberg, M.E., Burton, R.S., Neigel, J.E., and Palumbi, S.R. 2002. Genetic assessment of 790 connectivity among marine populations. B. Mar. Sci. 70: 273-290.

791 Hilborn, R. 1990. Determination of Fish Movement Patterns from Tag Recoveries using 792 Maximum Likelihood Estimators. Can. J. Fish. Aquat. Sci. 47: 635-643. 
793 Hilborn, R., and Walters, C.J. 1992. Quantitative fisheries stock assessment: choice, dynamics 794 and uncertainty. Rev. Fish Biol. Fisher. 2: 177-178.

795 Hinrichsen, H.-H., Dickey-Collas, M., Huret, M., Peck, M.A., and Vikebø, F.B. 2011.

796 Evaluating the suitability of coupled biophysical models for fishery management. ICES J.

797 Mar. Sci. 68: 1478-1487.

798 Hintzen, N.T., Roel, B., Benden, D., Clarke, M., Egan, A., Nash, R.D.M., Rohlf, N. and 799 Hatfield, E. M. C. 2015. Managing a complex population structure: exploring the importance 800 of information from fisheries-independent sources. ICES J. Mar. Sci. 72(2) : 528-542.

801 Hulson, P.J. F., Quinn, T.J., Hanselman, D.H. and Ianelli, J.N. 2013. Spatial modeling of 802 Bering Sea walleye pollock with integrated age-structured assessment models in a changing 803 environment. Can. J. Fish. Aquat. Sci. 70(9), 1402-1416.

804 ICES 2010. Report of the Working Group on the Assessment of Demersal Stocks in the North 805 Sea and Skagerrak (WGNSSK), 5-11 May 2010. ICES CM 2010/ ACOM:13. Copenhagen, 806 ICES Headquarters, 1058 pp.

807 ICES. 2013. Report of the Working Group on the Assessment of Demersal Stocks in the 808 North Sea and Skagerrak (WGNSSK), 24-30 April 2013, ICES Headquarters, Copenhagen. 809 ICES Document CM 2013/ACOM:13. 1435 pp.

810 Iles, T.C., and Beverton, R.J.H. 2000. The concentration hypothesis: the statistical evidence. 811 ICES J. Mar. Sci. 57: 216-227.

812 Korman, J., Martell, S.J.D., Walters, C.J., Makinster, A.S., Coggins, L.G., Yard, M.D., and 813 Persons, W.R. 2012. Estimating recruitment dynamics and movement of rainbow trout 814 (Oncorhynchus mykiss) in the Colorado River in Grand Canyon using an integrated 815 assessment model. Can. J. Fish. Aquat. Sci. 69(11): 1827-1849.

816 Kotthaus, A. 1963. Tagging experiments with the North Sea sole (Solea solea) in 1959 and 817 1960. In Special Publication number 4 of the International Commission for the Northwest 818 Atlantic Fisheries, pp. 123-129. Headquarters of the Commission, Darthmouth, Nova Scotia, 819 Canada.

820 Le Pape, O., Chauvet, F., Mahévas, S., Lazure, P., Guérault, D., and Désaunay, Y. $2003 a$.

821 Quantitative description of habitat suitability for the juvenile common sole (Solea solea, L.) in 822 the Bay of Biscay (France) and the contribution of different habitats to the adult population. J. 823 Sea Res. 50: 139-149. 
824 Le Pape, O., Chauvet, F., Désaunay, Y., Guérault, G. 2003b. Relationship between

825 interannual variations of the river plume and the extent of nursery grounds for the common

826 sole (Solea solea, L.) in Vilaine Bay. Effects on recruitment variability. J. Sea Res. 50: 177827185.

828 Le Pape, O., and Bonhommeau, S. 2015. The food limitation hypothesis for juvenile marine 829 fish. Fish Fish. 16(3): 373-398.

830 Le Pape, O. and Cognez, N. 2016. The range of juvenile movements of estuarine and coastal 831 nursery dependent flatfishes: estimation from a meta-analytical approach. J. Sea Res. 107(1): $832 \quad 43-55$

833 Levin, P.S., and Stunz, G.W. 2005. Habitat triage for exploited fishes: Can we identify 834 essential ‘Essential Fish Habitat?’ Estuar. Coast. Shelf S. 64: 70-78.

835 Liebhold, A., Koenig, W. D., and Bjørnstad, O.N. 2004. Spatial synchrony in population 836 dynamics. Annu. Rev. Ecol. Evol. S. 35(1) 467-490.

837 Massiot-Granier, F., Prévost, E., Chaput, G., Potter, T., Smith, G., White, J., Mantyniemi, S., 838 Rivot, E. 2014. Embedding stock assessment within an integrated hierarchical Bayesian life 839 cycle modelling framework: an application to Atlantic salmon in the Northeast Atlantic. ICES 840 J. Mar. Sci. 71(7): 1653-1670.

841 McAllister, M., Hill, S., Agnew, D., Kirkwood, G., and Beddington, J. 2004. A Bayesian 842 hierarchical formulation of the De Lury stock assessment model for abundance estimation of 843 Falkland Islands' squid (Loligo gahi). Can. J. Fish. Aquat. Sci. 61:1048-1059.

844 Miller, T.J. 2007. Contribution of individual-based coupled physical-biological models to 845 understanding recruitment in marine fish populations. Mar. Ecol. Prog. Ser. 347: 127-138.

846 Parent, E., and Rivot, E. 2013. Introduction to Hierarchical Bayesian Modeling for Ecological 847 Data. Applied Environmental Statistics. Chapman \& Hall/CRC. 427 pp.

848 Peck, M., and Hufnagl, M. 2012. Can IBMs tell us why most larvae die in the sea? Model 849 sensitivities and scenarios reveal research needs. J. Marine Syst. 93: 77-93.

850 Petitgas, P., Rijnsdorp, A., Dickey-Collas, M., Engelhard, G., Peck, M., Pinnegar, J., 851 Drinkwater, K., Huret, M., and Nash, R.D.M. 2013. Impacts of climate change on the 852 complex life cycles of fish. Fish Oceanogr. 22: 121-139. 
853 Planque, B., Loots, C., Petitgas, P., Lindstrom, U., and Vaz, S. 2011. Understanding what

854 controls the spatial distribution of fish populations using a multi-model approach. Fish.

855 Oceanogr. 20: 1-17.

856 Polacheck, T., Paige Eveson, J., and Laslett, G.M. 2010. Classifying tagging experiments for

857 commercial fisheries into three fundamental types based on design, data requirements and

858 estimable population parameters. Fish and Fish. 11(2): 133-148.

859 Punt, A.E., Hilborn, R. 1997. Fisheries stock assessment and decision analysis: the Bayesian

860 approach. Rev. Fish Biol. Fisher. 7: 35-63.

861 Ranta, E., Kaitala, V., Lindström, J., and Helle, E. 1997. The Moran effect and synchrony in 862 population dynamics. Oikos, 78(1): 136-142.

863 Rijnsdorp, A.D., and Pastoors, M.A. 1995. Modelling the spatial dynamics and fisheries of

864 North Sea plaice (Pleuronectes platessa L.) based on tagging data. ICES J. Mar. Sci. 52: $963-$ 865980.

866 Rijnsdorp, A.D., Van Beek, F.A., Flatman, S., Millner, R.M., Riley, J.D., Giret, M., and De

867 Clerck, R. 1992. Recruitment of sole stocks, Solea solea (L.), in the Northeast Atlantic. Neth.

868 J. Sea Res. 29: 173-192.

869 Riou, P., Le Pape, O., and Rogers, S.I. 2001. Relative contributions of different sole and 870 plaice nurseries to the adult population in the Eastern Channel : application of a combined 871 method using generalized linear models and a geographic information system. Aquat. Living 872 Resour. 14: 125-135.

873 Rivot, E., Prévost, E., Parent, E., and Baglinière, J.L. 2004. A Bayesian state-space modelling 874 framework for fitting a salmon stage-structured population dynamic model to multiple time 875 series of field data. Ecol. Model. 179: 463-485.

876 Rivot, E., Prévost, E. 2002. Hierarchical bayesian analysis of capture-mark-recapture data.

877 Can. J. Fish. Aquat. Sci. 59: 1768-1784

878 Rochette, S., Huret, M., Rivot, E., and Le Pape, O. 2012. Coupling hydrodynamic and 879 individual-based models to simulate long-term larval supply to coastal nursery areas. Fish.

880 Oceanogr. 21: 229-242.

881 Rochette, S., Le Pape, O., Vigneau, J., and Rivot, E. 2013. A hierarchical Bayesian model for 882 embedding larval drift and habitat models in integrated life cycles for exploited fish. Ecol. 883 Appl. 23: 1659-1676. 
884 Rochette, S., Rivot, E., Morin, J., Mackinson, S., Riou, P., and Le Pape, O. 2010. Effect of

885 nursery habitat degradation on flatfish population: Application to Solea solea in the Eastern

886 Channel (Western Europe). J. Sea Res. 64: 34-44.

887 Rolland, J.-L., Bonhomme, F., Lagardere, F., Hassan, M., and Guinand, B. 2007. Population

888 structure of the common sole (Solea solea) in the Northeastern Atlantic and the Mediterranean

889 Sea: revisiting the divide with EPIC markers. Mar. Biol. 151: 327-341.

890 Rooper, C.N., Gunderson, D.R., and Armstrong, D.A. 2004. Application of the concentration

891 hypothesis to English sole in nursery estuaries and potential contribution to coastal fisheries.

892 Estuaries 27: 102-111.

893 Ruiz, J., González-Quirós, R., Prieto, L., and Navarro, G. 2009. A Bayesian model for 894 anchovy (Engraulis encrasicolus): the combined forcing of man and environment. Fish.

895 Oceanogr. 18: 62-76.

896 Sackett, D.K., Able, K.W., and Grothues, T.M. 2008. Habitat dynamics of summer flounder

897 Paralichthys dentatus within a shallow USA estuary, based on multiple approaches using

898 acoustic telemetry. Mar. Ecol. Prog. Ser. 364: 199-212.

899 Savina, M., Lacroix, G., and Ruddick, K. 2010. Modelling the transport of common sole

900 larvae in the southern North Sea: Influence of hydrodynamics and larval vertical movements.

901 J. Marine Syst. 81: 86-98.

902 Savina, M., Lunghi, M., Archambault, B., Baulier, L., Huret, M., and Le Pape, O. in press.

903 Sole larval supply to coastal nurseries: Interannual variability and connectivity at

904 interregional and interpopulation scales. J. Sea. Res.

905 http://doi.org/10.1016/j.seares.2015.11.010.

906 Selkoe, K., Henzler, C., and Gaines, S. 2008. Seascape genetics and the spatial ecology of

907 marine populations. Fish and Fish. 9: 363-377.

908 Smedbol, R.K., McPherson, A., Hansen, M.M., and Kenchington, E. 2002. Myths and

909 moderation in marine 'metapopulations'? Fish Fish. 3: 20-35.

910 Spiegelhalter, D.J., Best, N.G., Carlin, B.P., and van der Linde, A. 2014. The deviance

911 information criterion: 12 years on. J. Roy. Statist. Soc. Ser. B. 76(3): 485-493.

912 Stelzenmuller, V., Schulze, T.F.H.O., and Berkenhagen, J. 2011. Integrating modelling tools

913 to support risk-based decision-making in marine spatial management. Mar. Ecol. Prog. Ser.

914 441: 197-212. 
915 Strathmann, R.R., Hughes, T.P., Kuris, A.M., Lindeman, K.C., Morgan, S.G., Pandolfi, J.M.,

916 and Warner, R.R. 2002. Evolution of local recruitment and its consequences for marine

917 populations. B. Mar. Sci. 70: 377-396.

918 Taylor, N.G., McAllister, M.K., Lawson, G.L., Carruthers, T., and Block, B.A. 2011. Atlantic

919 bluefin tuna: A novel multistock spatial model for assessing population biomass. PLoS One

920 6(12): e27693.

921 Tidd, A.N., Vermard, Y., Marchal, P., Pinnegar, J, Blanchard, J.L., Milner-Gulland E.J. 2015.

922 Fishing for space: Fine-scale multi-sector maritime activities influence fisher location choice.

923 PLos One 10(1): e0116335.

924 Tuck, G., and Possingham, H. 1994. Optimal harvesting strategies for a metapopulation. B.

925 Math. Biol. 56(1): 107-127.

926 Vasconcelos, R., Eggleston, D.B., Le Pape, O., Tulp, I. 2014. Patterns and processes of

927 habitat-specific demographic variability in exploited marine species. ICES J. Mar. Sci. 71:

928 638-647.

929 Waples, R.S. 1998. Separating the wheat from the chaff: patterns of genetic differentiation in

930 high gene flow species. J. Hered. 89: 438-450.

931 Ward, R.D., Woodwark, M., and Skibinski, D.O.F. 1994. A comparison of genetic diversity

932 levels in marine, freshwater, and anadromous fishes. J. Fish Biol. 44: 213-232.

933 Warner, R.R., and Cowen, R.K. 2002. Local retention of production in marine populations:

934 Evidence, mechanisms, and consequences. B. Mar. Sci. 70: 245-249.

935 Wolfshaar, K. E. van de, HilleRisLambers, R., and Grdmark, A. 2011. Effect of habitat

936 productivity and exploitation on populations with complex life cycles. Mar. Ecol. Prog. Ser.

937 438: 175-184.

938 Yau, A.J., Lenihan, H.S., and Kendall, B.E. 2014. Fishery management priorities vary with

939 self-recruitment in sedentary marine populations. Ecol. Appl. 24(6): 1490-1504.

940 Ying, Y., Chen, Y., Lin, L., Gao, T., and Quinn, T. 2011. Risks of ignoring fish population

941 spatial structure in fisheries management. Can. J. Fish. Aquat. Sci. 68: 2101-2120. 


\section{Appendix A}

\section{Equations for the Hierarchical Bayesian Life-cycle Model}

944 The equation below stand for the model considering three loosely connected subpopulations.

945 The model is written in a state-space form that integrates stochasticity in both the process

946 equations of the population dynamics (process errors) and the observation equations

947 (observation errors). Following this logic, the appendix below first provides the equation for

948 the population dynamics and then provides the equation for the observation process.

949 Subscript $y$ denotes the years in the time series, $i$ denotes the nursery sector $(i=1, \ldots, 5$, with

$9501=$ Seine, $2=$ Veys, $3=$ UK West, $4=$ Rye, $5=$ Somme), and $r$ denotes the component of the

951 metapopulation ( $r=1,2,3$ with $1=$ West FR, associated with nursery grounds Seine and Veys;

$9522=\mathrm{UK}$, associated with nursery grounds UK West and Rye; $3=$ =East FR, associated with

953 nursery ground Somme).

954 Prior distribution or fixed values for parameters are defined in Table A1. The surface of each 955 nursery sector (in $\mathrm{km}^{2}$ ) is given in Table A.2.

\section{Process equations}

\section{Eggs and larval drift}

958 The number of settling larvae (i.e., post-larvae) in nursery sector $i$ at year $y, L_{y, i}$, is defined as 959 follows:

960 (A.1)

$$
L_{y, i}=\sum_{r=1}^{r=3} \omega_{y, r} \cdot D_{y, r, i}
$$

961 where $\omega_{y, r}$ is the egg pool for the subpopulation $r$ at year $y$ and $D_{y, r, i}$ is the probability of

962 success for an egg from the egg pool $r$ to reach the nursery sector $i$ at year $y$ (fixed). The egg

963 pool for each year and each subpopulation is calculated from the spawning stock biomass (all

964 fish between age 3 and 15 take part in reproduction; ICES (2010)):

965 (A.2)

$$
\omega_{y, r}=\sum_{a \geq 3} N_{a, y, r} \cdot p f_{a} \cdot f e c_{a, y}
$$

966 where $p f_{a}$ is the proportion of females for age class $a$ (known, considered constant over the 967 time series and homogeneous across areas), and $f e c_{a, y}$ is the number of eggs per female of 968 age $a$, calculated from the weight at age $w_{a, y}$ as (ICES, 2010; Rochette et al., 2012):

$$
f e c_{a, y}=e^{5.6+1.17 * \log \left(w_{a, y}\right)}
$$

Post-larvae to juvenile on nursery grounds, from settlement to summer's end

971 The expected number of age-0 fish at year $y$ in nursery $i, E\left(N_{0_{y, i}}\right)$, is defined from a density

972 dependent lognormally distributed around an expected mean defined from a Beverton-Holt

973 equation parameterized with $\alpha_{i}$, the nursery-specific maximum survival rate (estimated); $K_{i}$, 
974 the nursery-specific carrying capacity per unit of surface (1000 fish $\cdot \mathrm{km}^{-2}$, estimated); and $S_{i}$, 975 the surface of nursery sector $i\left(\mathrm{~km}^{2}\right.$, fixed; Tab. A.2):

976

$$
E\left(N_{0_{y, i}}\right)=\frac{\alpha_{i} \cdot L_{y, i}}{1+\frac{\alpha_{i}}{K_{i} \cdot S_{i}} \cdot L_{y, i}}
$$

977 Unexplained random variations are captured by independent lognormal random noise with the 978 same variance $\sigma_{B H}^{2}$ for all nurseries (estimated):

$$
N_{0, y, i}=E\left(N_{0_{y, i}}\right) \cdot e^{\varepsilon_{L, y, i}-0.5 \cdot \sigma_{B H}^{2}}
$$

\section{Natural mortality of age 0 from summer's end to December}

981 The number of age- 1 fish in nursery $i, N_{1, y+1, i}$, is defined as

$$
N_{1, y+1, i}=N_{0, y, i} \cdot e^{-1 / 3 \cdot M_{0}} \cdot e^{\varepsilon_{0, y, i}-0.5 \cdot \sigma_{0}^{2}}
$$

983 where $N_{0, y, i}$ is the number of age-0 fish in the nursery $i, M_{0}$ is the annual natural mortality 984 rate at age 0 (fixed) and $\varepsilon_{0, y, i}$ is normal environmental noise with variance $\sigma_{0}^{2}$ (estimated).

\section{Natural and fishing mortality at age 1 and emigration from nursery to adult population}

998

(A.8)

$$
\text { (A.7) } \quad N_{2, y+1, i}=N_{1, y, i} \cdot e^{-Z_{1, y, i}} \cdot e^{\varepsilon_{1, y, i}-0.5 \cdot \sigma_{p}^{2}}
$$

where $Z_{1, y, i}=M_{1}+F_{1, y, r}$ is the total mortality, $M_{1}$ is the annual natural mortality rate at age 1 (fixed), $F_{1, y, r}$ is the fishing mortality in subpopulation $r$ associated with nursery $i$ (estimated), and $\varepsilon_{1, y, i}$ is normal environmental noise with variance $\sigma_{p}^{2}$.

Age-2 fish leave nurseries at the very beginning of the year and are supposed to contribute directly to the subpopulation $r$ adjacent to the nursery. Fish from the Seine and Veys nurseries contribute to subpopulation $r=1=$ West FR; UK West and Rye nurseries contribute to subpopulation $r=2=\mathrm{UK}$; and the Somme nursery contributes to subpopulation $r=3=$ East FR. Starting from $N_{2, y+1, i}$ as defined in eq. (A.7), the number of age-2 fish in each subpopulation $r, N_{2, y+1, r}$ (note the subscript $r$ and not $i$ ), is defined as follows:

\section{Natural and fishing mortality at the adult stage}

1000 The number of fish from age 2 to 15 then follows the classical dynamics:

1001 (A.9)

$$
N_{a+1, y+1, r}=N_{a, y, r} \cdot e^{-z_{a, y, r}} \cdot e^{\varepsilon_{a, y, r}-0.5 \cdot \sigma_{p}^{2}}
$$


1002 where $N_{a, y, r}$ is the number of fish of age $a$ in component $r$ at year $y, Z_{a, y, r}$ is the total 1003 mortality rate and $\varepsilon_{a, y, r}$ is a normal environmental noise with variance $\sigma_{p}^{2}$. All remaining fish 1004 are assumed to die at age 15 .

\section{Model for total mortality $Z$}

$1006 Z_{a, y, r}$ is defined as the sum of natural mortality $M_{a}$, considered constant across years and 1007 subpopulations (Tab. A.1), and fishing mortality $F_{a, y, r}$. For any given age, year and 1008 subpopulation $\mathrm{r}$, the expected mean of the fishing mortality is defined as $E\left(F_{a, y, r}\right)=S_{a} \cdot E_{y, r}$ 1009 with $S_{a}$ as an age-specific selectivity (logistic function considered homogeneous in time and 1010 space, estimated, Tab. A.1) and $E_{y, r}$ as the fishing effort specific to each year and 1011 subpopulation. The time variability of fishing effort $E_{y, r}$ was a priori modeled as a random 1012 walk in the log-scale (Tab. A.1). Additional random variability of $F_{a, y, r}$ around the expected 1013 mean $E\left(F_{a, y, r}\right)$ was captured through a random gamma hierarchical structure with the 1014 coefficient of variation $C V_{F}$ (Tab A.1).

\section{Observation equations}

\section{Juvenile abundance indices}

1017 The abundance indices of age- 0 and age- 1 juveniles in nursery $i$ are considered as lognormal random observations of abundance $N_{0, y, i}$ and $N_{1, y, i}$, respectively:

1019 (A.10)

1020

$$
\begin{aligned}
& I_{0, y, i}=q_{0} \cdot N_{0, y, i} \cdot e^{\varepsilon_{I_{0}, y, i}-0.5 \cdot \sigma_{I_{j u v}}^{2}} \\
& I_{1, y, i}=q_{1} \cdot N_{1, y, i} \cdot e^{\varepsilon_{I_{1}, y, i}-0.5 \cdot \sigma_{I_{j u v}}^{2}}
\end{aligned}
$$
with $q_{0}$ and $q_{1}$ the age-specific catchability, $\varepsilon_{I_{0}, y, i}$ and $\varepsilon_{I_{1}, y, i}$ independent normal random noise with the same observation error variance $\sigma_{I_{j u v}}^{2}$ (estimated).

\section{Adult abundance indices}

1024 In the model considering three subpopulations, three time series of abundance indices (AI) of 1025 age-2 to age-15 fish are used: CPUEs from the UK and Belgium commercial fleet (UKBCT 1026 and BEBCT, respectively), both of which are available on the scale of the entire Eastern 1027 Channel, and UK bottom-trawl surveys available for each subpopulations $(r=1,2,3)$. One 1028 observation equation is written for each AI, with each observation equation contributing to the 1029 whole likelihood function. The same general form of observation equation is used for all AIs, 1030 which are all considered as lognormal random observations of the abundance at age but with 1031 parameters specific for the fleet (UKBCT, BEBCT, UKBTS) age, year (and eventually 1032 subpopulation for UKBTS):

$$
\text { AI }_{\text {fleet }_{a, y,(r)}}=q_{\text {fleet }} \cdot S_{a} \cdot N_{a_{y, i,(r)}} \cdot e^{\varepsilon_{f l e e t, a, y,(r)}-0.5 \cdot \sigma_{I}^{2}}
$$

1034 where $A I_{\text {fleet }_{a, y,(r)}}$ is the observed AI of age $a$ at year $y$ on a different spatial scale (in

1035 subpopulations $r$ for the UKBTS survey; in the whole EC for other indices), $q_{\text {fleet }}$ is the fleet- 
1036 specific catchability, $S_{a}$ is the age-specific selectivity (considered homogeneous among fleets),

1037 and $\varepsilon_{\text {fleet,a, } y,(r)}$ is independent random noise with the same observation error variance $\sigma_{I_{A d}}^{2}$

1038 (estimated; homogeneous among fleets).

\section{Catches-at-age aggregated on the scale of the Eastern Channel}

1040 Catches-at-age predicted by the model $\left(H_{a, y, r}\right)$ were calculated for each subpopulation with 1041 the standard Baranov equation:

$$
H_{a, y, r}=N_{a, y, r} \cdot\left(\frac{F_{a, y, r}}{F_{a, y, r}+M_{a}}\right) \cdot\left(1-e^{-\left(F_{a, y, r}+M_{a}\right)}\right)
$$

1043 Annual catches-at-age $\left(C_{a, y}\right.$; observed) were available from stock assessment reports only on 1044 the scale of the Eastern Channel; however, they were not available separately for the three 1045 subpopulations. Catches-at-age predicted by the model were then first aggregated at the scale 1046 of the Eastern Channel $\left(H_{a, y}=\sum_{r=1}^{r=3} H_{a, y, r}\right)$ and considered observed with lognormal errors:

$$
C_{a, y}=H_{a, y} \cdot e^{\varepsilon_{C a, y}-0.5 \cdot \sigma_{C}^{2}}
$$

1048 where $\varepsilon_{C a, y}$ are independent normal random noise with observation error variance $\sigma_{C}^{2}$ 1049 (estimated).

\section{Spatial repartition of catches (weight) among subpopulations}

A likelihood function for the catch weight ratio per subpopulation $\left(p w_{t, r}, \sum_{r=1: 3} p w_{t, r}=1\right)$ was also incorporated into the model. The catch weight ratio was originally available using the ICES statistical rectangle from 2003 to 2011; however, it was here aggregated at the scale of the three areas associated with each subpopulation. Before 2003, the catch weight ratio per subpopulation was derived from the catch ratio per country (weight; known for the entire time series) combined with the average repartition of catches (weight) among the three areas calculated for each country over the most recent time series 2003-2011. This procedure only assumes a constant spatial repartition of national fleets among the three areas and is a reasonable hypothesis because no major change in the national fleet strategies has been observed between 1982 and 2011 (Y. Vermard, com. Pers.). The catch ratio predicted by the model $\left(\pi_{y, r}\right)$ was calculated from the catches-at-age predicted by the model $\left(C_{a, y, r}\right)$ and the weight-at-age ( $w_{a, y}$; observed). A Dirichlet likelihood function was used to capture observation errors between the observed and predicted catch ratio. The predicted catch weight ratio was scaled to mimic the precision that would be obtained with a sample of 500 tones:

$$
\text { (A.15) } \quad\left(p w_{t, r=1}, p w_{t, r=2}, p w_{t, r=2}\right) \sim \operatorname{Dirichlet}\left(500 \times\left(\pi_{t, r=1}, \pi_{t, r=2}, \pi_{t, r=3}\right)\right)
$$

\section{Parameters and priors}

\section{Prior distributions or fixed values of parameters are given in Tab. A1.}

Following Rochette et al. (2013), informative priors were set for parameters of the selectivity $S_{a}$, based on ICES (2013). The priors on the carrying capacity of nursery sectors, $K_{i}$ 's, were weakly informative in the sense of Gelman (2009), i.e., it allows the data to speak while being strong enough to exclude unrealistic values (the $90 \%$ percentile of the prior predictive 
1072 distribution is more than 100 times greater than the highest estimated density in nurseries of 1073 the Bay of Biscay; Le Pape et al., 2003a).

1074 Informative priors were set on the nursery-specific maximum survival rates $\alpha_{i}$. Taking away 1075 the EC sole dataset from the database used for the meta-analysis in Archambault et al. (2014), 1076 the posterior predictive distribution of $\alpha$ was derived and considered to build an informative 1077 prior for this study. The method developed in Archambault et al. (2014) provides a predictive 1078 distribution for the slope at origin calculated from a Beverton-Holt relationship calculated 1079 from egg-to-egg (denoted $\alpha_{\text {meta }}$ ). By contrast, parameter $\alpha$ in our model (denoted $\left.\alpha_{H B M}\right)$ 1080 stands for the survival rate from settled larvae to 0+ juveniles (in September). To transfer the 1081 information from $\alpha_{\text {meta }}$ to $\alpha_{H B M}$, average demographic parameters specific to the Eastern 1082 Channel were used to complete the life cycle from the age-0 juveniles in September to eggs:

$$
S_{\omega-L} \cdot \alpha_{H B M} \cdot e^{-M_{0} \cdot 4 / 12} \cdot \overline{F e c} \cdot S P R_{F=0}=\alpha_{m e t a}
$$

1084 with $S_{\omega-L}$ as the average eggs to post-larvae survival, $\overline{F e c}$ as the average fecundity, $S P R_{F=0}$ 1085 the spawning biomass produced in the absence of fishing and $e^{-M_{0} \cdot 4 / 12}$ as the natural 1086 mortality from observation in September to recruitment at age 1 in January. Finally, because 1087 the meta-analysis of Archambault et al. (2014) was derived using recruitment estimated by 1088 ICES (recruitment at age 1 back-calculated from age 2), we also took into account the 1089 differences between the mortality used by ICES $\left(M_{1 \text { ICES }}=0.1\right)$ and the one used in our model $1090\left(M_{1_{H B M}}=2.6\right)$. The following final equation was then used to scale the posterior predictive of $1091 \alpha_{\text {meta }}$ to obtain the informative prior of $\alpha_{H B M}$ :

1092

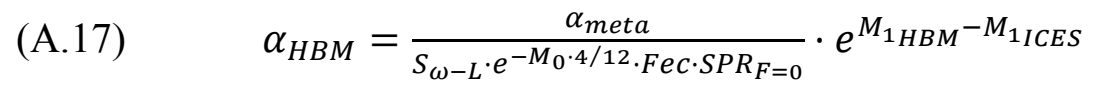


1094 Table A.1. Prior distribution (or fixed values) for the parameters of the Hierarchical Bayesian 1095 Life-cycle Model.

\begin{tabular}{|c|c|c|}
\hline Parameters & Value / prior / structure & Description \\
\hline$M_{a}$ & $\begin{array}{l}\text { Age } 0: 1.5 \text {; Age } 1: 2.6 ; \text { Age } 3-11: 0.1 ; \text { Age } 12: 0.2 ; \text { Age } 13: 0.3 \text {; } \\
\text { Age 14: } 0.4 ; \text { Age } 15: 0.5\end{array}$ & Natural mortality at age $a\left(y^{-1}\right)$ \\
\hline$S_{a}$ & $\begin{array}{l}a_{50} \sim \operatorname{Gamma}(E=3, C V=0.1) \\
\delta \sim \operatorname{Gamma}(E=1, C V=0.2)\end{array}$ & $\begin{array}{l}\text { Age-specific gear selectivity. } \\
\text { Logistic curve parameterized with } \\
\left(a_{50}, \delta\right) . a_{50}: \text { the age at which } \\
S_{a}=0.5 ; \delta: \text { the difference (in years) } \\
\text { between } S_{a}=0.25 \text { and } S_{a}=0.75 \\
S_{a} \text { is scaled to } 1 \text { for a }=15 .\end{array}$ \\
\hline$\sigma_{p}^{2}$ & $\sigma_{p}^{2}=0.001$ & $\begin{array}{l}\text { Variance of process errors on the } \\
\text { dynamics of adult stages (fixed to a very } \\
\text { low value) }\end{array}$ \\
\hline$E_{y, r}$ & $\begin{array}{l}\log \left(E_{y=1, r}\right) \sim \operatorname{Norm}(E=0, \sigma=\sqrt{10}) \\
\left.\log \left(E_{y, r}\right) \sim \operatorname{Norm}\left(E=\log \left(E_{y-1, r}\right), \sigma_{E}\right)\right) \\
\sigma_{E} \sim \operatorname{Unif}(0.01,0.5)\end{array}$ & $\begin{array}{l}\text { Fishing effort } \\
\text { Prior defined as a random walk in the log- } \\
\text { scale }\end{array}$ \\
\hline $\mathrm{F}_{\mathrm{a}, \mathrm{y}, \mathrm{r}}$ & $\begin{array}{l}\mathrm{F}_{\mathrm{a}, \mathrm{y}, \mathrm{r}} \sim \operatorname{Gamma}\left(\mathrm{E}=\mathrm{E}_{\mathrm{y}, \mathrm{r}} \cdot \mathrm{S}_{\mathrm{a}}, \mathrm{CV}_{\mathrm{F}}\right) \\
\mathrm{CV}_{\mathrm{F}} \sim \operatorname{Unif}(0,1)\end{array}$ & $\begin{array}{l}\text { Fishing mortality } \\
\text { Exchangeable hierarchical structure }\end{array}$ \\
\hline$\alpha_{i}$ & $\begin{array}{l}\log \left(\alpha_{i}\right) \sim \operatorname{Norm}\left(E=\mu_{\log \alpha}, \sigma=\sigma_{\log \alpha}\right)[, 0] \\
\mu_{\log \alpha} \sim \operatorname{Norm}(E=-3, \sigma=\sqrt{0.1}) \\
\sigma_{\log \alpha} \sim \operatorname{Unif}(0,2.5)\end{array}$ & $\begin{array}{l}\text { Nursery-specific maximum survival rates. } \\
\text { Hierarchical structure with informative } \\
\text { priors derived from Archambault et al. } \\
\text { (2014) }\end{array}$ \\
\hline$K_{i}$ & $\begin{array}{l}K_{i} \sim \operatorname{Norm}\left(E=\mu_{K}, \sigma=\sigma_{K}\right) 1_{>0} \\
\mu_{K} \sim \operatorname{Norm}(E=100, \sigma=100) \\
\sigma_{K} \sim \operatorname{Unif}(10,300)\end{array}$ & $\begin{array}{l}\text { Nursery-specific carrying capacity per } \\
\text { unit of surface }\left(1000 \text { fish } \cdot \mathrm{km}^{-2}\right) \text {. } \\
\text { Hierarchical structure with weakly } \\
\text { informative priors }\end{array}$ \\
\hline$\sigma_{B H}^{2}$ & $\log \left(\sigma_{B H}^{2}\right) \sim \operatorname{Unif}(-10,10)$ & $\begin{array}{l}\text { Variance of process errors on the post- } \\
\text { larvae to juvenile BH relationship }\end{array}$ \\
\hline$\sigma_{0}^{2}$ & $\log \left(\sigma_{0}^{2}\right) \sim \operatorname{Unif}(-10,10)$ & $\begin{array}{l}\text { Variance of process errors from age- } 0 \text { to } \\
\text { age- } 1 \text { fish }\end{array}$ \\
\hline$\sigma_{I j u v}^{2}$ & $\sigma_{I j u v}^{2} \sim \operatorname{Unif}(-10,10)$ & $\begin{array}{l}\text { Variance of observation errors on surveys } \\
\text { of juveniles on nurseries }\end{array}$ \\
\hline$\sigma_{I_{A d}}^{2}$ & $\sigma_{I_{A d}}^{2} \sim \operatorname{Unif}(-10,10)$ & $\begin{array}{l}\text { Variance of observation errors on all } \\
\text { abundance indices of adults (UKCBT, } \\
\text { BECBT, UKBTS) }\end{array}$ \\
\hline$\sigma_{C}^{2}$ & $\sigma_{C}^{2} \sim \operatorname{Unif}(-10,10)$ & Variance of observation errors on catches \\
\hline$q_{0}$ & $\log \left(q_{0}\right) \sim \operatorname{Unif}(-10,10)$ & Catchability of age- 0 \\
\hline$q_{1}$ & $\log \left(q_{1}\right) \sim \operatorname{Unif}(-10,10)$ & Catchability of age-1 \\
\hline$q_{\text {fleet }}$ & $\log \left(q_{\text {fleet }}\right) \sim \operatorname{Unif}(-10,10)$ & $\begin{array}{l}\text { Catchability related to abundance indices } \\
\text { of adults (fleet: UKCBT, BECBT, } \\
\text { UKBTS) }\end{array}$ \\
\hline
\end{tabular}


1098 Table A.2. Surface of nursery sector $i\left(\mathrm{~km}^{2}\right)$. All surfaces are derived from the habitat 1099 suitability model in Rochette et al. (2010).

\begin{tabular}{lll}
\hline Subpopulation & Nursery sector & Surface $\left(\mathrm{km}^{2}\right)$ \\
\hline West Fr $(r=1)$ & Seine $(i=1)$ & 967 \\
& Veys $(i=2)$ & 320 \\
UK $(r=2)$ & UK West $(i=3)$ & 1,650 \\
& Rye $(i=4)$ & 504 \\
East FR $(r=3)$ & Somme $(i=5)$ & 1,680 \\
\hline
\end{tabular}

1100

1101 


\section{Appendix B}

\section{Catches at equilibrium as a function of fishing mortality}

1104 Empirical equilibrium curves were obtained by Monte Carlo simulations. The population was

1105 simulated with constant $F$ in time and space during 200 years to reach an equilibrium state.

1106 Results obtained by varying $F$ in a wide range (from 0 to 2, with a step of 0.01 ) were used to

1107 empirically construct the equilibrium curve relating Catches and SSB at equilibrium, thus

1108 enabling the estimation of management reference points such as $B_{M S Y}, F_{M S Y}$ and $C_{M S Y}$. Drift

1109 and survival parameters for eggs and larvae were considered constant during the simulations

1110 and set to their average values (1982-2007). In the model considering three subpopulations,

1111 reference equilibrium points for each subpopulation $r$ (denoted $B_{M S Y, r}, F_{M S Y, r}$ and $C_{M S Y, r}$ )

1112 were estimated conditionally by fixing the fishing pressure for the two other subpopulations

1113 equal to the estimates averaged over the last five years of the data series (2007-2011).

1114 Monte Carlo simulations were run to account for both process errors and parameters

1115 uncertainty. For a given value of $F$, the population dynamics was simulated over 200 years,

1116 including process error. The equilibrium (ergodic) state is considered after 100 years of

1117 simulation and the process error was integrated out by considering the distribution of the

1118 results between year 101 and 200. To integrate the parameter uncertainty, the procedure was

1119 repeated 1,500 times with 1,500 sets of parameters directly drawn in the joint posterior

1120 distribution of model parameters, ensuring that the statistical covariance structure between the

1121 parameters is fully accounted for (Punt and Hilborn, 1997; Parent and Rivot, 2013). 


\section{Supplementary Material S1}

\section{MCMC simulations and convergence diagnosis}

3 Bayesian posterior distributions were approximated via Monte Carlo Markov Chain (MCMC)

4 methods using the JAGS software (http://mcmc-jags.sourceforge.net ; release 3.4.0) through

5 the Rjags (www.Rproject.org) package. The same procedure detailed below was used for all

6 model configurations.

7 Following the seminal idea of Meyer and Millar (1999) who proposed a parameterization of

8 the biomass dynamic production model in terms of biomass relative to the carrying capacity

9 to improve the convergence speed of the MCMC sampler, equations for the cohort dynamics

10 (eqs. A.7 and A.9) in the JAGS code was written with numbers at age relative to the

11 recruitment of the cohort measured at age 1.

12 Three MCMC-independent chains with dispersed initialization points were used. For each

13 chain, the first 10,000 iterations were first discarded. The three chains were run during $10^{6}$

14 iterations. Autocorrelation in the MCMC sampling process was rather high ( $>0.5$ at lag 50

15 for almost all variables). To reduce the autocorrelation in the sample used for inferences, one

16 out of 100 iterations was kept (thinning $=100$ ). The autocorrelation in the resulting thinned

17 chained was less than 0.2 for all variables. Final inferences were derived from a sample of

$183 \times 10,000$ iterations resulting from merging the three chains.

19 Convergence of the MCMC chains was assessed using the Gelman-Rubin (Brooks and

20 Gelman, 1998) and the Heidelberg and Welch tests as implemented in the R Coda package

21 (gelman.diag() and heidel.diag() function, respectively). The Gelman-Rubin tests for the

22 mixing of multiple chains. It is based on the computation of the R-ratio that compares within

23 and between-chain variances. Values of the R-ratio substantially above 1 indicate lack of 
24 convergence. The Heidelberg and Welch diagnostic is a "single chain diagnostic" that

25 calculates a statistics to test for the null hypothesis that the chain is from a stationary

26 distribution.

27 For both models, trace plot display good mixing for all variables (see examples in Fig. S1.1).

28 All variables pass the two convergence diagnostics. The $\mathrm{R}$ ratio of the Gelman Rubin test was

$29<1.05$ for all variables and p-values of the Heidelberg test were all $<0.05$. However, it is

30 worth noting that convergence was more difficult to achieve for the parameters of the

31 BevHolt density dependence recruitment process associated with nursery sector "Bay of Veys"

32 for which the juveniles abundance indices are only available for 3 years. 
$\alpha_{1}$

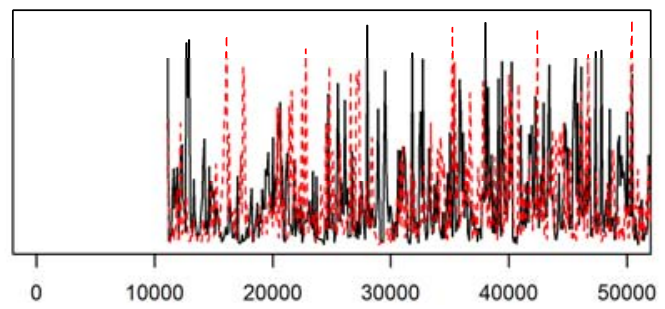

$\alpha_{2}$

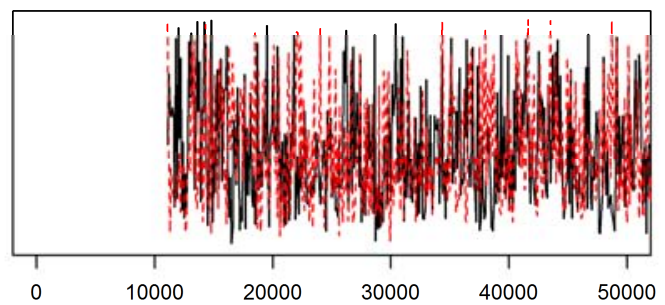

$\alpha_{3}$

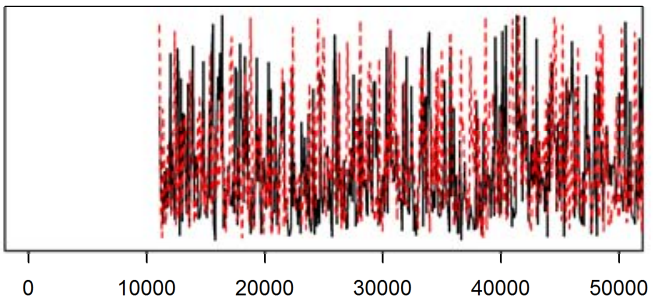

$\alpha_{4}$

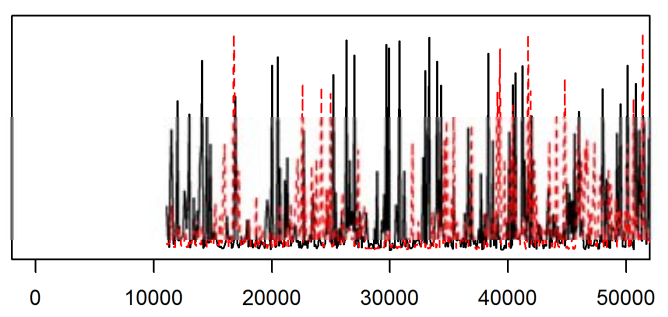

$\alpha_{5}$

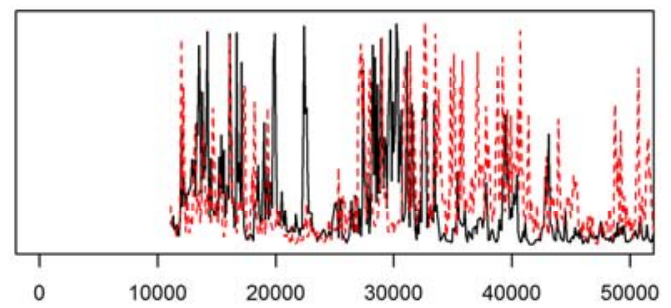

$\mathrm{K}_{1}$

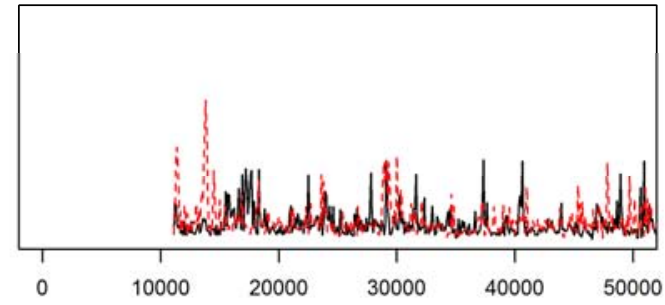

$\mathrm{K}_{2}$

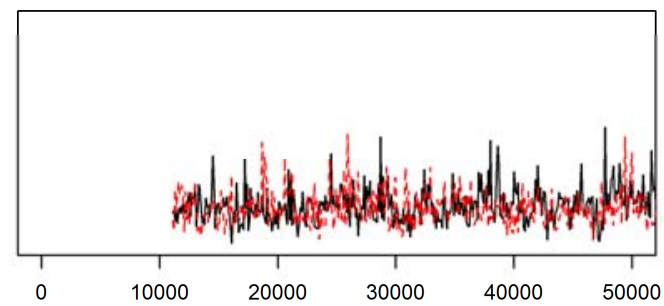

$\mathrm{K}_{3}$

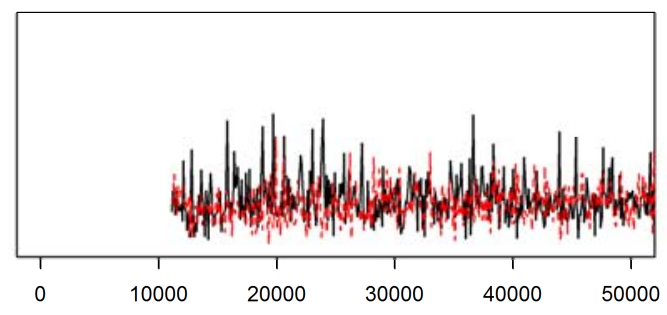

$\mathrm{K}_{4}$

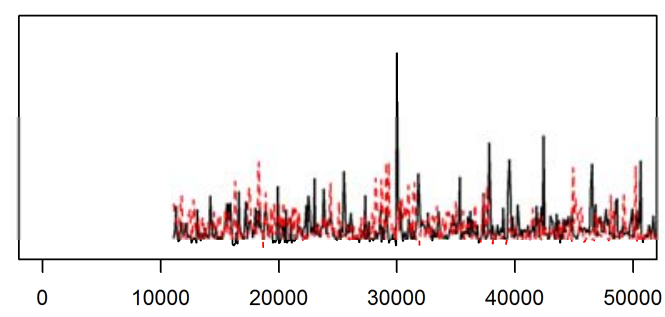

$\mathrm{K}_{5}$

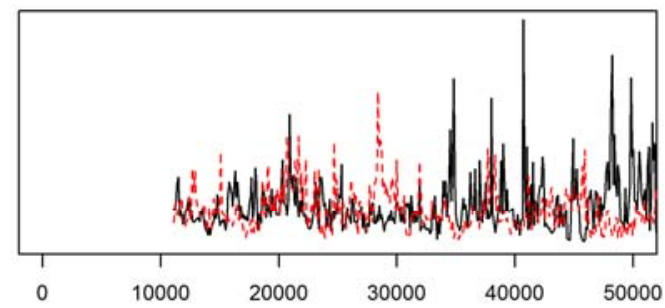

34 Fig. S1.1. Trace plots of Beverton-Holt parameters $\left(\alpha_{i}, K_{i}\right)$ in the 5 nursery sectors (for the 35 model considering three sub-populations). To keep the figure as clear as possible, trace plots 36 are drawn for two independent chains (out of three) and for the first 100000 iterations (out of 37 a total of $10^{6}$ ). But final inferences have been drawn from longer MCMC chains of length $10^{6}$. 
41 Posterior predictive distribution for the different sources of observations in the model

42 considering three subpopulations.
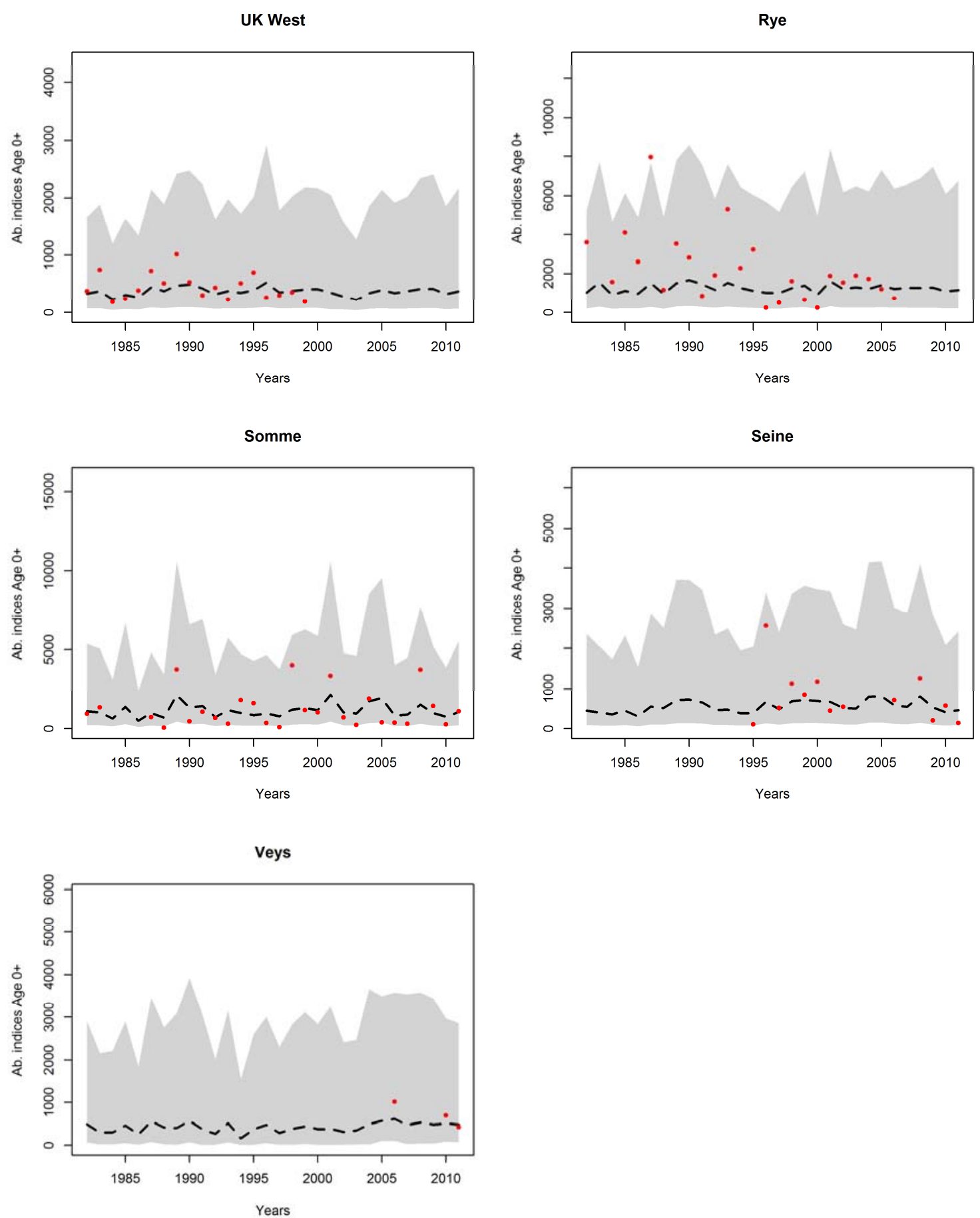

44 Fig. S2.1. Posterior predictive distribution and observations for Age-0 abundance indices in

45 the five nursery sectors. Dots : Observations; Dotted lines: medians of the posterior predictive

46 distribution; Shaded areas: 90\% Bayesian credible intervals for the posterior predictive

47 distribution. 

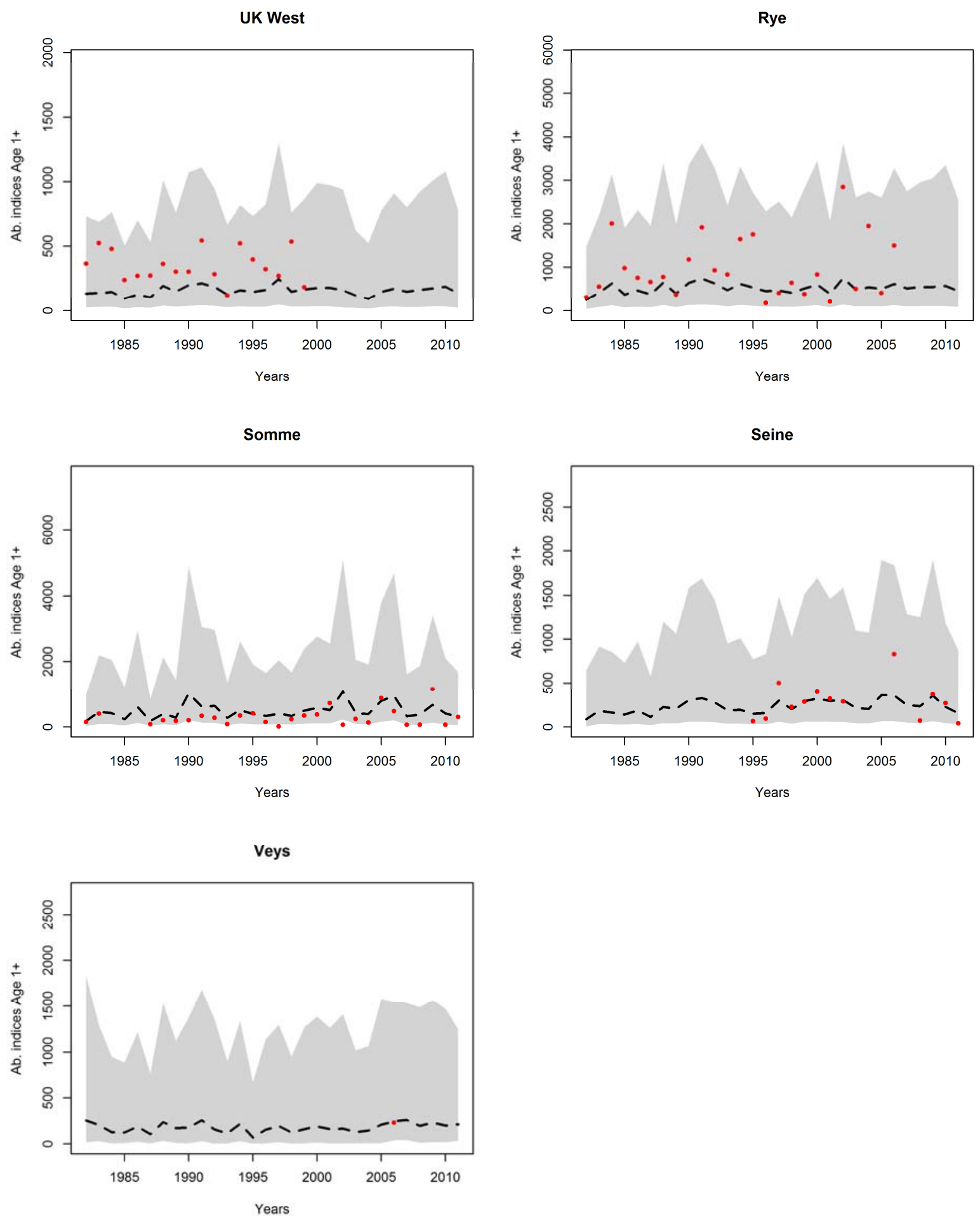

49 Fig. S2.2. Posterior predictive distribution and observations for Age-1 abundance indices in 50 the five nursery sectors. Dots : Observations; Dotted lines: medians of the posterior predictive 51 distribution; Shaded areas: 90\% Bayesian credible intervals for the posterior predictive 52 distribution. 

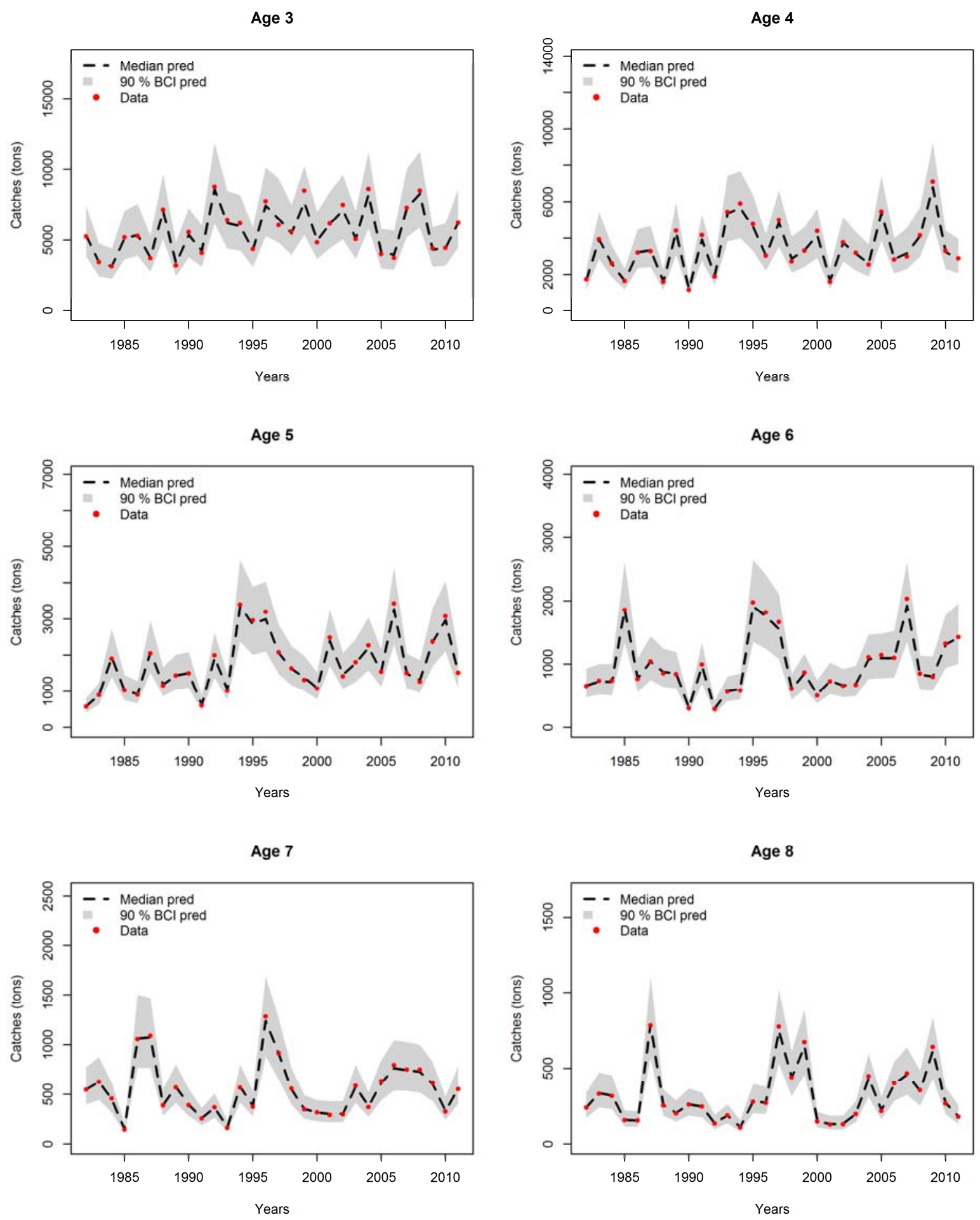

55 Fig. S2.3. Posterior predictive distribution and observations for catches (tons) of age- 3 to age-

568 fish in the Eastern Channel. Dots : Observations; Dotted lines: medians of the posterior

57 predictive distribution; Shaded areas: 90\% Bayesian credible intervals for the posterior

58 predictive distribution. 
Age 3

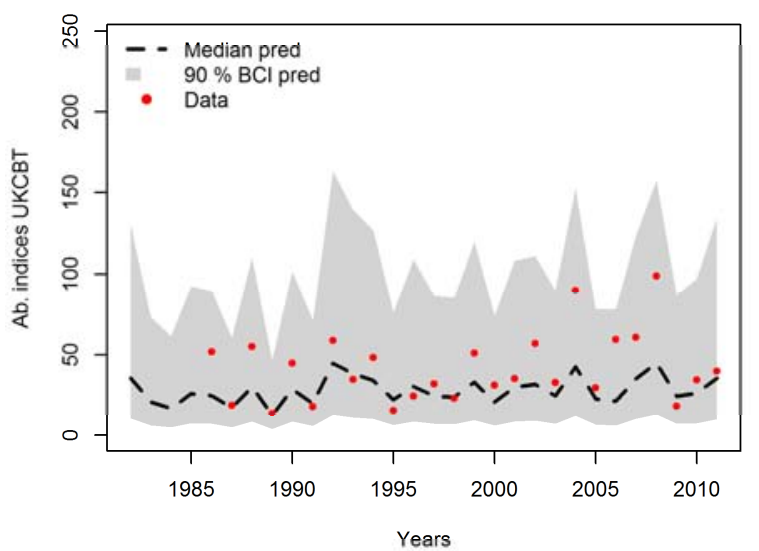

Age 5

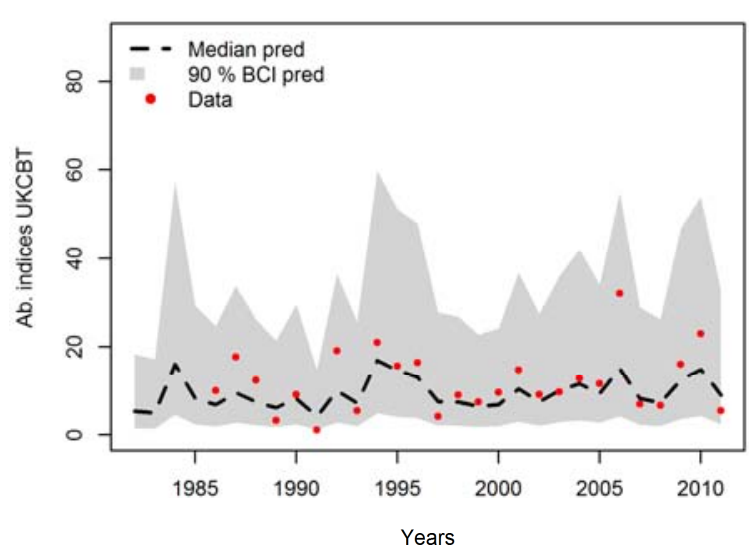

Age 7

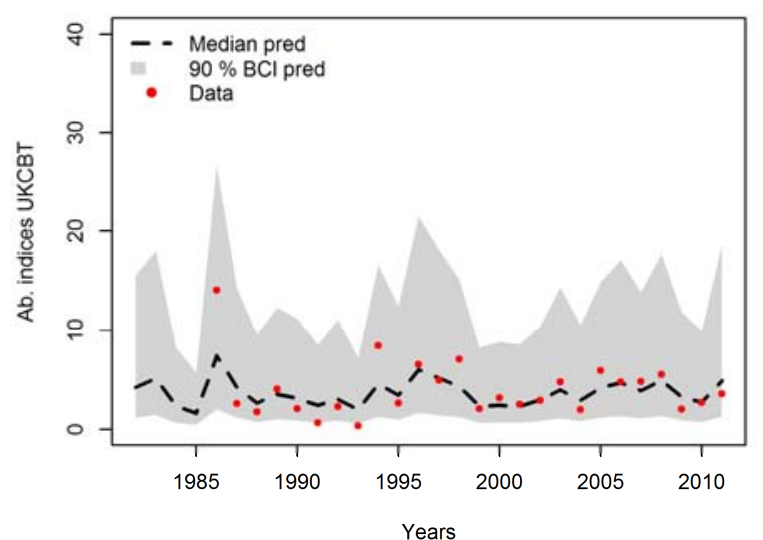

Age 4

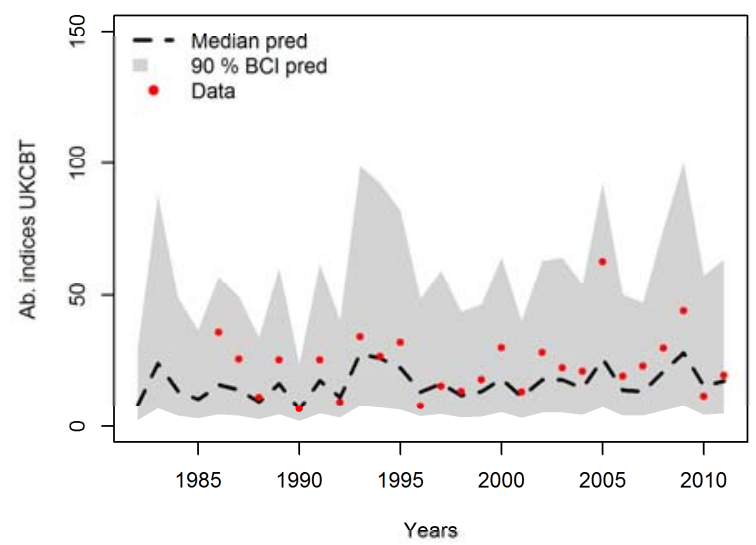

Age 6

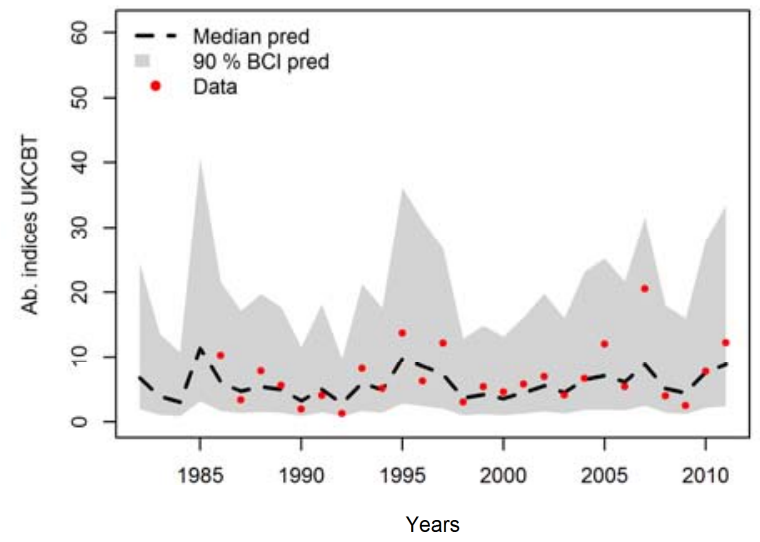

Age 8

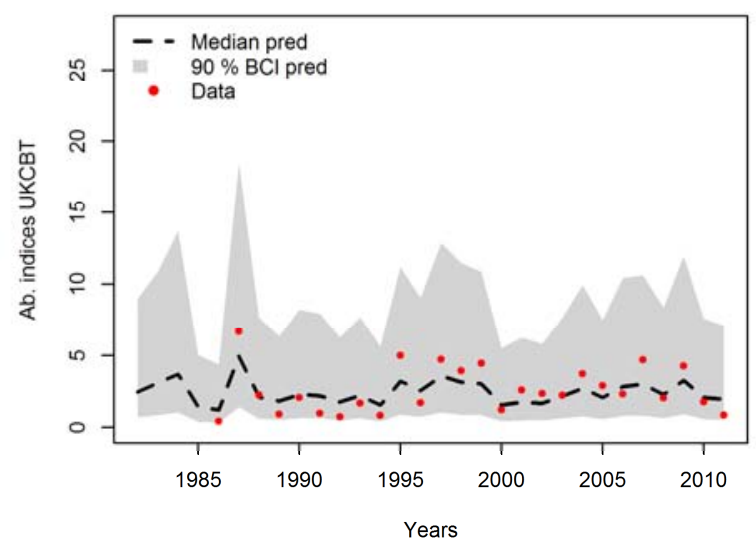

62 Fig. S2.4. Posterior predictive distribution and observations for commercial abundance

63 indices UKCBT (age-3 to age-8 fish) in the Eastern Channel. Dots : Observations; Dotted

64 lines: medians of the posterior predictive distribution; Shaded areas: 90\% Bayesian credible

65 intervals for the posterior predictive distribution. 
Age 3

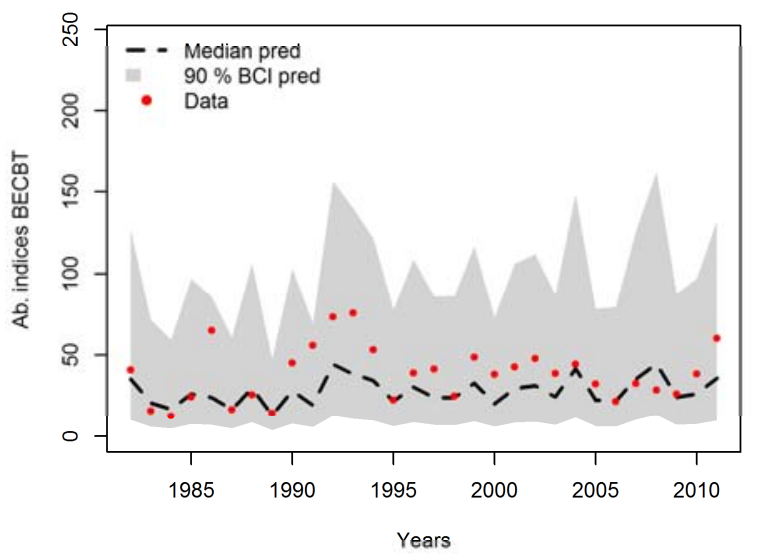

Age 5

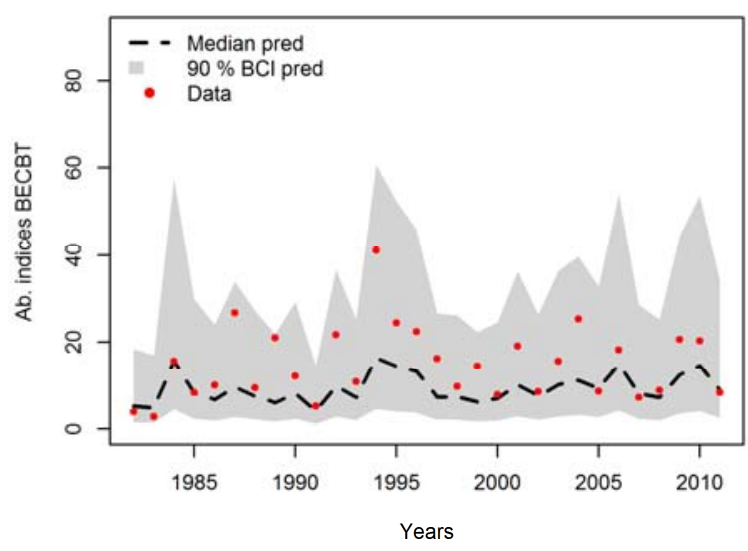

Age 7

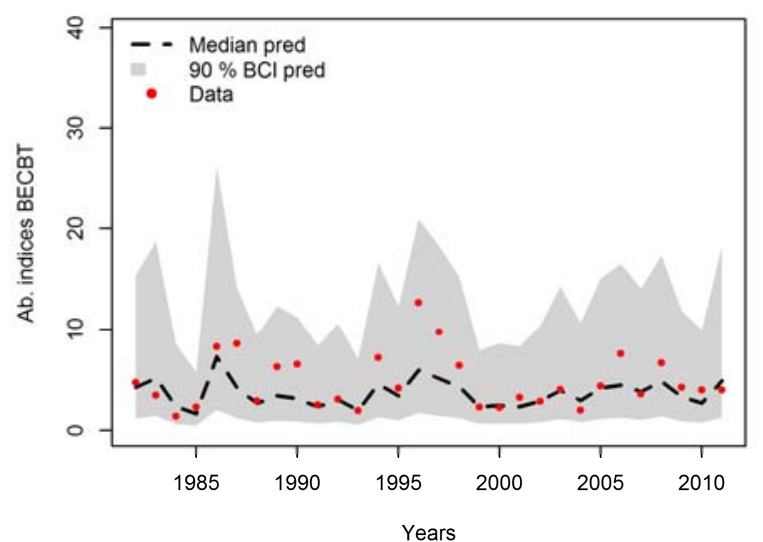

Age 4

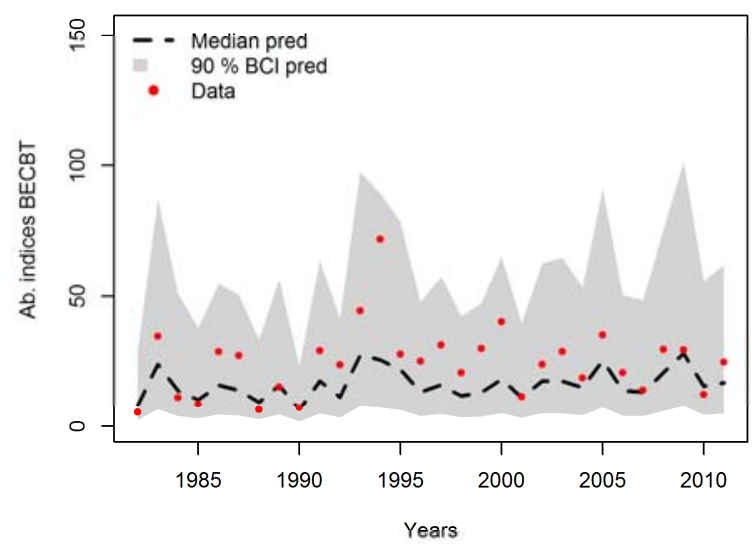

Age 6

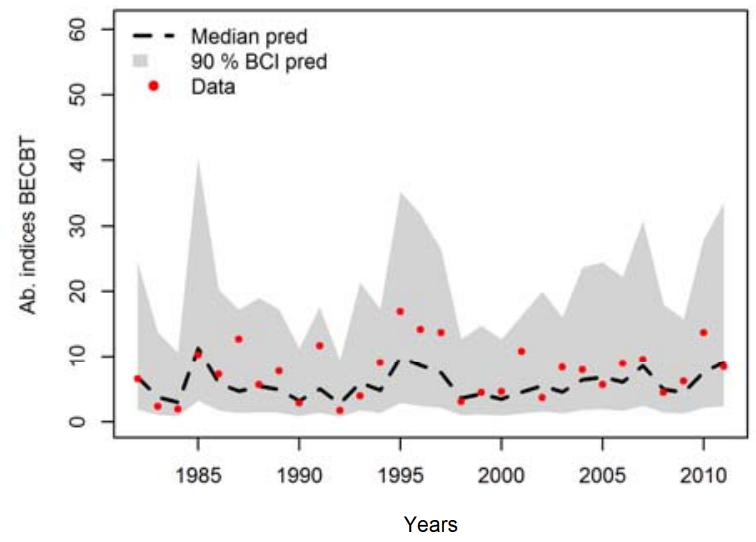

Age 8

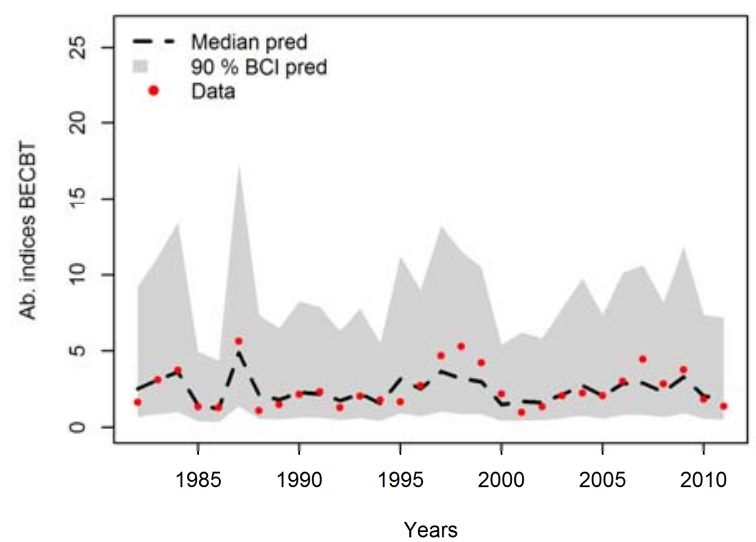

69 Fig. S2.5. Posterior predictive distribution and observations for commercial abundance

70 indices BECBT (age-3 to age- 8 fish) in the Eastern Channel. Dots : Observations; Dotted

71 lines: medians of the posterior predictive distribution; Shaded areas: 90\% Bayesian credible

72 intervals for the posterior predictive distribution. 

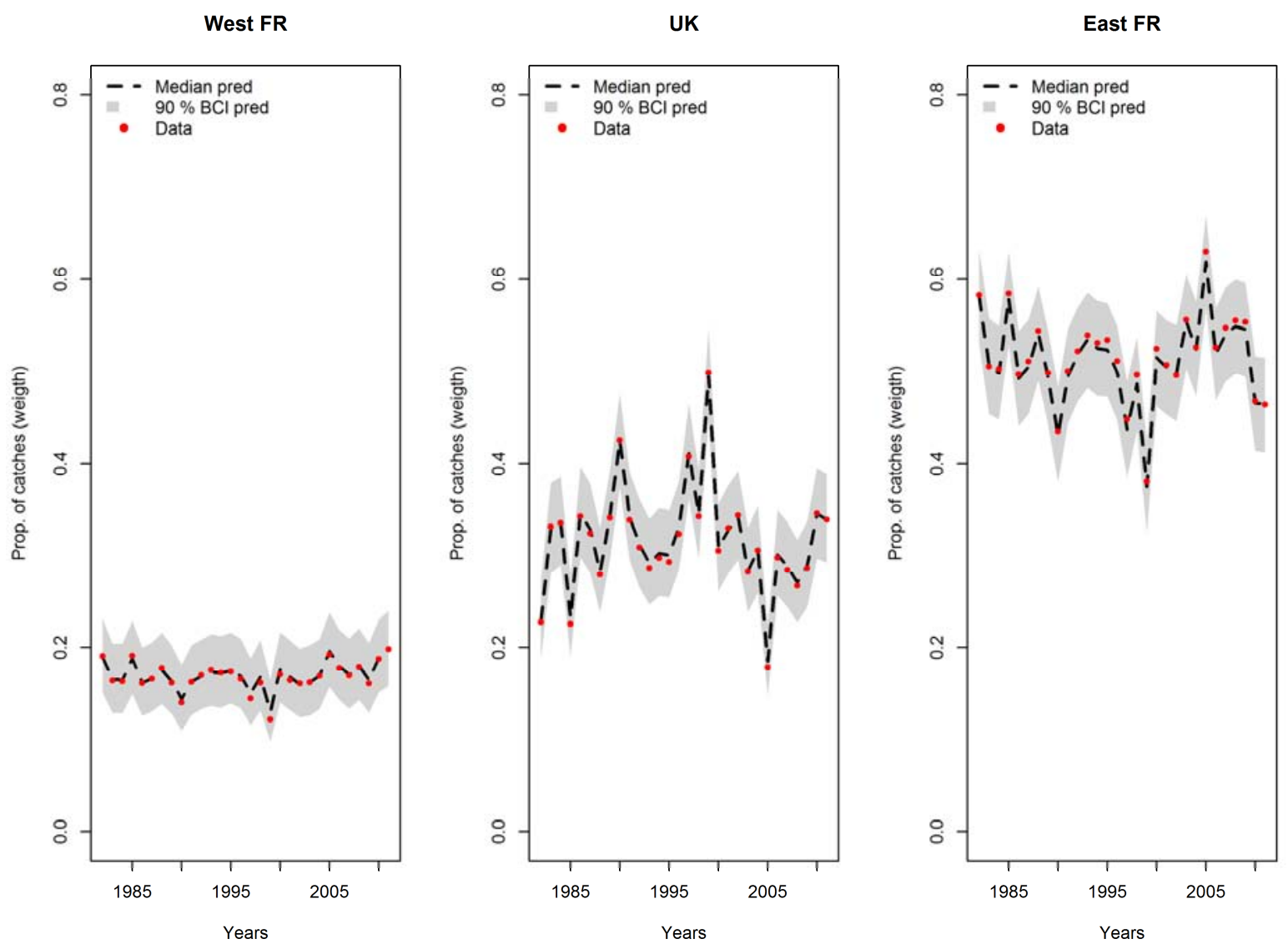

76 Fig. S2.6. Posterior predictive distribution and observations for the proportion of catches

77 (total weight) in the three areas considered in the Eastern Channel. Dots : Observations;

78 Dotted lines: medians of the posterior predictive distribution; Shaded areas: 90\% Bayesian

79 credible intervals for the posterior predictive distribution. 

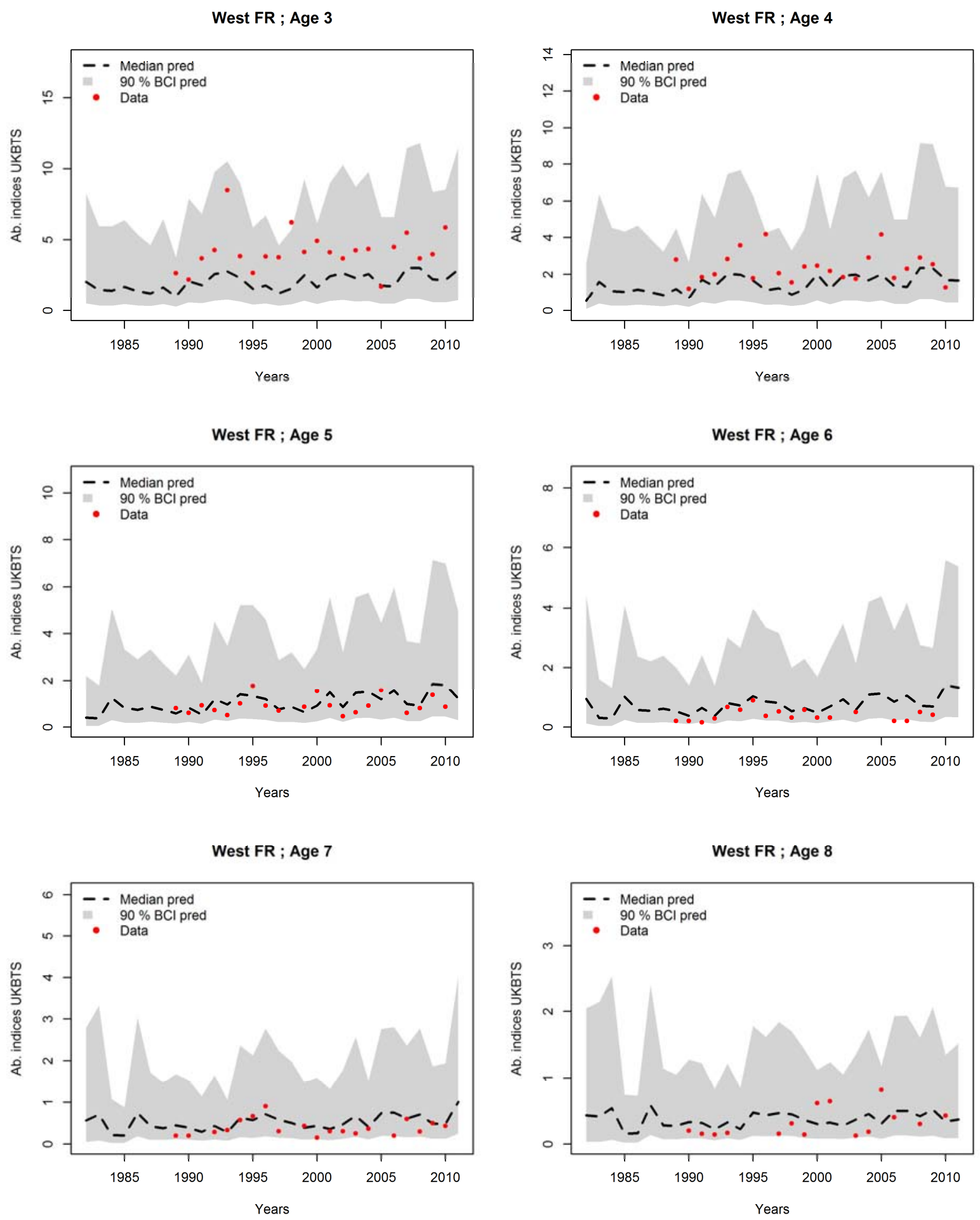

93 Fig. S2.7. Posterior predictive distribution and observations for the spatial scientific

94 abundance indices in the West FR area (age-3 to age-8). Dots : Observations; Dotted lines:

95 medians of the posterior predictive distribution; Shaded areas: 90\% Bayesian credible

96 intervals for the posterior predictive distribution. 
UK ; Age 3

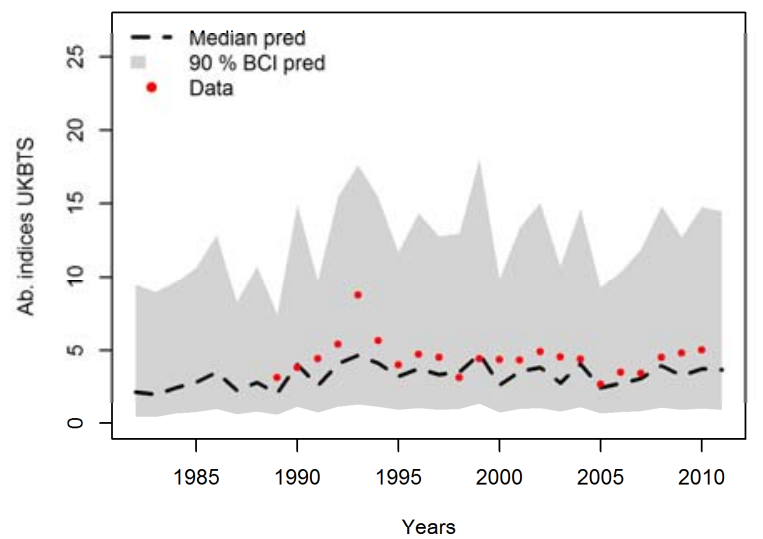

UK ; Age 5

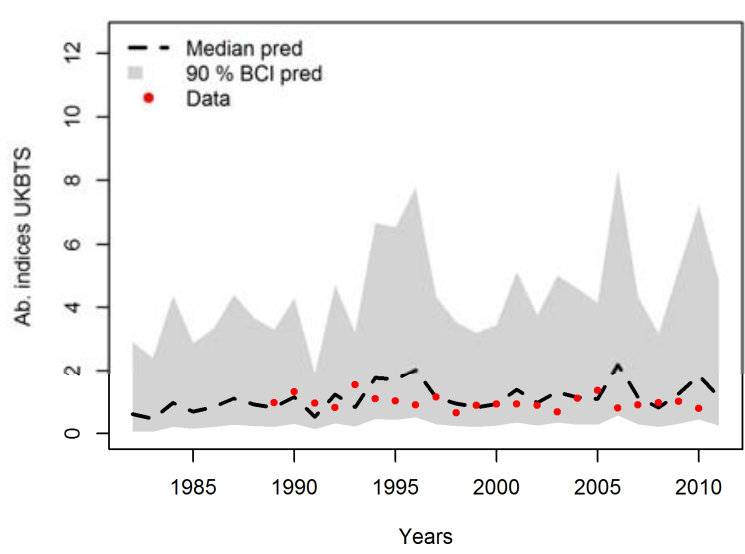

UK ; Age 7

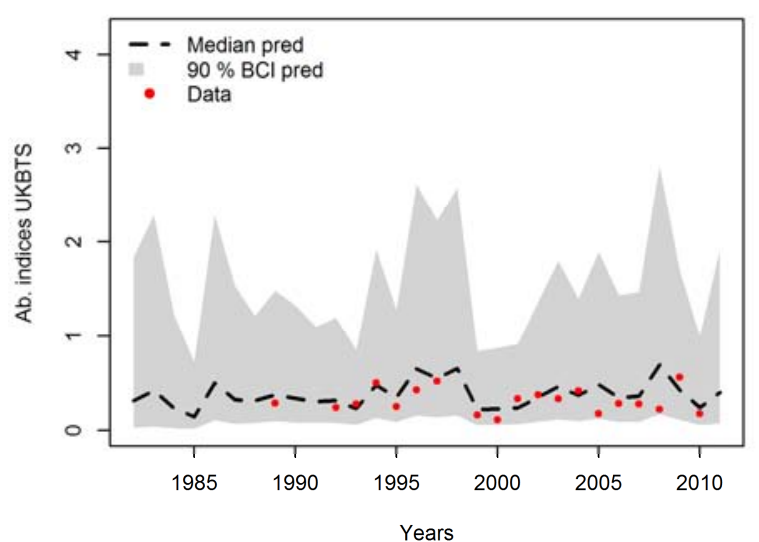

UK ; Age 4

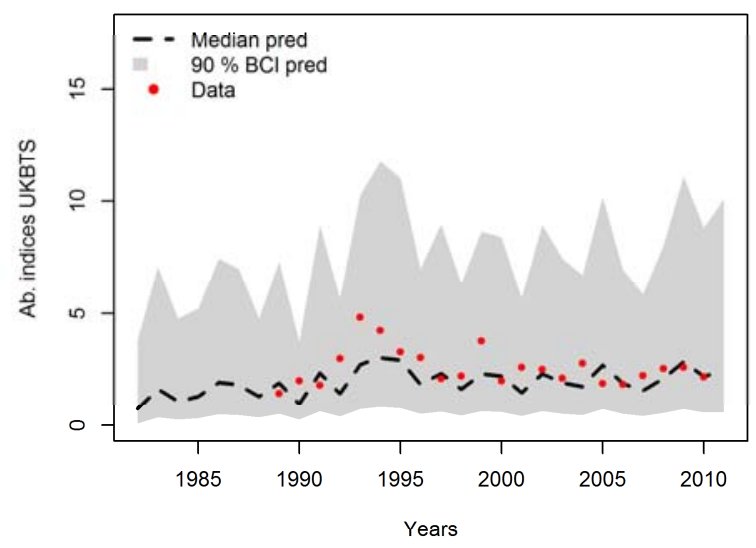

UK ; Age 6

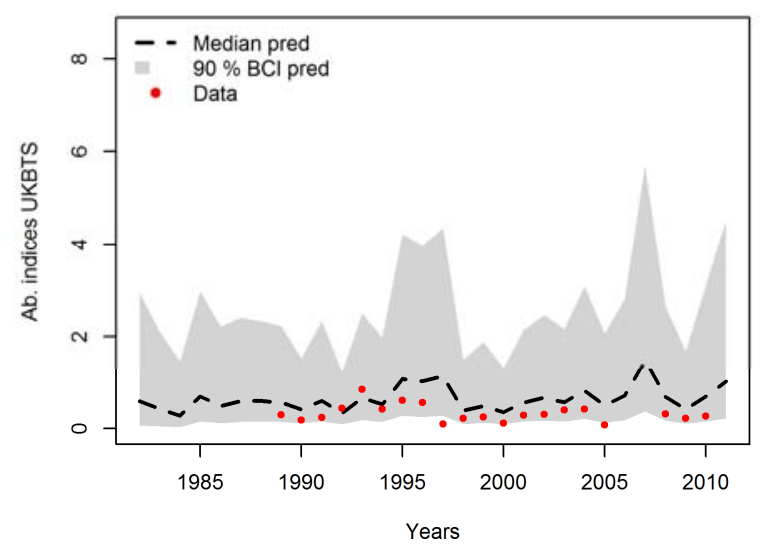

UK ; Age 8

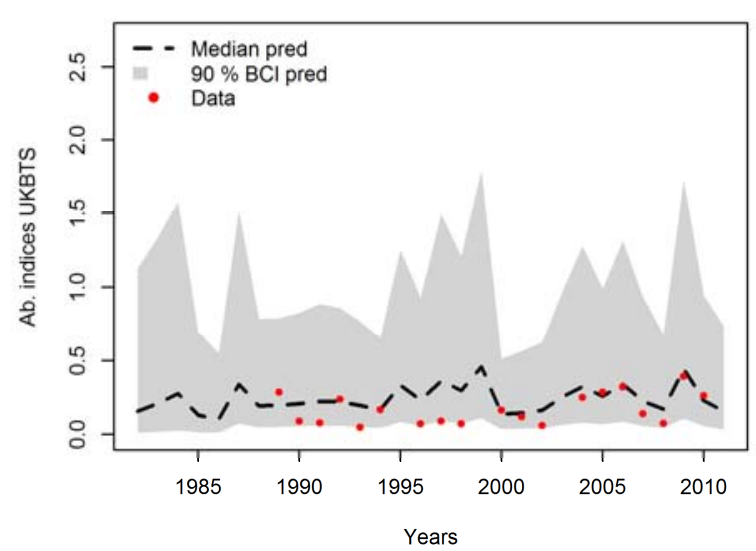

100 Fig. S2.8. Posterior predictive distribution and observations for the spatial scientific

101 abundance indices in the UK area (age-3 to age-8). Dots : Observations; Dotted lines:

102 medians of the posterior predictive distribution; Shaded areas: 90\% Bayesian credible

103 intervals for the posterior predictive distribution. 
East FR ; Age 3

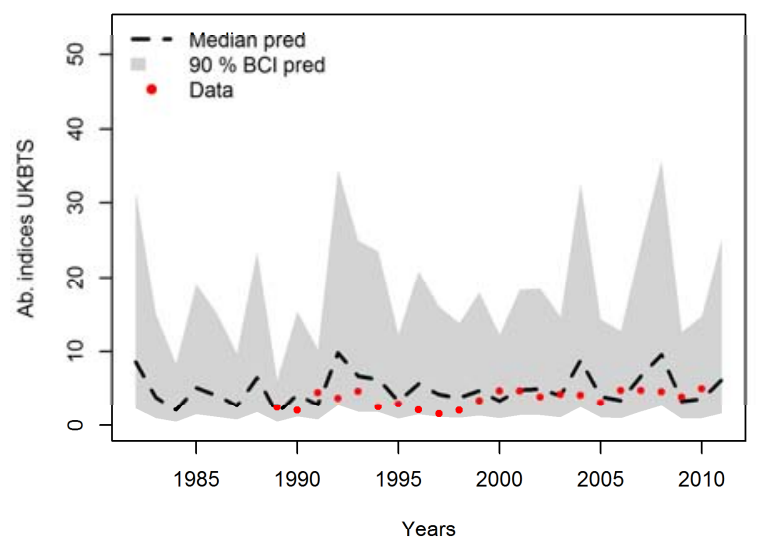

East FR ; Age 5

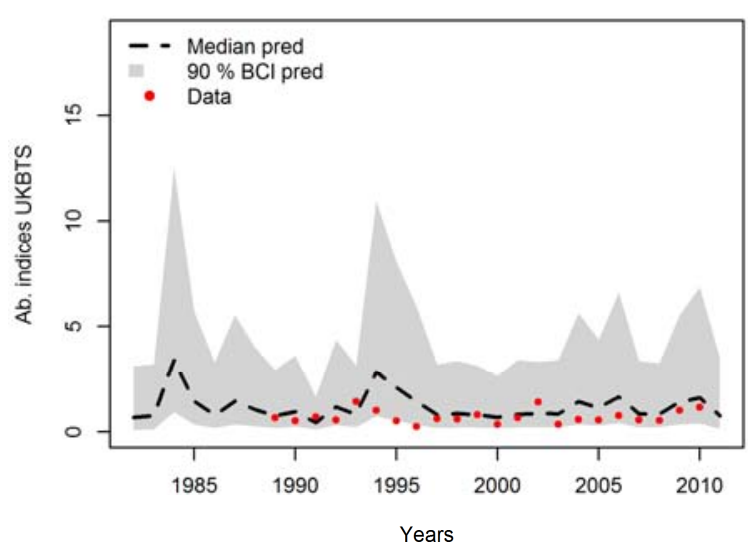

East FR ; Age 7

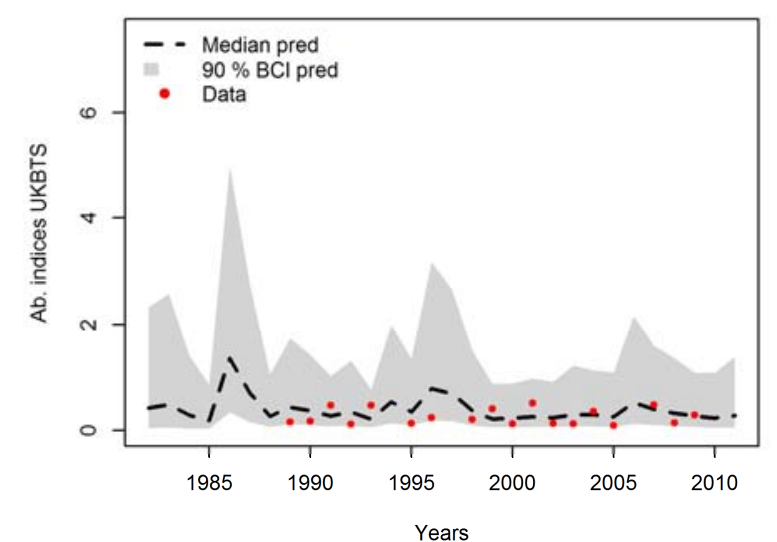

East FR ; Age 4

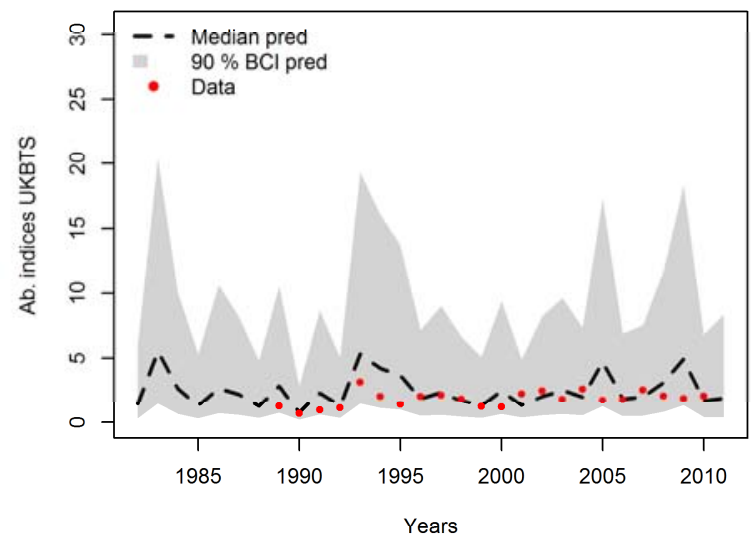

East FR ; Age 6

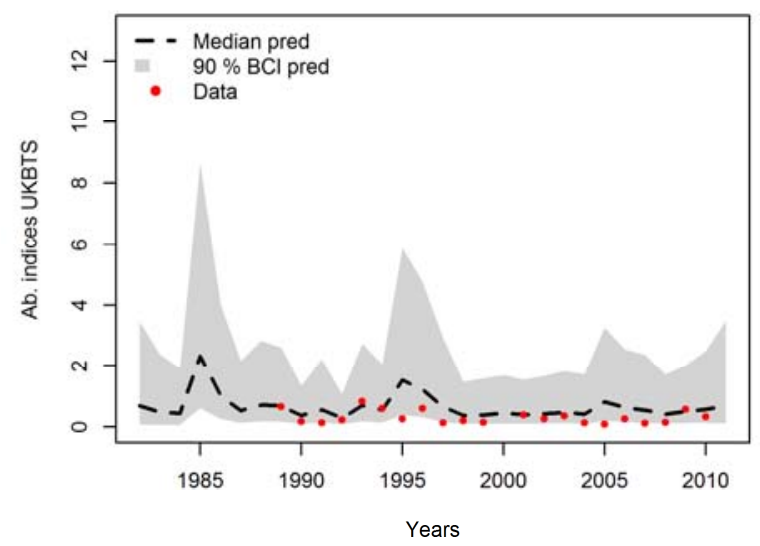

East FR ; Age 8

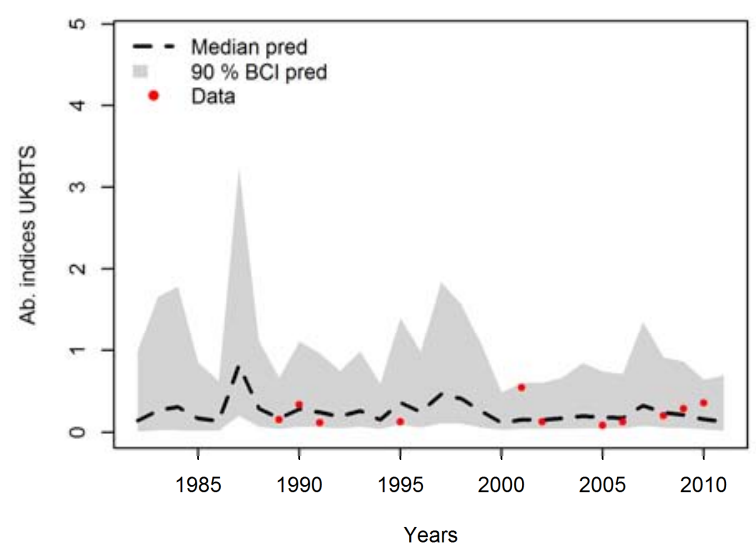

107 Fig. S2.9. Posterior predictive distribution and observations for the spatial scientific

108 abundance indices in the East FR area (age-3 to age-8). Dots : Observations; Dotted lines:

109 medians of the posterior predictive distribution; Shaded areas: 90\% Bayesian credible

110 intervals for the posterior predictive distribution. 


\section{Supplementary Material S3}

113 Posterior distributions of estimated parameters for the model considering one single 114 populations and the model considering three subpopulations.

115
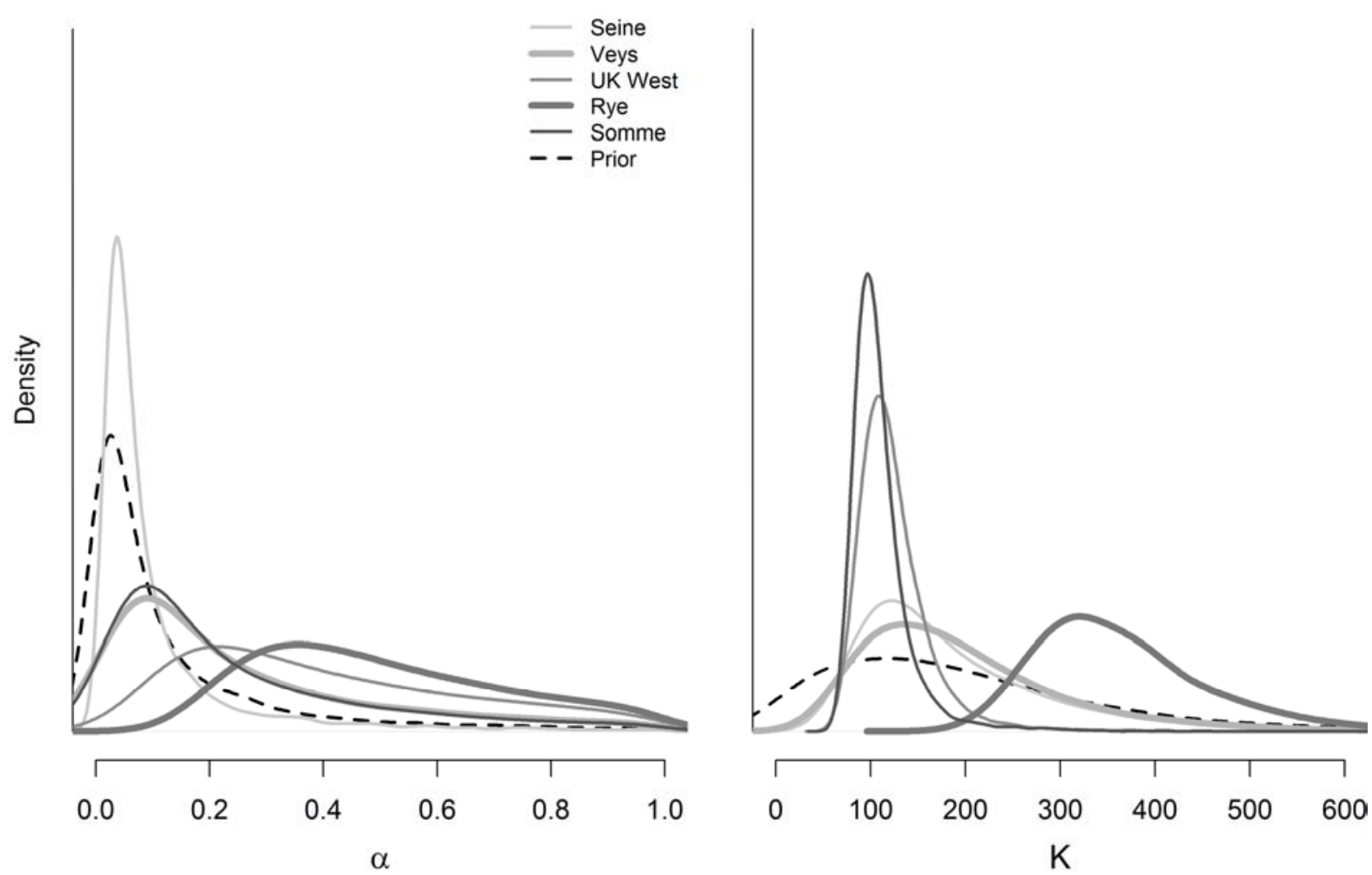

117 Fig. S3.1. Prior and marginal posterior distributions of the parameters $\alpha_{i}$ 's and $K_{i}$ 's (in $\log$ -

118 scale) for the five nursery sectors obtained with the model considering one single

119 homogeneous population. The prior distributions on the $\alpha_{i}$ 's is informative (See Appendix A).

120 The prior distribution on the $K_{i}$ 's is weakly informative. An additional constraint $(\alpha<1)$ is

121 introduced in the model ( $\alpha>1$ would mean more $0+$ juveniles than settled larvae). 

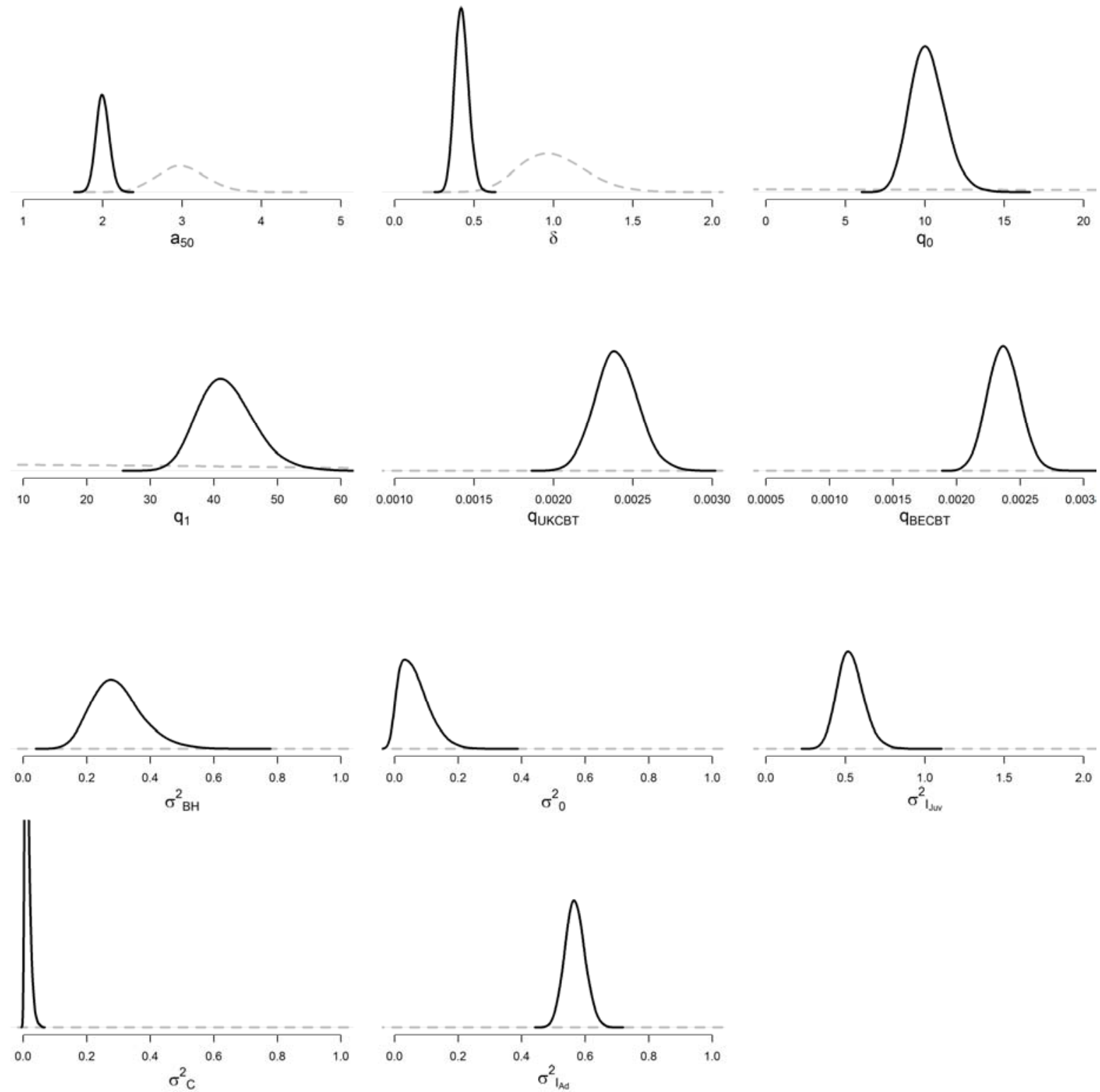

124 Fig. S3.2 Prior and marginal posterior distributions of all parameters obtained with the model 125 considering one single homogeneous population. Dotted gray line: prior; Solid black line:

126 posterior. 

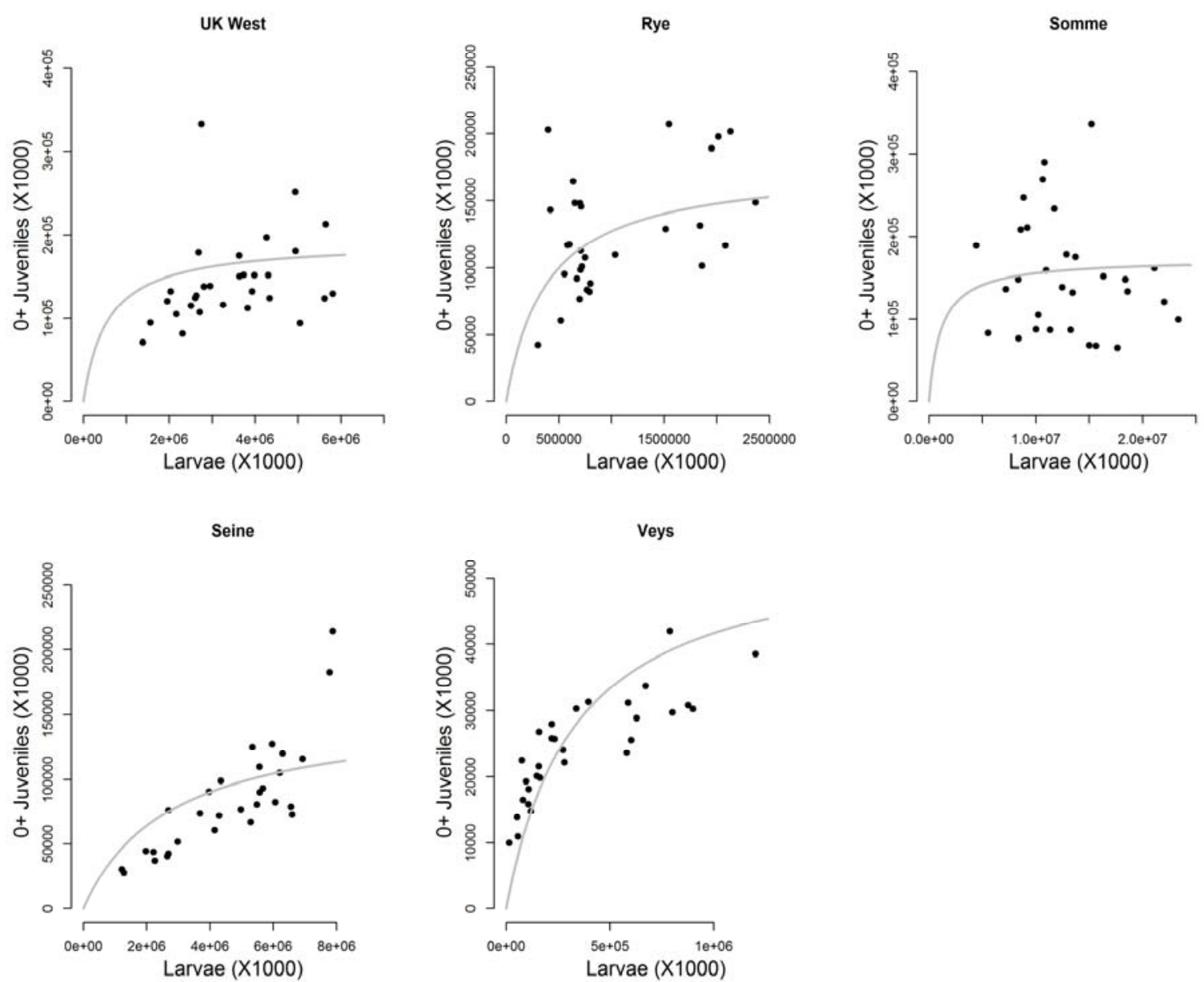

136 Fig. S3.3. Fit of the Beverton-Holt recruitment curve in each nursery sectors obtained with the 137 model considering one single homogeneous population. Plain line: Bev-Holt curve drawn 138 with the posterior medians of the $(\alpha, K)$ parameters. Black points: posterior medians of the 139 number of larvae (x-axis) and age-0 juveniles (y-axis). 

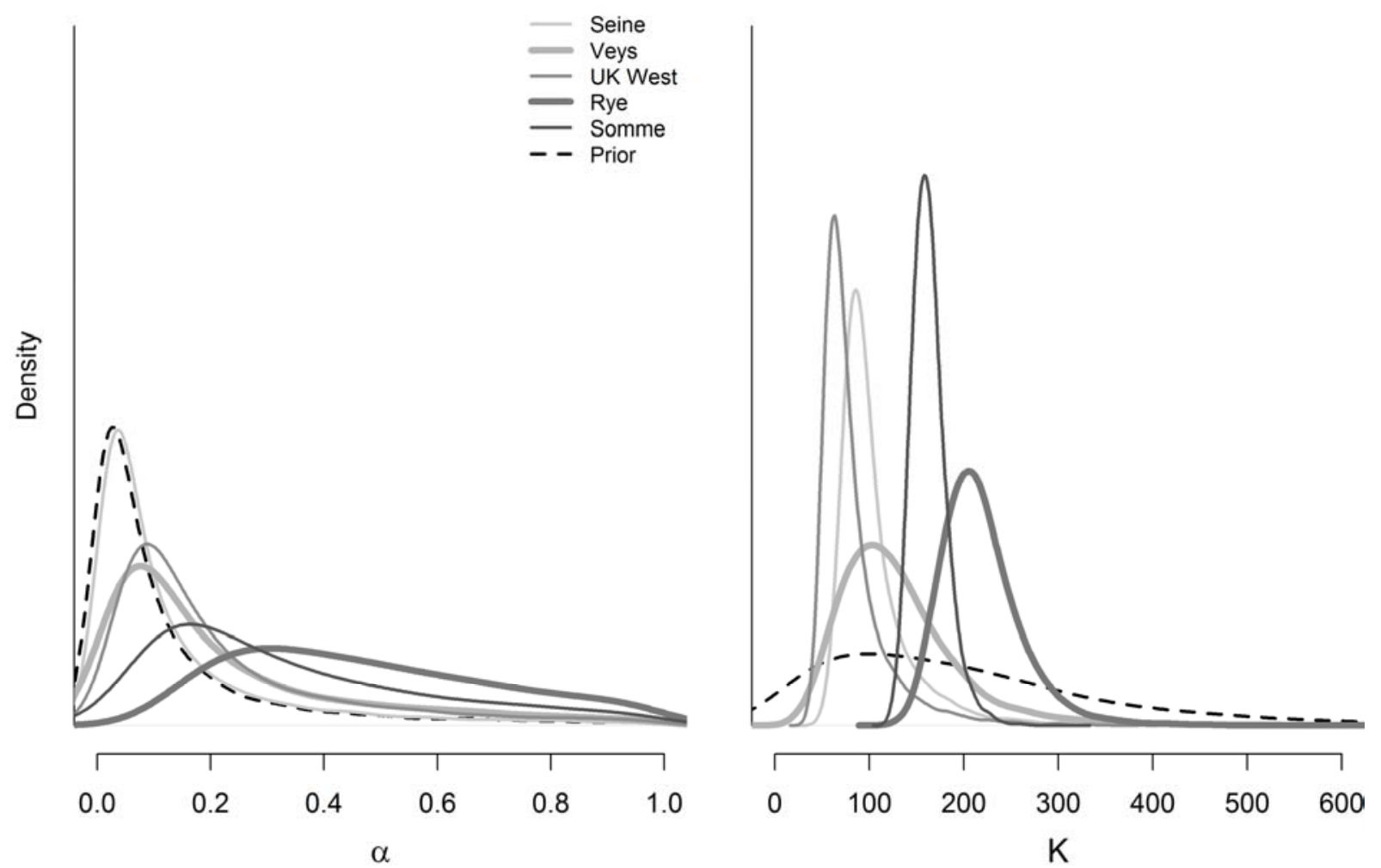

142 Fig. S3.4. Prior and marginal posterior distributions of the parameters $\alpha_{i}$ 's and $K_{i}$ 's (in log143 scale) for the five nursery sectors obtained with the model considering three subpopulations. 144 The prior distributions on the $\alpha_{i}$ 's is informative (See Appendix A). The prior distribution on 145 the $K_{i}$ 's is weakly informative. An additional constraint $(\alpha<1)$ is introduced in the model 146 ( $\alpha>1$ would mean more $0+$ juveniles than settled larvae). 

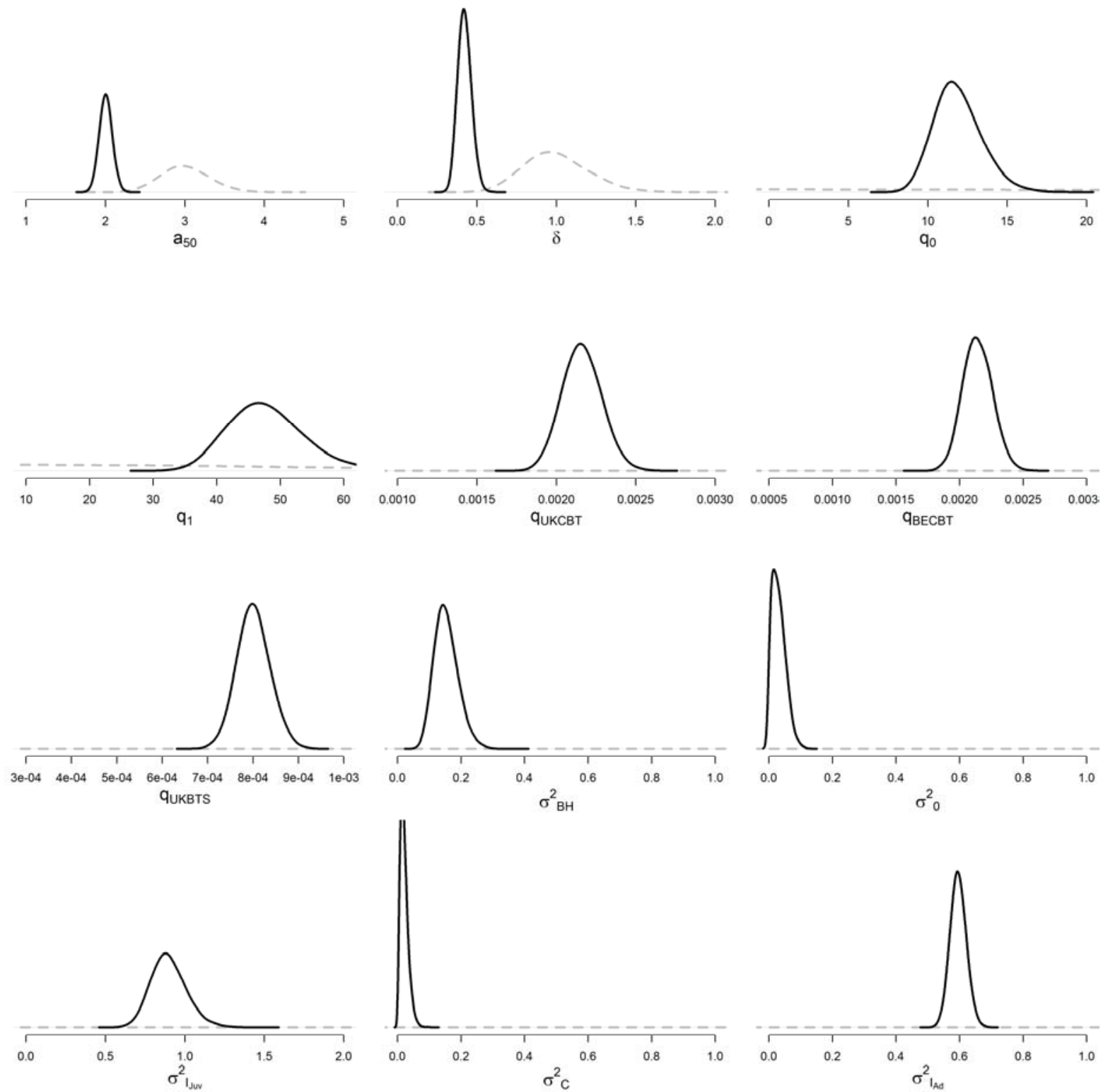

149 Fig. S3.5. Prior and marginal posterior distributions of all parameters obtained with the model 150 considering three subpopulations. Dotted gray line: prior; Solid black line: posterior. 

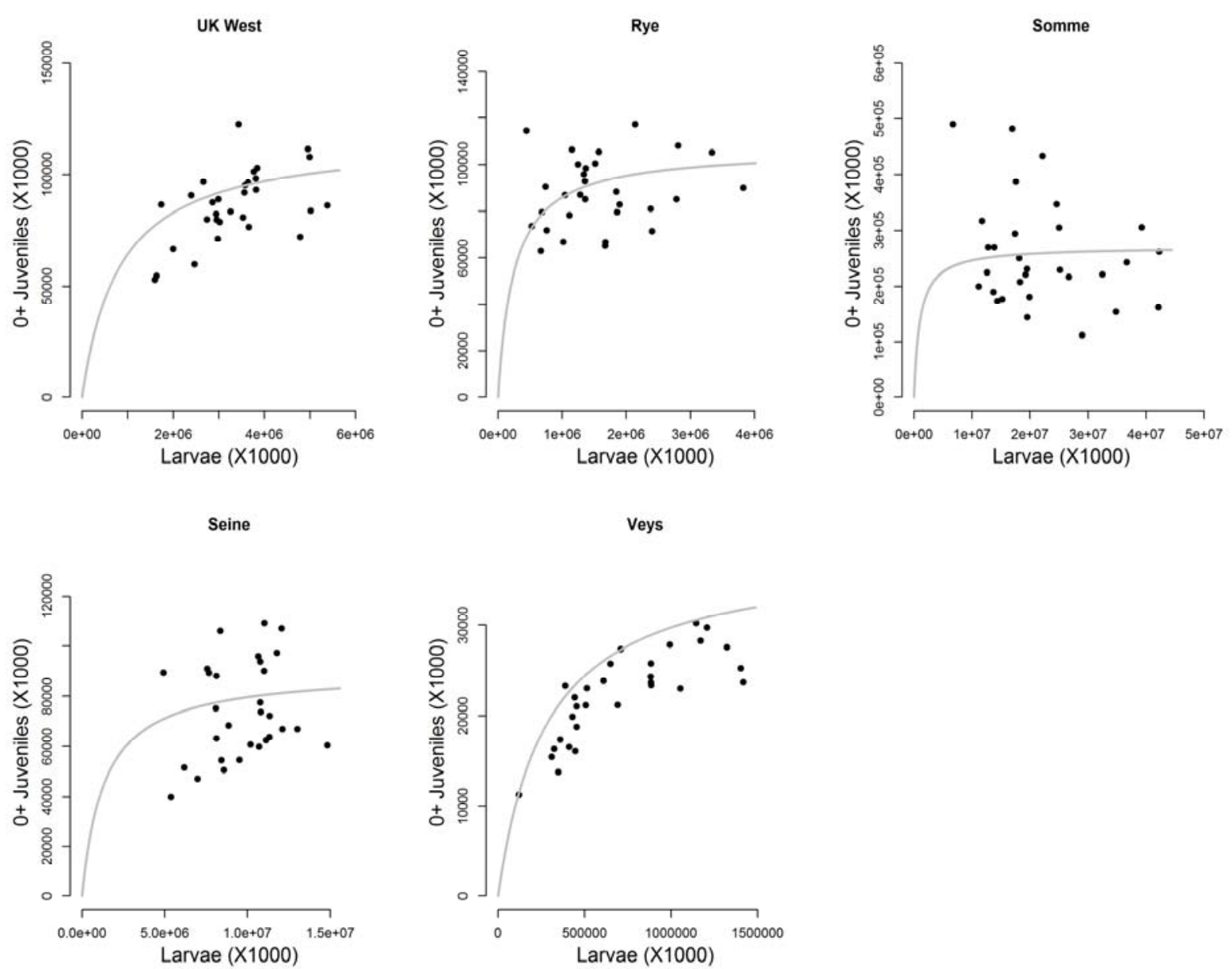

153 Fig. S3.6. Fit of the Beverton-Holt recruitment curve in each nursery sectors obtained with the 154 model considering three subpopulations. Plain line: Bev-Holt curve drawn with the posterior 155 medians of the $(\alpha, K)$ parameters. Black points: posterior medians of the number of larvae (x156 axis) and age-0 juveniles (y-axis). 
157 Tab. S3.1. Mean, median, standard deviation (sd) and quantiles 10 and $90 \%$ for marginal 158 posterior distributions of parameters in the model considering one single homogeneous 159 population.

160

\begin{tabular}{cccccc}
\hline Parameters & Mean & Median & Sd & $\mathbf{q 1 0}$ & $\mathbf{q 9 0}$ \\
\hline$\alpha_{1}$ & 0.41 & 0.35 & 0.24 & 0.13 & 0.78 \\
$\alpha_{2}$ & 0.5 & 0.46 & 0.21 & 0.25 & 0.83 \\
$\alpha_{3}$ & 0.24 & 0.16 & 0.22 & 0.044 & 0.58 \\
$\alpha_{4}$ & 0.11 & 0.056 & 0.15 & 0.024 & 0.25 \\
$\alpha_{5}$ & 0.25 & 0.17 & 0.23 & 0.041 & 0.61 \\
$\mathrm{~K}_{1}$ & 120 & 120 & 39 & 87 & 170 \\
$\mathrm{~K}_{2}$ & 370 & 350 & 96 & 260 & 490 \\
$\mathrm{~K}_{3}$ & 110 & 100 & 38 & 82 & 140 \\
$\mathrm{~K}_{4}$ & 190 & 160 & 110 & 89 & 330 \\
$\mathrm{~K}_{5}$ & 200 & 170 & 110 & 86 & 340 \\
$\mathrm{a}_{50}$ & 2 & 2 & 0.034 & 1.9 & 2 \\
$\delta$ & 0.44 & 0.44 & 0.019 & 0.41 & 0.46 \\
$\sigma_{\mathrm{BH}}^{2}$ & 0.3 & 0.29 & 0.078 & 0.2 & 0.4 \\
$\sigma_{0}^{2}$ & 0.064 & 0.056 & 0.046 & 0.012 & 0.13 \\
$\sigma_{\mathrm{C}}^{2}$ & 0.013 & 0.012 & 0.0083 & 0.0048 & 0.025 \\
$\sigma_{\mathrm{I}_{\mathrm{juv}}}^{2}$ & 0.53 & 0.53 & 0.082 & 0.44 & 0.64 \\
$\sigma_{\mathrm{I}_{\mathrm{Ad}}}^{2}$ & 0.57 & 0.57 & 0.03 & 0.53 & 0.61 \\
$\mathrm{q}_{0}$ & 10 & 10 & 1.1 & 8.9 & 12 \\
$\mathrm{q}_{1}$ & 42 & 42 & 4.4 & 37 & 48 \\
$\mathrm{q}_{\mathrm{BECBT}}$ & 0.0024 & 0.0024 & 0.00012 & 0.0022 & 0.0025 \\
$\mathrm{q}_{\mathrm{UKCBT}}$ & 0.0024 & 0.0024 & 0.00013 & 0.0022 & 0.0026 \\
\hline & & & & & \\
\hline
\end{tabular}

161 
163 Tab. S3.2. Mean, median, standard deviation (sd) and quantiles 10 and $90 \%$ for marginal 164 posterior distributions of parameters in the model considering three subpopulations.

165

\begin{tabular}{|c|c|c|c|c|c|}
\hline Parameters & Mean & Median & Sd & q10 & q90 \\
\hline$\alpha_{1}$ & 0.22 & 0.14 & 0.2 & 0.051 & 0.53 \\
\hline$\alpha_{2}$ & 0.48 & 0.44 & 0.23 & 0.2 & 0.82 \\
\hline$\alpha_{3}$ & 0.34 & 0.27 & 0.24 & 0.096 & 0.72 \\
\hline$\alpha_{4}$ & 0.14 & 0.068 & 0.18 & 0.017 & 0.37 \\
\hline$\alpha_{5}$ & 0.22 & 0.14 & 0.22 & 0.034 & 0.56 \\
\hline$K_{1}$ & 82 & 71 & 39 & 53 & 120 \\
\hline$K_{2}$ & 220 & 210 & 43 & 170 & 270 \\
\hline$K_{3}$ & 160 & 160 & 19 & 140 & 190 \\
\hline$K_{4}$ & 110 & 93 & 47 & 72 & 150 \\
\hline$K_{5}$ & 130 & 120 & 65 & 66 & 210 \\
\hline$a_{50}$ & 2 & 2 & 0.026 & 1.9 & 2 \\
\hline$\delta$ & 0.4 & 0.4 & 0.014 & 0.38 & 0.42 \\
\hline$\sigma_{B H}^{2}$ & 0.15 & 0.15 & 0.037 & 0.11 & 0.2 \\
\hline$\sigma_{0}^{2}$ & 0.031 & 0.027 & 0.021 & 0.0054 & 0.06 \\
\hline$\sigma_{C}^{2}$ & 0.021 & 0.019 & 0.013 & 0.0073 & 0.038 \\
\hline$\sigma_{\mathrm{I}_{\mathrm{juv}}}^{2}$ & 0.9 & 0.89 & 0.11 & 0.77 & 1 \\
\hline$\sigma_{\mathrm{I}_{\mathrm{Ad}}}^{2}$ & 0.6 & 0.59 & 0.025 & 0.56 & 0.63 \\
\hline $\mathrm{q}_{0}$ & 12 & 12 & 1.5 & 10 & 14 \\
\hline $\mathrm{q}_{1}$ & 48 & 47 & 5.9 & 41 & 56 \\
\hline $\mathrm{q}_{\mathrm{BECBT}}$ & 0.0021 & 0.0021 & 0.00011 & 0.002 & 0.0023 \\
\hline $\mathrm{q}_{\mathrm{UKCBT}}$ & 0.0022 & 0.0022 & 0.00012 & 0.002 & 0.0023 \\
\hline $\mathrm{q}_{\text {uKBts }}$ & 0.0008 & 0.0008 & 0.000036 & 0.00076 & 0.00085 \\
\hline
\end{tabular}

166 
Tab. S3.3. Correlation matrix (joint posterior distribution) for parameters in the model considering one single homogeneous population.

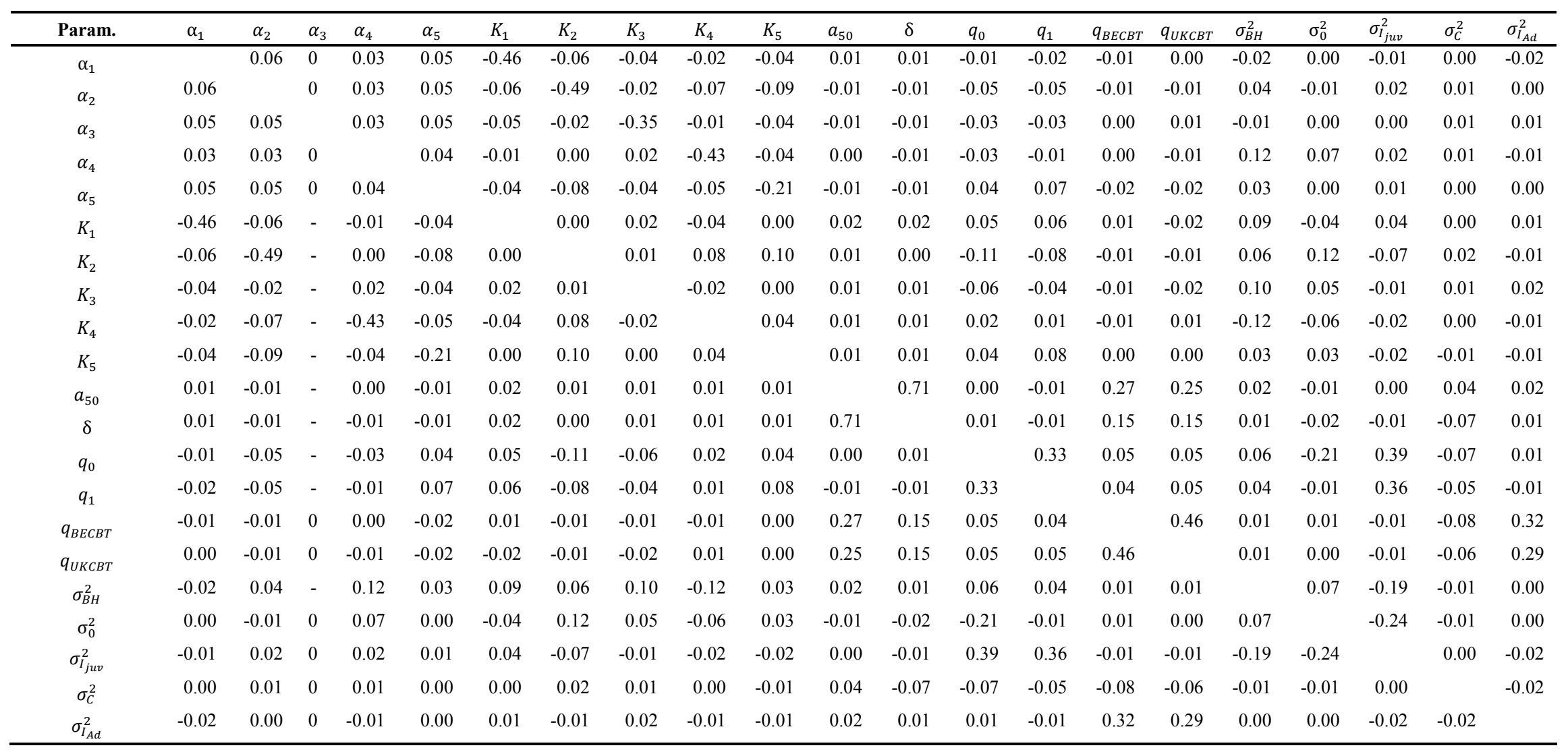

169 
171 Tab. S3.4. Correlation matrix (joint posterior distribution) for parameters of parameters in the model considering three subpopulations.

\begin{tabular}{|c|c|c|c|c|c|c|c|c|c|c|c|c|c|c|c|c|c|c|c|c|c|c|}
\hline Param. & $\alpha_{1}$ & $\alpha_{2}$ & $\alpha_{3}$ & $\alpha_{4}$ & $\alpha_{5}$ & $K_{1}$ & $K_{2}$ & $K_{3}$ & $K_{4}$ & $K_{5}$ & $a_{50}$ & $\delta$ & $q_{0}$ & $q_{1}$ & $q_{B E C B T}$ & $q_{U K B T S}$ & $q_{U K C B T}$ & $\sigma_{B H}^{2}$ & $\sigma_{0}^{2}$ & $\sigma_{I j u v}^{2}$ & $\sigma_{C}^{2}$ & $\sigma_{I_{A d}}^{2}$ \\
\hline$\alpha_{1}$ & & 0.02 & 0 & 0.03 & 0.07 & -0.45 & -0.04 & -0.04 & 0.01 & -0.02 & 0.00 & 0.00 & -0.01 & $\begin{array}{l}-0.01 \\
\end{array}$ & 0.00 & 0.01 & -0.01 & 0.00 & 0.00 & -0.02 & 0.01 & 0.00 \\
\hline$\alpha_{2}$ & 0.02 & & 0 & 0.03 & 0.08 & -0.02 & -0.46 & -0.08 & 0.00 & -0.05 & 0.01 & -0.01 & -0.03 & -0.02 & -0.01 & 0.00 & 0.00 & -0.05 & 0.02 & 0.01 & 0.01 & -0.01 \\
\hline$\alpha_{3}$ & 0.04 & 0.11 & & 0.03 & 0.05 & -0.03 & -0.10 & -0.38 & 0.02 & -0.02 & 0.00 & -0.01 & -0.01 & -0.01 & 0.00 & 0.02 & -0.01 & -0.07 & -0.02 & 0.00 & 0.02 & 0.01 \\
\hline$\alpha_{4}$ & 0.02 & 0.03 & 0 & & -0.02 & -0.04 & -0.01 & 0.01 & -0.35 & -0.05 & -0.01 & 0.00 & 0.00 & -0.01 & 0.00 & 0.01 & 0.02 & 0.02 & 0.01 & 0.01 & -0.01 & 0.02 \\
\hline$\alpha_{5}$ & 0.07 & 0.08 & 0 & -0.02 & & -0.04 & -0.07 & -0.05 & -0.03 & -0.29 & 0.01 & -0.01 & 0.01 & 0.03 & 0.02 & 0.01 & 0.01 & 0.04 & 0.01 & -0.04 & 0.02 & 0.00 \\
\hline$K_{1}$ & -0.45 & -0.02 & - & -0.04 & -0.04 & & -0.06 & 0.04 & 0.04 & 0.05 & 0.01 & 0.00 & 0.00 & 0.02 & 0.00 & -0.02 & 0.00 & 0.06 & -0.01 & 0.01 & 0.01 & 0.01 \\
\hline$K_{2}$ & -0.04 & -0.46 & - & -0.01 & -0.07 & -0.06 & & 0.10 & 0.00 & 0.08 & 0.01 & 0.01 & -0.08 & -0.07 & -0.02 & -0.02 & -0.02 & 0.08 & 0.06 & -0.05 & 0.03 & 0.00 \\
\hline$K_{3}$ & -0.04 & -0.08 & - & 0.01 & -0.05 & 0.04 & 0.10 & & -0.01 & 0.03 & 0.03 & 0.00 & -0.02 & 0.00 & -0.06 & -0.05 & -0.05 & 0.15 & -0.02 & 0.04 & 0.03 & -0.02 \\
\hline$K_{4}$ & 0.01 & 0.00 & 0 & -0.35 & -0.03 & 0.04 & 0.00 & -0.01 & & -0.01 & 0.01 & 0.01 & -0.03 & -0.01 & 0.00 & -0.02 & -0.02 & -0.05 & -0.01 & 0.00 & 0.02 & -0.01 \\
\hline$K_{5}$ & -0.02 & -0.05 & - & -0.05 & -0.29 & 0.05 & 0.08 & 0.03 & -0.01 & & 0.01 & 0.00 & -0.01 & 0.02 & -0.01 & -0.01 & -0.01 & 0.01 & 0.01 & -0.01 & 0.01 & 0.01 \\
\hline$a_{50}$ & 0.00 & 0.01 & 0 & -0.01 & 0.01 & 0.01 & 0.01 & 0.03 & 0.01 & 0.01 & & 0.66 & 0.00 & 0.00 & 0.25 & 0.31 & 0.24 & 0.02 & 0.00 & 0.02 & -0.02 & 0.02 \\
\hline$\delta$ & 0.00 & -0.01 & - & 0.00 & -0.01 & 0.00 & 0.01 & 0.00 & 0.01 & 0.00 & 0.66 & & 0.00 & 0.00 & 0.17 & 0.22 & 0.16 & 0.04 & 0.01 & 0.00 & -0.15 & 0.00 \\
\hline$q_{0}$ & -0.01 & -0.03 & - & 0.00 & 0.01 & 0.00 & -0.08 & -0.02 & -0.03 & -0.01 & 0.00 & 0.00 & & 0.27 & 0.01 & 0.05 & 0.04 & 0.04 & -0.04 & 0.47 & -0.07 & 0.00 \\
\hline$q_{1}$ & -0.01 & -0.02 & - & -0.01 & 0.03 & 0.02 & -0.07 & 0.00 & -0.01 & 0.02 & 0.00 & 0.00 & 0.27 & & 0.03 & 0.04 & 0.05 & 0.03 & 0.01 & 0.45 & -0.07 & 0.01 \\
\hline$q_{B E C B T}$ & 0.00 & -0.01 & 0 & 0.00 & 0.02 & 0.00 & -0.02 & -0.06 & 0.00 & -0.01 & 0.25 & 0.17 & 0.01 & 0.03 & & 0.41 & 0.48 & 0.03 & 0.01 & -0.02 & -0.16 & 0.26 \\
\hline$q_{U K B T S}$ & 0.01 & 0.00 & 0 & 0.01 & 0.01 & -0.02 & -0.02 & -0.05 & -0.02 & -0.01 & 0.31 & 0.22 & 0.05 & 0.04 & 0.41 & & 0.41 & 0.05 & 0.02 & -0.01 & -0.20 & 0.32 \\
\hline$q_{U K C B T}$ & -0.01 & 0.00 & - & 0.02 & 0.01 & 0.00 & -0.02 & -0.05 & -0.02 & -0.01 & 0.24 & 0.16 & 0.04 & 0.05 & 0.48 & 0.41 & & 0.03 & 0.00 & 0.01 & -0.14 & 0.24 \\
\hline$\sigma_{B H}^{2}$ & 0.00 & -0.05 & - & 0.02 & 0.04 & 0.06 & 0.08 & 0.15 & -0.05 & 0.01 & 0.02 & 0.04 & 0.04 & 0.03 & 0.03 & 0.05 & 0.03 & & -0.19 & -0.04 & -0.18 & 0.02 \\
\hline$\sigma_{0}^{2}$ & 0.00 & 0.02 & - & 0.01 & 0.01 & -0.01 & 0.06 & -0.02 & -0.01 & 0.01 & 0.00 & 0.01 & -0.04 & 0.01 & 0.01 & 0.02 & 0.00 & -0.19 & & -0.03 & -0.07 & 0.02 \\
\hline$\sigma_{I_{j u v}}^{2}$ & -0.02 & 0.01 & 0 & 0.01 & -0.04 & 0.01 & -0.05 & 0.04 & 0.00 & -0.01 & 0.02 & 0.00 & 0.47 & 0.45 & -0.02 & -0.01 & 0.01 & -0.04 & -0.03 & & -0.01 & 0.00 \\
\hline$\sigma_{C}^{2}$ & 0.01 & 0.01 & 0 & -0.01 & 0.02 & 0.01 & 0.03 & 0.03 & 0.02 & 0.01 & -0.02 & -0.15 & -0.07 & -0.07 & -0.16 & -0.20 & -0.14 & -0.18 & -0.07 & -0.01 & & -0.04 \\
\hline$\sigma_{I_{A d}}^{2}$ & 0.00 & -0.01 & 0 & 0.02 & 0.00 & 0.01 & 0.00 & -0.02 & -0.01 & 0.01 & 0.02 & 0.00 & 0.00 & 0.01 & 0.26 & 0.32 & 0.24 & 0.02 & 0.02 & 0.00 & -0.04 & \\
\hline
\end{tabular}

